\title{
NASA's Advanced Exploration Systems Mars Transit Habitat Refinement Point of Departure Design
}

\author{
Matthew Simon, Kara Latorella, John Martin, Jeff \\ Cerro, Roger Lepsch, Sharon Jefferies, Kandyce Goodliff \\ NASA Langley Research Center \\ Hampton VA 23681 \\ matthew.a.simon@nasa.gov, k.a.latorella@nasa.gov, \\ john.g.martin@nasa.gov, jeffrey.a.cerro@nasa.gov, \\ roger.a.lepsch@nasa.gov, sharon.a.jefferies@nasa.gov, \\ kandyce.e.goodliff@nasa.gov, \\ Carey McCleskey \\ NASA Kennedy Space Center, FL 32899 \\ carey.m.mccleskey@nasa.gov
}

\author{
David Smitherman \\ NASA Marshall Space Flight Center \\ Redstone Arsenal \\ Huntsville, AL 35812 \\ david.smitherman@nasa.gov
}

\author{
Chel Stromgren \\ Binera Inc. \\ 912 Thayer Avenue, Suite 209 \\ Silver Spring, MD \\ c.stromgren@binera.com
}

\begin{abstract}
This paper describes the recently developed point of departure design for a long duration, reusable Mars Transit Habitat, which was established during a 2016 NASA habitat design refinement activity supporting the definition of NASA's Evolvable Mars Campaign. As part of its development of sustainable human Mars mission concepts achievable in the 2030s, the Evolvable Mars Campaign has identified desired durations and mass/dimensional limits for long duration Mars habitat designs to enable the currently assumed solar electric and chemical transportation architectures. The Advanced Exploration Systems Mars Transit Habitat Refinement Activity brought together habitat subsystem design expertise from across NASA to develop an increased fidelity, consensus design for a transit habitat within these constraints. The resulting design and data (including a mass equipment list) contained in this paper are intended to help teams across the agency and potential commercial, academic, or international partners understand: 1) the current architecture/habitat guidelines and assumptions, 2) performance targets of such a habitat (particularly in mass, volume, and power), 3) the driving technology/capability developments and architectural solutions which are necessary for achieving these targets, and 4) mass reduction opportunities and research/design needs to inform the development of future research and proposals. Data presented includes: an overview of the habitat refinement activity including motivation and process when informative; full documentation of the baseline design guidelines and assumptions; detailed mass and volume breakdowns; a moderately detailed concept of operations; a preliminary interior layout design with rationale; a list of the required capabilities necessary to enable the desired mass; and identification of any worthwhile trades/analyses which could inform future habitat design efforts. As a whole, the data in the paper show that a transit habitat meeting the 43 metric tons launch mass/trans-Mars injection burn limits specified by the Evolvable Mars Campaign is achievable near the desired timeframe with moderate strategic investments including maintainable life support systems, repurposable structures and packaging, and lightweight exercise modalities. It also identifies operational and technological options to reduce this mass to less than 41 metric tons including staging of launch structure/packaging and alternate structural materials.
\end{abstract}

\section{TABLE OF CONTENTS}

1. INTRODUCTION .....................................................1

2. APPROACH AND METHODS...................................2

3. MISSION CONTEXT .......................................................4

4. TRANSIT HABITAT DESIGN DESCRIPTION .............8

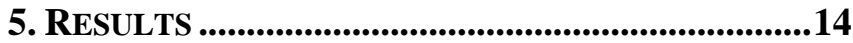

ACKNOWLEDGEMENTS .......................................15

REFERENCES ........................................................16

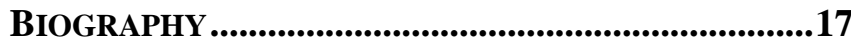

APPENDICES ..........................................................................20

A. MASTER EQUIPMENT LIST ..................................20

B. COMMON FUNCTIONAL MEL FUNCTIONAL

CATEgORY DEFINITIONS ........................................32

\section{INTRODUCTION}

NASA is developing a strategy for sending humans to the Mars vicinity in the mid-2030s known broadly as NASA's Journey to Mars [1,2]. Within this effort, an Evolvable Mars Campaign (EMC) study team has been tasked by the Human Exploration and Operations Mission Directorate to perform trade analyses and define the capabilities and elements necessary to sustainably expand human presence from lowEarth orbit (LEO) into deep space and Mars. The purpose of developing this evolvable campaign is not to produce "The Plan" for sending humans to Mars, but it is to inform nearterm key decisions and investment priorities to prepare for those types of missions. In particular, the Evolvable Mars Campaign differs from previous Mars mission planning efforts in that it attempts to implement sustainability through a set of guiding principles for sustainable exploration outlined in $[1,2]$ including:

- Development of a Capability Driven Framework that features incremental investment in capabilities to enable a cadence of incrementally more complex missions

- Minimization of major, unique developments 
- Reuse of elements and commonly applied technologies where possible

\section{- Leveraging international and commercial participation}

In 2014-2016, the team designing the EMC performed and published analysis of integrated mission architecture options to identify technically appealing transportation strategies, logistics build-up strategies, and vehicle designs for reaching and exploring Mars moons and Mars surface more sustainably than previous efforts. [1, 2, 3, 4, 5 \& 6]

A critical part of this campaign is the development of substantially capable habitation systems capable of extending human presence beyond LEO. EMC Mars missions feature in-space transit and surface habitats supporting crews for the 1100-1200 day missions to Mars vicinity. These deep space habitats are complex elements which must keep crewmembers healthy and happy "in challenging environments with limited resupply, no crew abort, and long communication delays; all within constrained mass, volume, and power budgets" [6]. These habitats must provide space for the astronauts to live/work and be capable of accommodating all of the equipment and consumables to support human life (a breathable atmosphere, clean water, food, a place to sleep, exercise, workstations to support crew tasks, etc.).

The design of these habitats is critical to enabling Mars architectures for several reasons. First, habitats are often large, massive elements and primary drivers for the size of the transportation systems and required propellant for propulsive maneuvers. Long duration habitats push the limits of available launch vehicle payload to aggregation orbits and lander payloads to the Martian surface. Additionally, habitats, such as the transit habitat, are carried through most of the propulsive maneuvers of the mission. This large 'gear ratio' can often drive the cost and complexity of a mission by increasing the number of flights and overall timeline of each mission. Second, habitats are complex, highly integrated elements critical to the safety and wellbeing of the crew. Modifying design decisions and imposing additional constraints on habitat design can have broad, complex effects on subsystems and overall crew safety, so a careful, integrated approach to design considering these interactions is required. Finally, because there are limited abort and resupply opportunities on Mars missions, the integrated habitats must be designed for reliability and maintainability while adhering to mass constraints of the propulsion systems. Novel sparing and waste disposal strategies must be considered early in the design to ensure mission feasibility.

Due to the criticality of habitat designs to enable current NASA Mars Campaigns, NASA's Advanced Exploration Systems Transit Habitat Refinement Activity was chartered to improve upon existing EMC habitat design fidelity while improving coordination between Agency discipline experts and Mars mission designers. Specifically, The Habitat Refinement Activity was tasked to answer two questions:
- Is a reusable, $\sim 1100$ day habitat meeting the EMC habitat mass, volume, and power targets viable?

- If so what are the most reasonable/cost effective combination of capabilities to achieve these targets?

The output of this activity is an updated mass/volume/power breakdown, the identification of the required capabilities necessary to enable this mass/volume/power estimate, and the identification of any worthwhile trades/analyses which could be performed to inform future habitat design efforts. The intent of the authors is to publish this data to serve as a baseline Transit Habitat design for the Mars mission design community and a reference point for future habitat design efforts in NASA, industry, and academia.

This paper documents the approach, assumptions, and results of this Habitat Refinement Activity's efforts to develop an improved fidelity, consensus habitat system meeting the transportation architecture constraints outlined in the EMC [4]. Section 2 describes the approach to collect discipline expert data feeding into the activity's products. Section 3 describes the guidelines and assumptions, concept of operations, and constraints which establish the mission context for the habitat design including identification of the performance targets of the Mars Transit Habitat (MTH). Section 4 describes the outputs of the activity including mass/power/volume summaries and a detailed Master Equipment List (MEL) with descriptions of assumptions and design features by subsystem. Finally, Section 5 describes the impacts of this activity including recommendations for how the habitat data could/should be used in the future and a list of potential future trades.

\section{APPROACH AND METHODS}

As shown in Error! Reference source not found., the purpose of the Habitat Refinement Activity was to bring together habitat design and subsystem inputs from four exploration-focused teams within the Human Exploration and Operations Mission Directorate to increase the fidelity and performance of EMC habitat concepts. Each of these groups brought the following perspectives to the habitat design activity:

- Evolvable Mars Campaign (EMC): Develops sustainable human Mars exploration campaigns and required elements, including the long and short duration habitats necessary for Mars missions. Identifies long term exploration capability needs. [1-6]

- Future Capabilities Team (FCT): Develops concepts and requirements for testing and demonstration of capabilities needed for future missions in cislunar space on an initial cislunar habitat. Prioritizes near term needs to support cislunar objectives.

- Systems Maturation Team (SMT): Identifies capabilities and capability maturation plans which have been identified by Agency Points of Contact (POC)s or SMT Leads as needed for the future missions. Communicates testing and demonstration needs of the 


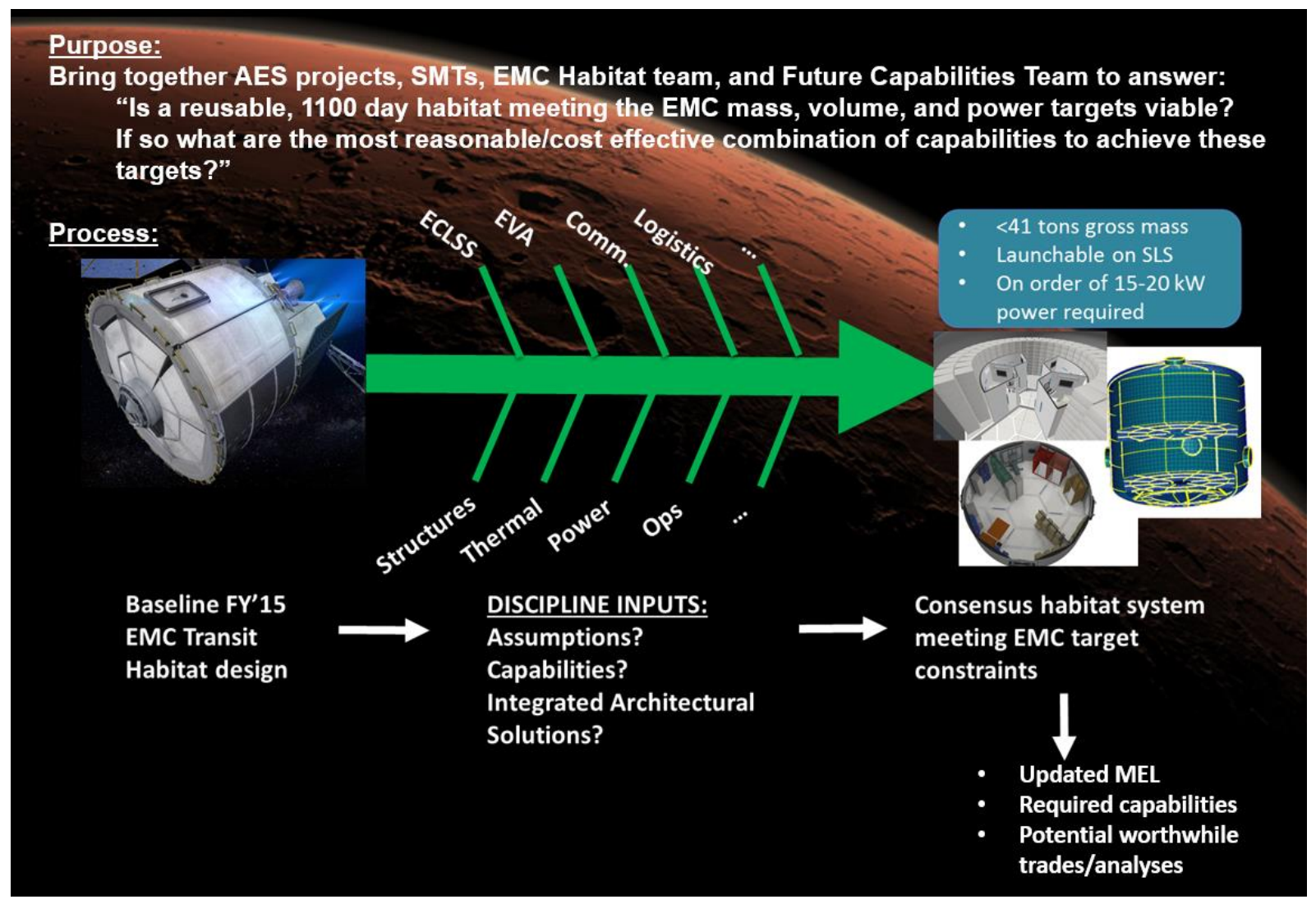

Figure 1. Habitat Refinement Activity Purpose and Process

capabilities to architecture teams (EMC, FCT, etc.)

- Advanced Exploration Systems (AES) Projects: Directed to conduct projects to demonstrate capabilities needed for future missions, usually through design, build, test methods.

Members of these teams made up the refinement activity team, which included multiple participants representing each of the following categories: EMC Habitation, EMC Integration, SMT Integration, FCT Integration, Extravehicular Activity (EVA), Robotics, Fire Safety, Environmental Control and Life Support (ECLS), Thermal Control, Autonomous Mission Operations, Communications \& Navigation, Command, Control and Data Handling (CC\&DH), Power, Structures, Logistics, In-Space Manufacturing, Human Factors/Crew Accommodations, Crew Health \& Radiation, and Utilization \& Payloads.

This team sought to accomplish the following objectives:

- Develop a Mars Transit Habitat capable of meeting EMC transportation constraints for habitat mass, power, and volume

- Identify the capabilities necessary to achieve these targets

- Deliver a mass equipment list (MEL) consistent with these assumptions and capabilities with an associated Basis of Estimate (BoE) and other element data products documenting the Transit Habitat design

- Identify beneficial trade studies for future teams to refine these designs

A workshop was held to communicate these objectives, the point of departure EMC habitat, and associated constraints to the team members. This baseline design and associated constraints are briefly discussed in Section 3. The team scrutinized the EMC habitat and associated MEL, and the underpinning guidelines and assumptions. Then the team brainstormed potential technology and cross-disciplinary architectural options to improve habitat designs through reduced habitat mass or risk. The results of this brainstorming effort were discussed to identify system interfaces and interactions. Following the workshop, EMC Integration personnel consolidated workshop data and identified outstanding issues. Follow-up interviews were held with representative subject matter experts from the aforementioned system element categories to validate changes to the MEL (and mass, power, volume estimates); identify additional sources of technical data; further discuss enabling future capabilities and trades that should be done to investigate these; identify cross-discipline/system element issues; and to discuss what may be differences between this Transit Habitat and designs for Mars and Mars Moons' surface habitats. Results from these sixteen interviews were compiled and resulted in a revised MEL and a list of enabling capabilities. This MEL has been iterated in subsequent work to address updated data and resolve integration concerns. These results from this activity directly affect Mars mission planning efforts, inform near term capability testing efforts on the International Space Station (ISS) and cislunar habitats, 
and have been delivered to NASA HQ.

\section{Mission CONTEXT}

Before discussing the resulting Transit Habitat design in Section 4, this section describes the mission context used to arrive at the current baseline design. This mission context includes information such as the guidelines and assumptions, performance targets/constraints, and a description of the baseline Mars Transit Habitat concept of operations. While there are several alternate assumptions, constraints, and operations possible for Mars missions, the ones described in this section represent the latest attempt to put the sustainability principles mentioned in Section 1 into practice. The habitat design and associated architecture presented in this paper should represent a baseline or point of departure for the comparison of alternatives.

\section{Guidelines and Assumptions}

The guidelines and assumptions shown in Table 1 represent programmatic and transportation architecture constraints, human spaceflight standards, standard design practices, and assumptions specifying the required functional capabilities provided by the habitat during the transit and orbital portions of the Mars mission. These guidelines and assumptions, as well as the transit habitat concept presented in this paper, are specific to an EMC mission architecture featuring a Hybrid Propulsion Stage which combines storable propulsion with a high power Solar Electric Propulsion system to perform interplanetary trajectory departure and insertion burns [4]. Other architectures leveraging other transportation stages mentioned in [3] are available, but are not reported in this paper due to their lack of extensive vetting.

One additional guideline and assumption is derived from the sustainable principle of minimizing unique developments. There are three habitats needed in the current campaign of Mars missions: a Mars transit habitat to support crew during the trip and from the destination, a Mars Moons Habitat to support crew at Mars moons destinations, and a Mars Surface Habitat to support crew on the surface of Mars. To reduce the cost of development, manufacture, and certification of these habitats, their design is constrained to maximize commonality between the habitats. Most notably is the commonality of the pressure vessels as much as is reasonable to allow for the same manufacturing line and structural validation of the habitats. Furthermore, the subsystems will be common between the habitats to the maximum extent practical.

\section{Performance Targets}

In order to enable Mars missions described in Reference 1 and 2 utilizing the HPS transportation architecture described in Reference 4, several performance targets were implemented to facilitate integration of a transit habitat into these architectures. First, several mass limits were placed on habitats in the Mars campaign. These limits, shown in Table 2 , provide performance targets for the design of the habitat elements, which can be achieved through a combination of mass-reducing technologies or cross-disciplinary architectural solutions. Gross mass limits at Trans-Mars Injection are a due to the power levels performance limits of the Asteroidal Retrieval Mission-derived solar electric propulsions systems to deliver large payloads to Mars orbit. The empty mass limits at launch are driven by the launch payload limits to Lunar Distant Retrograde Orbit (LDRO) when launched with a partially full HPS. Additionally, there are some constraints which might affect the Transit Habitat due to the desired commonality with the surface habitat. In particular, the minimum empty mass capable of remaining operational when packaged on a lander may constrain the design of the habitat. Alternatively, more custom modifications of only the surface habitat for the tight mass and dimensional constraints of payloads within entry, descent, and landing system performance may be used to alleviate these concerns.

Second, peak power levels less than $24 \mathrm{~kW}$ are desired to enable the use of a modular power system currently being designed for cislunar space. The desired power allocation is closer to $15-20 \mathrm{~kW}$, which is currently being provided by the HPS solar arrays that by decreasing the power available for solar electric thrusting.

The final performance target is to ensure that the "-ilities" such as reliability, maintainability, commonality, etc. are factored into all habitat designs. As these are somewhat difficult to measure, this performance target is met when designers choose redundancies, technologies, and other design features which are anticipated to have improve these "-ilities." Work to verify these choices is needed utilizing novel quantitative analysis methods compatible with PrePhase A conceptual designs. This need for analysis methods and benefit verification is discussed more in the future work section of Section 5. 
Table 1. Transit Habitat Refinement Activity Guidelines and Assumptions

\begin{tabular}{|c|c|}
\hline & Transit Habitat Guidelines and Assumptions \\
\hline Crew Number & 4 crew assumed for all missions is EMC baseline \\
\hline Mass Limits & $\begin{array}{l}\text { Launch mass limit: Habitat launched mass limit is based upon the Space Launch System } \\
\text { capability to launch the combined mass of the Hybrid Propulsion Stage (HPS) attached to the } \\
\text { Transit Habitat.[4] } \\
\text { Interplanetary mass limit: < 43 metric tons gross mass for Transit Habitat ( } 4 \text { crew, } ~ 1100 \\
\text { days of logistics) [4] }\end{array}$ \\
\hline $\begin{array}{l}\text { Mass Growth / } \\
\text { Margin }\end{array}$ & $\begin{array}{l}\text { Mass growth allowances for each subsystem are provided by subsystem experts based upon the } \\
\text { maturity of the subsystem as described in American Institute of Aeronautics and Astronautics } \\
\text { (AIAA) mass growth standards [7]. Margins and Program Manager's Reserve (PMR), are not } \\
\text { carried in this habitat estimate. They are carried at the architecture modeling and launch vehicle } \\
\text { integration levels. }\end{array}$ \\
\hline Duration & $\begin{array}{l}\text { Habitat are sized for } \sim 1100 \text { days crewed + uncrewed duration to Distant Retrograde Orbit } \\
\text { (DRO) and time for checkout. }\end{array}$ \\
\hline Habitat Lifetime & $\begin{array}{l}\text { Habitat are assumed to last for } 15 \text { years. Subsystem mass deltas for multi-mission reuse are not } \\
\text { captured at this time in EMC habitat estimates, but would be needed for logistics delivery and } \\
\text { refurbishment flights. The } 15 \text { year lifetime includes up to } 3 \text { years of dormancy operations. }\end{array}$ \\
\hline $\begin{array}{l}\text { Packaging/ } \\
\text { Offloading } \\
\text { Constraints }\end{array}$ & $\begin{array}{l}\text { Dimensional limits: Assume habitat compatible with } 8.4 \mathrm{~m} \text { diameter shroud for Space Launch } \\
\text { System (SLS) which corresponds to a } 7.5 \mathrm{~m} \text { diameter usable envelope that limits habitat } \\
\text { diameter to }<7.5 \mathrm{~m} \text { stowed diameter (expandables may grow to larger diameters). This diameter } \\
\text { maintains flexibility to use } 8.4 \mathrm{~m} \text { or } 10 \mathrm{~m} \text { diameter shrouds. Length limits set by } 8.4 \mathrm{~m} \text { diameter } \\
\text { shroud usable envelope when co-manifested with hybrid propulsive stage. } \\
\text { Transit habitat launched with the HPS, with the habitat on the top of the propulsion stage. These } \\
\text { launch vehicles are packaged with adaptors such that neither payload carries the loads of the } \\
\text { other. They are assumed to be launched on the } 10 \mathrm{~m} \text { SLS shroud which is necessary for } \\
\text { packaging of the large hybrid propulsion system solar arrays around the habitat. }\end{array}$ \\
\hline Geometry/Structure & $\begin{array}{l}\text { Geometry/structure must provide sufficient (load bearing) interfaces for integration with } \\
\text { propulsion stage or other elements above or below the habitat in the launch-vehicle stack. } \\
\text { Factors of safety to comply with JSC } 65828 \text { "Structural Design Requirements and Factors of } \\
\text { Safety for Spaceflight Hardware" (Factor of Safety } 2.0 \text { on ultimate load for habitable modules) } \\
\text { [8] }\end{array}$ \\
\hline $\begin{array}{l}\text { Net Habitable } \\
\text { Volume }\end{array}$ & $\begin{array}{l}\text { Transit habitat should provide at least } 25 \mathrm{~m} 3 / \mathrm{p} \text { (Human Research Program (HRP)/ Behavioral } \\
\text { Health and Performance (BHP) Consensus Session 2014) [9]. Also, it is assumed that no Orion } \\
\text { volume is leveraged to reduce the habitable volume requirement, as Orion is nominally not } \\
\text { transported with Transit Habitat in some mission concepts. }\end{array}$ \\
\hline Docking Guidelines & $\begin{array}{l}\text { The Transit Habitat should provide } 3 \text { docking mechanisms with hatches, which is driven by } \\
\text { aggregation operations requiring simultaneous docking with Initial Cislunar Habitat, logistics } \\
\text { delivery, and Orion. Hatch sizes should be allow for docking with other mission elements and } \\
\text { required functionality (translation of crew, logistics, and assembly/maintenance activities and } \\
\text { items). Any power, fluid, data, or other connections not integrated into the existing docking } \\
\text { interface may require separate connection across elements (assumed to be connectable without } \\
\text { Extravehicular Activities (EVAs)). Assume no drag-throughs. Additionally, another hatch } \\
\text { without a docking mechanism may be required for an airlock for emergency EVAs. }\end{array}$ \\
\hline $\begin{array}{l}\text { Interfaces (reliance } \\
\text { on other vehicles/ } \\
\text { elements, systems } \\
\text { guidance) }\end{array}$ & $\begin{array}{l}\text { Transit Habitat is responsible for maintenance and repair of all docked elements. Habitat } \\
\text { provides thermal control, deep space and proximity communications, ECLSS for all attached } \\
\text { elements. Common interfaces should be used across all mission elements to enable reusability. } \\
\text { Habitat receives power generation and stack control from propulsive element. }\end{array}$ \\
\hline $\begin{array}{l}\text { Micrometeoroid } \\
\text { Orbital Debris }\end{array}$ & $\begin{array}{l}\text { Micrometeoroid Orbital Debris (MMOD) protection will be provided for the habitat appropriate } \\
\text { to the lifetime and environment }\end{array}$ \\
\hline
\end{tabular}


Table 1. Transit Habitat Refinement Activity Guidelines and Assumptions (Continued)

\begin{tabular}{|c|c|}
\hline & Transit Habitat Guidelines and Assumptions \\
\hline $\begin{array}{l}\text { EVA Guidelines } \\
\text { (Baseline set) }\end{array}$ & $\begin{array}{l}\text { EVA Assumptions: Assume only contingency EVA for transit habitat utilizing modified Launch, } \\
\text { Entry, and Abort (LEA) suits and an inflatable airlock. Assume TBD amount of spares/logistics for } \\
\text { EVAs. Assume that surface EVA suits are delivered on the destination habitat and checked out in } \\
\text { orbit prior to crew descent. After operations at the destination are complete, surface EVA suits are } \\
\text { left at the destination if there is a pressurized IVA transfer capability available. Crewmembers then } \\
\text { ascend in their LEA suits (brought with them during landing) for planetary protection (backward). } \\
\text { Risks associated with cabin depress/docking failure to Mars Transit Habitat are future work. } \\
\text { Number and Types of Suits: Assume the number of LEA suits = number of crew. Also assume } 2 \\
\text { in-space Portable Life Support Systems (PLSSs). Crew brings these LEA suits along to the surface } \\
\text { and on the return trip. } \\
\text { Habitat EVA Services: The habitat has umbilical interface panels located where suit services or } \\
\text { suited crewmember operations occur. Suit services/umbilical interface panels provide: Recharge } \\
\text { capability for the suit includes: oxygen ( } 3000 \text { psia), water w/biocide (potable and cooling) resupply, } \\
\text { and battery recharge and utility services: power, communications (wireless and hardline), and } \\
\text { vacuum lines (if required). }\end{array}$ \\
\hline $\begin{array}{l}\text { Internal } \\
\text { Atmosphere }\end{array}$ & $\begin{array}{l}\text { Assume } 101.3 \mathrm{kPa}(14.7 \mathrm{psia}), 21 \% \mathrm{O} 2 \text { nominal atmosphere with capability to go down to } 70.3 \mathrm{kPa} \\
\text { (10.2 psia), } 26 \% \mathrm{O} 2 \text { for short durations to prep for landing or EVAs }\end{array}$ \\
\hline $\begin{array}{l}\text { ECLSS } \\
\text { Assumptions }\end{array}$ & $\begin{array}{l}\text { Assume closed-loop life support systems for transit habitats and consistently apply baseline } \\
\text { technology choices across investigated transit habitation concepts. Assume ECLSS architectures } \\
\text { will also be designed to handle long dormancy, possibly requiring regular keep-alive activities while } \\
\text { unmanned, and flow paths very different from ISS to enable automated recirculation and } \\
\text { reprocessing of fluids. Additionally, increased reliability and maintainability are required to prevent } \\
\text { multiple, fully functional redundant units and reduce sparing masses. Adjustments to existing } \\
\text { exploration ECLSS technologies will be made to account for the additional requirements of long } \\
\text { lifetime, dormancy, increased reliability and maintainability. Assume low mass impacts for } \\
\text { maintainability/accessibility improvements. Assume } 30 \text { day open loop consumable backup for } \\
\text { critical systems (O2, H2O, CO2 Removal) to eliminate redundant units. }\end{array}$ \\
\hline $\begin{array}{l}\text { Logistics, Spares } \\
\text { and Maintenance } \\
\text { Guidelines and } \\
\text { Assumptions }\end{array}$ & $\begin{array}{l}\text { Transit habitat should provide logistics, spares, and maintenance for full crew for entire mission } \\
\text { duration ( } 1100 \text { days plus contingency). Assume no Orion may be leveraged for logistics. Gas and } \\
\text { fluids are stored internally and sized for partially closed ECLSS with no laundry. Assume } \\
\text { components are common across other habitat elements (TBR). Spares/Maintenance equipment is } \\
\text { assumed to support the expected repair and maintenance requirements for the Transit Habitat for } \\
1000 \text { days. Maintenance capability is assumed to be capable of servicing both the habitat and } \\
\text { attached vehicles. Dry goods are stored in CTBs with a 15\% packing factor assumed for storage } \\
\text { volume loss and an additional internal packaging penalty (TBR). In situ manufacturing, alternative } \\
\text { packing (CTBs), and potential food resupply kept as trade options. }\end{array}$ \\
\hline $\begin{array}{l}\text { Radiation } \\
\text { protection }\end{array}$ & $\begin{array}{l}\text { The baseline Transit Habitat will not provide additional GCR and SPE protection beyond onboard } \\
\text { logistics placement and layout options (May assume spent logistics may be necessary (not } \\
\text { jettisoned/destroyed) to increase radiation protection on return trip). This assumes that some } \\
\text { combination of a revised risk posture (based upon increased understanding of the incidence of space } \\
\text { radiation exposure induced effects such as fatal cancers, central nervous system damage, and } \\
\text { cardiovascular damage), operational planning, and biological mitigation methods will allow for } \\
\text { human participation in the planned missions within human requirements. Trades to be investigated } \\
\text { include increased SPE or GCR protection and mission duration changes to achieve acceptable risk } \\
\text { of loss of crew or loss of mission. }\end{array}$ \\
\hline Exercise & $\begin{array}{l}\text { Assume } 2.5 \mathrm{hrs} . / \text { crewmember/day for the entire } 1100 \text { day mission. Assume a combination of } \\
\text { resistance and cardiovascular exercise through an ergometer and rowing/resistive machine not to } \\
\text { exceed } \sim 350 \mathrm{~kg} \text {, not including spares. Assume low mass solution to vibration isolation system. }\end{array}$ \\
\hline Waste disposal & Assume waste storage. \\
\hline
\end{tabular}


Table 2. Mars Habitat Mass Constraints

\begin{tabular}{|l|l|}
\hline Mars Transit & $\begin{array}{l}\text { - Mass at Trans-Mars Injection (TMI) } \\
\text { burn }<43 \text { metric tons (Stretch Goal }< \\
40 \text { metric tons) } \\
\text { - Empty mass delivered at launch with } \\
\text { HPS }<22 \text { metric tons }\end{array}$ \\
\hline $\begin{array}{l}\text { Mars Moons } \\
\text { Habitat }\end{array}$ & $\begin{array}{l}\text { Total between Mars moons habitat, } \\
\text { rover, and landing/mobility equipment } \\
\text { mass at TMI < 43 metric tons (Stretch } \\
\text { Goal }<40 \text { metric tons) } \\
\text { - Empty mass delivered at launch with } \\
\text { HPS < 22 metric tons }\end{array}$ \\
\hline Mars Surface & $\begin{array}{l}\text { - Landed mass }<20 \text { metric tons (after } \\
\text { offloading logistics and other } \\
\text { offloadable items.) }\end{array}$ \\
\hline
\end{tabular}

\section{Concept of Operations}

The Transit Habitat is launched partially outfitted with the HPS and resupplied with a series of logistics flights prior to the interplanetary crew arrival. The Transit Habitat combined with this hybrid propulsion stage make up the transit vehicle that carries the crew on missions to Mars. A high-level overview of a Mars mission concept of operations is shown in Figure 2. The Transit Habitat is delivered to the Lunar Distant Retrograde Orbit (LDRO), either by the in-space transportation stage or on its own via a special propulsion kit. After arriving in cis-lunar space, the habitat mates with the initial cis-lunar habitat (ICH) to facilitate aggregation, crew checkout, and mission preparation. In architectures where the habitat and transportation stage are launched separately, the in-space transportation stage mates with the habitat in LDRO.

The habitat is launched in a dormant state. Prior to first use, the Transit Habitat will undergo a 180-day checkout period to shake out systems, install any components that were offloaded for launch, load supplies, and make sure the habitat is ready for the mission. During this time the habitat may have a logistics module and/or Orion mated to it in addition to the ICH. After the check-out period, the systems will be left in a quiescent state that minimizes the amount of preparation the mission crew will need to perform before departure. The transit vehicle departs from the ICH to a lunardistance highly elliptical orbit (LDHEO) where it picks up the mission crew then executes a lunar gravity assist to send the crew on to Mars.

The transit time to and from Mars with the HPS ranges from $\sim 230$ to 400 days. Once at Mars, the transit vehicle rendezvous with a destination vehicle, which is the Phobos taxi for Phobos missions or the crew descent lander for Mars surface missions. After a short period to prep and checkout the destination vehicle and prepare the Transit Habitat for uncrewed loiter, the crew departs. The loiter period lasts from 300 to 550 days depending on mission opportunity and inspace transportation system capabilities. During this time the habitat will need to function in an autonomous state, while the crew monitor the habitat from the surface. In the event of a contingency that prevents the crew from performing the destination phase of the mission or that requires early abort, the crew will return the Transit Habitat for the duration of the loiter period.

After completion of the Phobos or surface mission, the crew returns to the habitat and returns to Earth. The habitat is designed to support up to three crewed missions, so it will need to be reset and resupplied between missions. During the return trip, the mission crew can begin some of the activities necessary to refurbish the habitat for the next mission. After the returning mission crew transfers to the Orion in LDHEO, the transit vehicle returns to LDRO and the ICH, where a reset crew will come aboard and complete refurbishment and restocking of the habitat for the next mission.

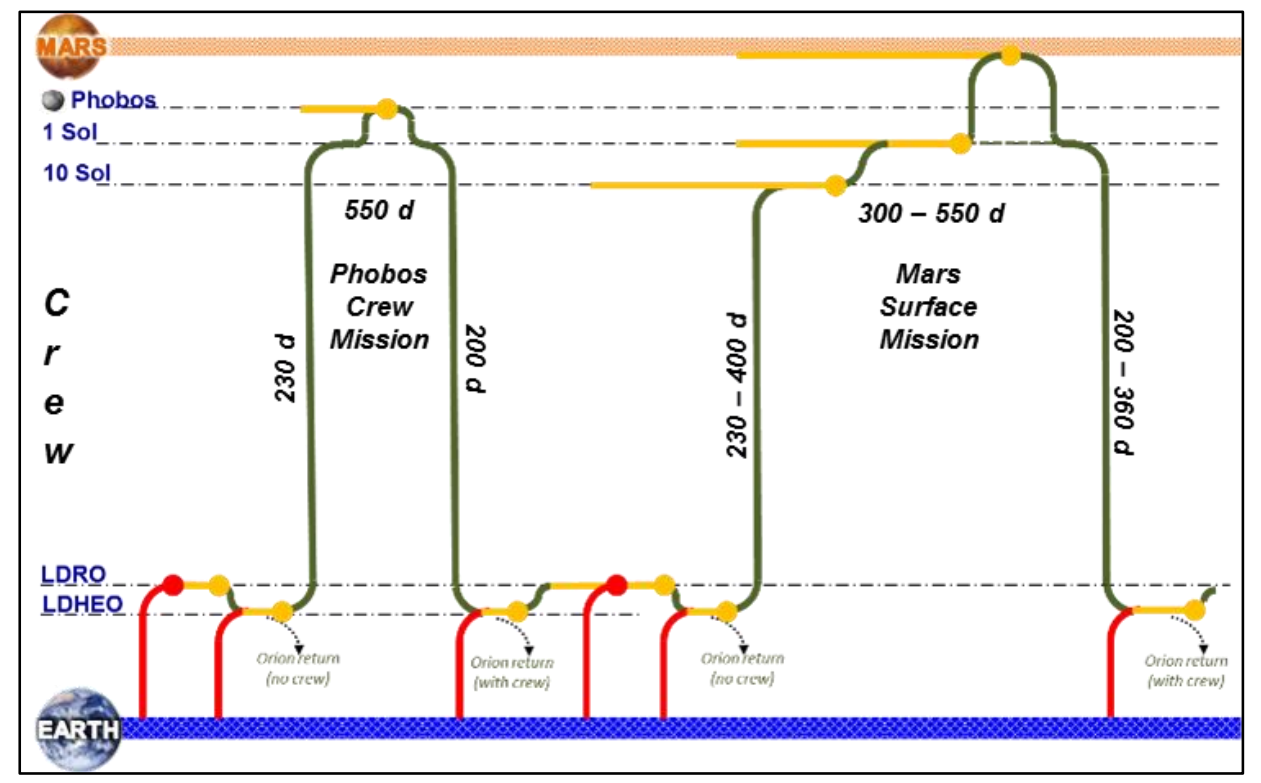

Figure 2. High-level Crewed Mission Concept of Operations. 


\section{Transit Habitat Design Description}

Utilizing the guidelines, assumptions, performance, targets, and concept of operations each of the habitat refinement activity team subject matter experts provided defendable subsystem designs with associated descriptions of the basis of estimate. This data was captured in multiple places.

\section{Master Equipment List}

First a detailed Master Equipment List (MEL) is provided in Appendix A. This MEL captures the detailed breakdown of each subsystem's mass, power, internal volume, and growths assumed for each of these measures. This MEL was provided in a new MEL format known as the Common Functional Master Equipment List (CF-MEL), which organizes subsystems by functional categories (i.e., what function is provided) instead of by discipline. The motivation behind the alternative MEL format was to eliminate interpretation-based differences between various space vehicle design documents which lead to uncertainty where certain components should be covered. Definitions for each functional category used in the CF-MEL are provided in Appendix B.

This Common Functional Master Equipment List is implemented through a spreadsheet-based tool which organizes spaceflight elements and classifies the equipment, by specification or allocation, at component and subassembly level during early stage concept development and analysis. The tool can facilitate standardization by using user-guided entered data to generate standard output products and building up groupings of elements to generate and convey vehicle-level concepts. For the Transit Habitat study, the CFMEL tool was mainly used to capture mass estimation data for the habitat element. Data for associated vehicle elements, such as the transit stage and launch vehicle payload adapter was not captured as part of this effort.

A summary level, top-tier mass breakdown for the Transit Habitat is shown in Table 3. The functional category masses sum to give what is referred to as the Manufacturer's Empty Mass. This represents the mass for the element as it would be delivered by the manufacturer, nominally including all of the fixed equipment associated with the design. A set of Operational Items are added to this to arrive at the Operational Empty Mass. The Operational Items are defined as those necessary to enable mission operations, excluding usable propellant and the payload. They typically consist of items such as the crew, non-fixed equipment, mission kits, spares, and consumables (or service items) that are loaded or stowed onboard the element. They also include residual propellant and service items, remaining onboard during operations, which are unusable. For the summary in Table 3, the mass of the crew is not shown as it was accounted for at the mission-architecture level. It should be noted that a decision was made to set an allocation for utilization and external robotics at $50 \%$ of the original estimate, which is reflected in the final estimate in Table 3. This allocation is discussed more in the basis of estimate section.
Table 3. Summary Tier 1 Mass Summary of Transit Habitat in CF-MEL format

\begin{tabular}{|c|c|}
\hline Functional Category & Mass, kg \\
\hline BODY STRUCTURES & 7,361 \\
\hline CONNECTION \& SEPARATION SYSTEMS & 649 \\
\hline LAUNCH/TAKEOFF \& LANDING SUPPORT SYSTEMS & 656 \\
\hline NATURAL \& INDUCED ENVIRON PROTECT SYSTEMS & 680 \\
\hline PROPULSION SYSTEMS & - \\
\hline POWER SYSTEMS & 1,231 \\
\hline COMMAND \& DATA HANDLING (C\&DH) SYSTEMS & 131 \\
\hline GUIDANCE, NAVIGATION \& CONTROL (GN\&C) SYSTEMS & 33 \\
\hline COMMUNICATIONS \& TRACKING (C\&T) SYSTEMS & 210 \\
\hline CREW DISPLAYS \& CONTROLS & 76 \\
\hline THERMAL CONTROL SYSTEMS & 1,811 \\
\hline ENVIRONMENTAL CONTROL SYSTEMS (ECS) & 1,078 \\
\hline CREW/HABITATION SUPPORT SYSTEMS & 2,324 \\
\hline EXTRAVEHICULAR ACTIVITY (EVA) SUPPORT SYSTEMS & 1,121 \\
\hline IN-SITU RESOURCE ACQUISITION \& CONSUMABLES PRODUCTION SYSTEMS & - \\
\hline IN-SPACE MANUFACTURING \& ASSEMBLY SYSTEMS & - \\
\hline MAINTENANCE \& REPAIR SYSTEMS & 363 \\
\hline PAYLOAD PROVISIONS & 3,732 \\
\hline ABORT \& DESTRUCT SYSTEMS & - \\
\hline MANUFACTURER'S EMPTY MASS & 21,455 \\
\hline OPERATIONAL ITEMS - MISSION KITTED OR STOWED & 1,896 \\
\hline OPERATIONAL ITEMS - EQUIPMENT SPARES \& PACKAGING & 14,353 \\
\hline OPERATIONAL ITEMS - CONSUMABLES \& PACKAGING & 6,082 \\
\hline \multicolumn{2}{|l|}{ OPERATIONAL ITEMS - CREW } \\
\hline OPERATIONAL EMPTY MASS & 43,786 \\
\hline PAYLOAD & 1,542 \\
\hline EXPENDABLES - POWER \& THERMAL CONTROL FLUIDS/GASES & - \\
\hline EXPENDABLES - PROPULSION \& REACTION CONTROL FLUIDS/GASES & - \\
\hline GROSS MASS & 45,329 \\
\hline AFTER MANAGEMENT ALLOCATIONS FOR UTILIZATION AND & 423 \\
\hline EXTERNAL ROBOTICS & טגולו \\
\hline
\end{tabular}

According to the EMC concept of operations, the Transit Habitat is assumed to be delivered to orbit by the Space Launch System (SLS). Ideally, the Transit Habitat would be delivered as a complete element, and with all of the logistics and other operational items required for the mission. However, due to a combination of Transit Habitat design requirements and SLS payload mass/delivery constraints, it would be necessary to launch the habitat in an incomplete and/or partially loaded state. The remaining items would then be delivered later on other launches to allow completion of assembly and loading of the habitat while in space. To aid in assessing launch options for the habitat, the CF-MEL was used to estimate a minimum launch mass by assuming certain items could be "offloaded" from the habitat or left out for installation later. Assignments of offloading percentages were made down to the component/sub-assembly level.

Table 4 shows the top-tier mass summary of the habitat and the average offloading percentages and mass values for each functional category, based on the component/sub-assembly assignments. It was determined that a significant amount of fixed item mass bookkept under the Manufacturer's Empty Mass can be launched separately for relatively simple deferred installation. For the operational items, it is possible to completely launch and deliver them separately. For all of the offloaded items, it was necessary to account for the packaging (cargo transfer bags, pallets, containers, etc.) associated with launching and delivering them separately in order to understand the overall mass penalty for employing a deferred installation approach. It can be seen that the 22 metric ton goal for launch can be readily achieved. 
Table 4. Offloading Mass Summary of Transit Habitat in CF-MEL format

\begin{tabular}{|c|c|c|c|c|}
\hline Functional Category & MASS, kg & $\begin{array}{c}\text { OFFLOADED } \\
\text { MASS, } \%\end{array}$ & $\begin{array}{l}\text { OFFLOADED } \\
\text { MASS, kg }\end{array}$ & $\begin{array}{l}\text { LAUNCHED } \\
\text { MASS, kg }\end{array}$ \\
\hline BODY STRUCTURES & 7,361 & $0 \%$ & 0 & 7,361 \\
\hline CONNECTION \& SEPARATION SYSTEMS & 649 & $0 \%$ & 0 & 649 \\
\hline LAUNCH/TAKEOFF \& LANDING SUPPORT SYSTEMS & 656 & $0 \%$ & 0 & 656 \\
\hline NATURAL \& INDUCED ENVIRON PROTECT SYSTEMS & 680 & $0 \%$ & 0 & 680 \\
\hline \multicolumn{5}{|l|}{ PROPULSION SYSTEMS } \\
\hline POWER SYSTEMS & 1,231 & $0 \%$ & 0 & 1,231 \\
\hline COMMAND \& DATA HANDLING (C\&DH) SYSTEMS & 131 & $0 \%$ & 0 & 131 \\
\hline GUIDANCE, NAVIGATION, AND CONTROL (GN\&C) SYSTEMS & 33 & $0 \%$ & 0 & 33 \\
\hline COMMUNICATIONS \& TRACKING (C\&T) SYSTEMS & 210 & $0 \%$ & 0 & 210 \\
\hline CREW DISPLAYS \& CONTROLS & 76 & $0 \%$ & 0 & 76 \\
\hline THERMAL CONTROL SYSTEMS & 1,811 & $0 \%$ & 0 & 1,811 \\
\hline ENVIRONMENTAL CONTROL SYSTEMS (ECS) & 1,078 & $0 \%$ & 0 & 1,078 \\
\hline CREW/HABITATION SUPPORT SYSTEMS & 2,324 & $15 \%$ & 340 & 1,984 \\
\hline EXTRAVEHICULAR ACTIVITY (EVA) SYSTEMS & 1,121 & $100 \%$ & 1,121 & $\mathbf{0}$ \\
\hline \multicolumn{5}{|l|}{ IN-SITU RESOURCE ACQUISITION \& CONSUMABLES PRODUCTION SYSTEMS } \\
\hline \multicolumn{5}{|l|}{ IN-SPACE MANUFACTURING \& ASSEMBLY SYSTEMS } \\
\hline MAINTENANCE \& REPAIR SYSTEMS & 363 & $100 \%$ & 363 & $\mathbf{0}$ \\
\hline PAYLOAD PROVISIONS & 3,732 & $0 \%$ & 0 & 3,732 \\
\hline \multicolumn{5}{|l|}{ ABORT \& DESTRUCT SYSTEMS } \\
\hline MANUFACTURER'S EMPTY MASS & 21,455 & & & 19,632 \\
\hline \begin{tabular}{|l|} 
OPERATIONAL ITEMS - MISSION KITTED OR STOWED \\
\end{tabular} & 1,896 & $100 \%$ & 1,896 & $\mathbf{0}$ \\
\hline OPERATIONAL ITEMS - EQUIPMENT SPARES \& PACKAGING & 14,353 & $100 \%$ & 14,353 & 0 \\
\hline OPERATIONAL ITEMS - CONSUMABLES \& PACKAGING & 6,082 & $100 \%$ & 6,082 & 0 \\
\hline \multicolumn{5}{|l|}{ OPERATIONAL ITEMS - CREW } \\
\hline OPERATIONAL EMPTY MASS & 43,786 & & & 19,632 \\
\hline PAYLOAD & 1,542 & $100 \%$ & 1,542 & $\mathbf{0}$ \\
\hline \multicolumn{5}{|l|}{ EXPENDABLES - POWER AND THERMAL CONTROL FLUIDS/GASES } \\
\hline \multicolumn{5}{|l|}{ EXPENDABLES - PROPULSION \& REACTION CONTROL FLUIDS/GASES } \\
\hline GROSS MASS at TMI & 45,329 & MINIMUM EI & APTY MASS & 19,632 \\
\hline
\end{tabular}

\section{Basis of Estimate}

For each discipline represented by the CF-MEL, a detailed basis of estimate was provided to allow future designers to understand the assumed designs for each subsystem. Specifically, the basis of estimates included a list of assumptions that went into the subsystem designs including a list of the required capabilities to enable the desired element performance.

Structures and Launch Integration-The primary and secondary structure was sized using a Hypersizer/NASTRAN/PATRAN structural model approach. This is a physics-based bottoms up approach where a multidisciplinary launch and space vehicle parametric analysis element design program is used to create structural finite element models $[10,11]$. These are loads models of fairly course gridding (Figure 3) such that calculated panel and beam internal loads can eventually be processed by the structural component design program HyperSizer [12]. Processing in HyperSizer permits trades on structural materials, beam shape, and wall stiffening options. The parametric modeling program takes input regarding habitat size, and internal structural arrangement to define a geometry to be meshed. Features such as docking/berthing definition, floors, walls, and other secondary structural items are also modeled (Figure 3). Location of inertial load items, ex: internal system masses such as life support, power, stowage, waste, and exercise regions are placed in a parametric manner about the interior of the habitat (Figure 4).

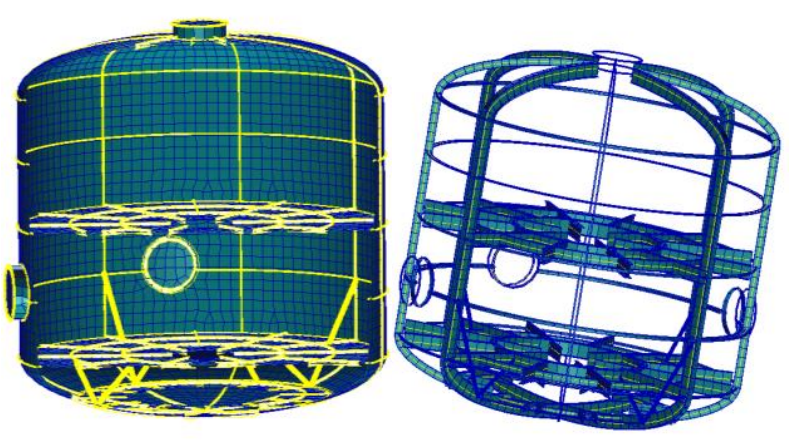

Figure 3. Parametric Modeling of Barrel, Framing and Internal Secondary Structure

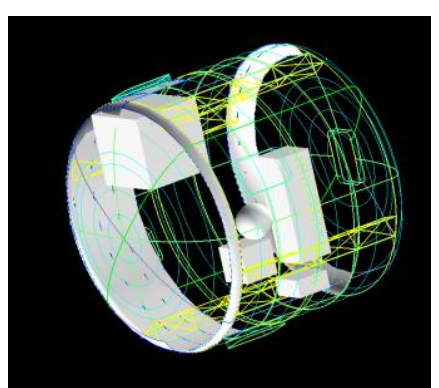

Figure 4. Examples of Inertial Mass Location \& Visualization for Structural Loads Estimation 
The primary structure of the Transit Habitat is assumed to be constructed of $2219 \mathrm{Al}$ orthogrid primary structure plates and 7075 aluminum bar/beam structure utilizing I-beam structural framing. The secondary structure is assumed to be constructed of 7075 aluminum tubing lightly loaded using 3inch diameter tubes with 0.125 inch wall thickness. The geometry of the primary structure is a vertical, monolithic cylinder with elliptical end-domes. It is sized to $7.2 \mathrm{~m}$ outer diameter, which allows $0.3 \mathrm{~m}(0.15 \mathrm{~m}$ on either side) outside of the habitat for the packaging of radiators, communications antennae, etc. within the usable envelope of the $8.4 \mathrm{~m}$ SLS payload shroud. The barrel section is assumed to be $5.2 \mathrm{~m}$ in height, which accommodates two $2.5 \mathrm{~m}$ ceiling heights with a $0.2 \mathrm{~m}$ floor separation between floors. The dome eccentricities ware assumed to be 0.95 eccentricity domes (1.125 m high, each).

The Transit Habitat is assumed to operate at an Earth-like atmospheric pressure $(101.4 \mathrm{kPa})$ and is designed to hold pressure to a factor of safety of 2.0. The structure is designed to hold this pressure and a combined $5 \mathrm{~g}$ axial $/ 1 \mathrm{~g}$ lateral load during launch. The current structural mass represents a launch when the habitat has been offloaded to meet launch vehicle constraints. An additional $15 \%$ penalty is added to the primary structure for fracture mechanics. This penalty captures either limiting minimum gage of pressure shell structure or the application of a $33 \%$ allowable reduction, to reduce operating stress and eliminate crack propagationbased failures.

Other structural features include: two $0.5 \mathrm{~m}$ diameter windows $(1.5 \mathrm{~cm}$ thick), three passive and one active International Docking Standard-compliant docking mechanisms with intravehicular activity hatches, and an inflatable airlock based upon the Minimal Airlock Softgoods Hatch airlock developed at NASA Langley [13]. This soft goods airlock estimate includes a softgoods, internal structure and hard ring interface to habitat. Additionally, a $10 \mathrm{~kg} / \mathrm{m}^{\wedge} 2$ structural penalty for providing MMOD protection is applied over the surface area of the airlock $\left(\sim 28.5 \mathrm{~m}^{\wedge} 2\right)$. Finally, for the Transit Habitat, a $2.5 \%$ penalty on launched mass (no logistics) is used to estimate launch integration structure. Currently this integration structure is assumed to be transported to Mars, but trade options should be investigated to stage this structure.

Micrometeoroid and Orbital Debris-In addition to the fracture mechanics penalty on primary structure, an $\mathrm{Al}$ $6061 \mathrm{~T} 6$ Whipple shield is provided at a $0.3 \mathrm{~m}$ stand-off distance. This shield has an areal density of $5.4 \mathrm{~kg} / \mathrm{m}^{2}$ [14], and is assumed to cover $\sim 50 \%$ of the habitat surface area. The other half is covered by a propulsion buss or dual purpose body-mounted radiators, which also protect against MMOD.

Power-The power system provided represents the Advanced Modular Power System (AMPS) project's design for the enhanced habitat designed by the Future Capabilities Team. Power generation for the habitat is assumed to be provided by the large HPS arrays. Power storage is assumed to be provided by lithium ion batteries and associated battery charge discharge units (BCDUs). More specifically, six $6 \mathrm{~kW}$ BCDUs and six $~ 5400 \mathrm{~W} * \mathrm{hrs} @ 60 \%$ depth of discharge lithium ion batteries are capable of providing $24 \mathrm{~kW}$ for approximately 1.5 hours or less power for longer. These batteries are stored externally to reduce risk to the crew.

The power management and distribution system also leverages the AMPS project design. It includes:

- 2 x DDCU (12kW DC to DC Converter Unit)

- 2 x BDDCU (2kW 120V -120V Bi-directional DC to DC Converter Unit

- 2 x MBSU (Main Bus Switching Unit 2-100A, 4-50A switches)

- 2 x MBSU (Main Bus Switching Unit 1-100A, 10-15A switches)

- 6 x PDU - Internal Power Distribution Unit

- 2 x PDU - External Power Distribution Unit

- 8 x PUP (Portable Utility Panel)

- 1 x Spacecraft Bus Power Harness

This system is rated for $24 \mathrm{~kW}$ with two cross-strapped power distribution paths facilitate bypass of components needing repair without interruption of power.

Life Support - The life support system on the Transit Habitat is based upon scaled ISS hardware as sized using the Advanced Life Support Sizing Analysis Tool (ALSSAT) [15]. This model was run for an 1100 day crewed mission with an assumption that increased reliability and maintainability can be provided with minimal mass increases.

Table 5. Life Support Technology Selection Baseline

\begin{tabular}{|l|l|}
\hline CO2 Removal & $\begin{array}{l}\text { Scaled ISS 4 bed molecular sieve with 30 } \\
\text { days contingency backup using lithium } \\
\text { hydroxide canisters }\end{array}$ \\
\hline CO2 Reduction & Sabatier reactor \\
\hline O2 Generation & $\begin{array}{l}\text { Solid phase electrolysis with 30 days of } \\
\text { contingency stored O2 }\end{array}$ \\
\hline Gas Storage & $\begin{array}{l}\text { Integral tanks sized for 1 cabin } \\
\text { repressurization, 6 pressurized mating } \\
\text { adapter repressurizations, EVA support } \\
\text { and contingency fluid. Assumes 300 m3 } \\
\text { pressurized volume cabin and 0.7 m3 } \\
\text { pressurized mating adapter volume }\end{array}$ \\
\hline $\begin{array}{l}\text { Waste } \\
\text { Management }\end{array}$ & $\begin{array}{l}\text { Basic storage waste collection system with } \\
\text { contingency bags with bulk compaction to } \\
\text { reduce stored volume }\end{array}$ \\
\hline $\begin{array}{l}\text { Water } \\
\text { Revitalization }\end{array}$ & $\begin{array}{l}\text { ISS water revitalization system } \\
\text { (Multifiltration beds and vapor } \\
\text { compression distillation urine processor) } \\
\text { with 30 days of contingency water. } \\
\text { Includes brine recovery. No large tanks } \\
\text { included for surplus water production. }\end{array}$ \\
\hline $\begin{array}{l}\text { EVA Habitat } \\
\text { Support }\end{array}$ & Nond recycle pump with compressor \\
\hline Laundry & None assembly \\
\hline
\end{tabular}


The existing technologies used for the life support functions on ISS are described in Table 5. Advances in these systems are needed to improve reliability and maintainability without compromising system closure. Single unit systems are provided for each with spares and 30 day open loop consumable backups for critical systems to eliminate fully redundant units. Within the MEL breakdown of these systems in Appendix A, the base system estimates are included in the Life Support Systems and Crew Support Equipment, and lifetime limit and failure based spares are captured in Operational Items.

Thermal Control-The Transit Habitat thermal control estimates were derived from the FCT Enhanced habitat design effort, and represent an extension of ISS technology to future destinations. This system is shown in Figure 5 with clarification of the internal and external components. Thermal control represents three functions: heat collection, heat rejection, and active/passive thermal insulation. Heat is collected utilizing a combination of cold plates and heat exchanges. For active heat rejection, the Transit Habitat utilizes a dual loop system with a water-propylene glycol inner loop and a HFE 7200 outer loop. A body-mounted radiator is used to reject heat to space requires $3.3 \mathrm{~kW}$ of heating to prevent freezing. At $130.5 \mathrm{~W} / \mathrm{m}^{2}$ a $15.8 \mathrm{~kW}$ radiator covers $121 \mathrm{~m}^{2}$ of the spacecraft. Additionally, this radiator serves as MMOD shielding for shell where covered.
In addition to the active heat rejection system, passive multilayer insulation is used to prevent heat loss over $229 \mathrm{~m}^{2}$ of the spacecraft surface. Additionally, Wall and hatch heaters are required to prevent heat loss and internal condensation

Communications and Command, Control, \& Data Handling - The Communications subsystem includes several functions including: television equipment, RF communications, optical/laser communication, a deep space atomic clock, advanced pointing imaging camera, space security system, and a proximity communications functionality. In particular, the RF communications system was based upon a combination of X-band and Ka-band systems designed for deep space communication. The optical communications system was based upon a current design for the Orion Lasercomm demonstrator (10 cm aperture). Also, the advanced pointing imaging camera was based upon the flight demonstration on a New Frontiers instrument.

The Command, Control, and Data Handling system was based upon a combination of components from the Altair Descent Module and the flight heritage displays and controllers.

Crew Support Equipment-The crew support equipment includes all of the human accommodations necessary to support crew life during transit. This includes galley/food storage/freezers/food prep, crew quarters, exercise, medical

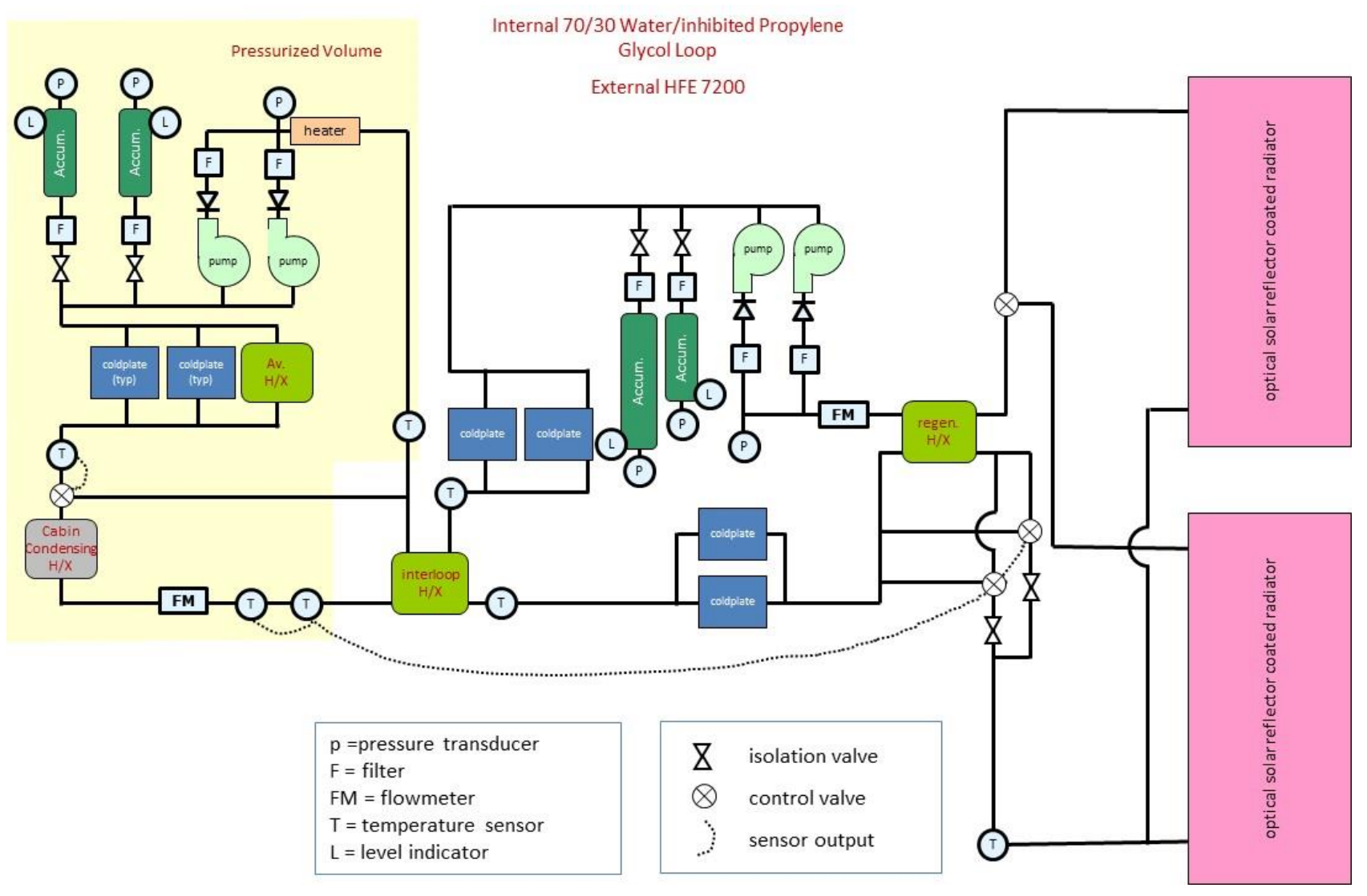

Figure 5. Thermal control system schematic 
care, housekeeping/waste processing, lighting, photography, furniture, and anything else critical to crew support. The galley includes a food warmer and rehydration spigot from [16] and a freezer estimated by the logistics community to be modeled by a $12 \%$ penalty on an assumed $50 \%$ of food which should be refrigerated. Crew quarters are assumed to be constructed from reclaimed secondary structures, but some additional non-reclaimed portions such as crew desks and acoustic partitions are modeled separately. These crew quarters are oriented horizontally for consistency with surface habitats. Crew health care is estimated through a combination of basic kits of medical/surgical/dental equipment (from the ISS Crew Health Care System (CHeCS) Hardware Catalog, Nov. 2011 [17] and the Habitat Demonstration Unit) and a $100 \mathrm{~kg}$ estimate to cover additional medical hardware specific to long duration exploration missions such as in-situ lab analysis or advanced ultrasound.

The exercise estimate provided in Appendix B is an allocation based upon [16] and is meant to represent an exercise suite such as an ergometer and a combination rowing/resistive exercise machine requiring no vibration isolation system. The waste processing equipment is assumed to capture a trash to gas system capable of heating trash sufficiently to convert it into gas which could be used as additional propellant after processing. Finally, all cameras on the habitat are assumed to be captured in a $120 \mathrm{~kg}$ estimate due to the miniaturization of high resolution cameras. The photography estimate assumed to include all cameras on habitat (internal and external) due to camera miniaturization

Extravehicular Activity-The EVA subsystem focuses on suits, spares, EVA tools and airlock services. Suits estimates include four Launch, Entry, and Abort Suits, two in-space Portable Life Support Systems, and an appropriate number of umbilicals. The EVA tools estimate includes suit sizing kit, stowage accessories, maintenance kit, generic tools, safety tethers, bags, etc. Airlock services are derived from Include EVA estimates from Constellation and other sources. Permanent hardware for conducting EVAs, handrails, and wireless EVA communications were also provided by the EVA team.

Logistics and Spares- Logistics are divided into three specific categories: crew consumables (food, clothing, water, gasses, etc.), maintenance and spares, and packaging and overhead. Crew consumption rates were defined using International Space Station (ISS) historical usage and resupply rates in combination with data from the Advanced Life Support Baseline Values and Assumptions Document (BVAD) [18], the Human Integration Design Handbook (HIDH) [19], and Orion/Commercial Crew Development (CCDev) design values [20]. The rates represent current "best estimate" for future exploration systems, and may change as NASA refines mission designs. Food and crew provisions are dependent on the number of crew and duration of the mission as outlined in the reference. Water and gas usage and recovery is based on the operation of the ECLSS and, if applicable, its ability to recycle water and carbon dioxide. The degree of ECLSS system closure determines the amount of water recovered and/or carbon dioxide reduced. For the Mars transit, a regenerative ECLSS is assumed with a Sabatier process reducing carbon dioxide to produce water and oxygen generation via electrolysis. This ECLSS approach results in a water surplus for the Mars transit case due to the water in the food. The gases required cover the assumed contingency period to protect against system downtime, leakage over the life of the mission, and the repressurization assumptions for the pressurized volume.

The second category for logistics is the maintenance and spares items. Maintenance items are comprised of limited lifetime subsystem components with fixed replacement intervals such as filters, adsorbant/dessicant beds, and smoke detectors. Maintenance items are allocated based on operational lifetime. Allocations are specific to habitat size, mission duration, crew count, and number of subsystems included in habitat. The maintenance item estimates are based on ISS historical and resupply rates for similar systems. The spares estimates are based on the Exploration Maintainability Analysis Tool [21]. EMAT probabilistically simulates failures and repairs for a candidate exploration mission to estimate sparing requirements. A Monte Carlo environment is used to simulate representative missions with stochastic failures. System logic diagrams for the habitation critical systems and spares availability are used to evaluate system and mission impacts.

Packaging and overhead is the third category in estimating logistics. All "solid" logistics elements (non-fluid) are assumed to be delivered and stored in standard Cargo Transfer Bags (CTB). A standard "single" CTB has an external volume of $0.053 \mathrm{~m} 3$. Historical ISS delivery data was used to define the average mass of a CTB as $0.83 \mathrm{~kg}$. For each type of logistic item, historical ISS data was used to establish an average "as loaded" density. These densities are then used to determine the number of CTBs required for the "solid" logistics. Fluids and gasses are assumed to be delivered in internal tanks. If needed, fluids can be delivered externally in Russian-designed Rodnik tanks. Each tank has a mass of $35 \mathrm{~kg}$ and can store up to 210 liters $(\mathrm{kg})$ of water, requiring $0.21 \mathrm{~m} 3$ of volume. Gases can be delivered in highpressure composite overwrap pressure vessels (COPVs), which have a mass of $74.8 \mathrm{~kg}$ and can store up to $38 \mathrm{~kg}$ of oxygen or $29 \mathrm{~kg}$ of nitrogen, occupying $0.39 \mathrm{~m} 3$ of volume. Both types of tanks have been used extensively on ISS.

Utilization - The baseline utilization estimate/allocation is a combination of desired equipment which would specifically be useful on long-duration, deep space transits. It includes a multi-purpose workstation (based upon ISS Express rack), a glovebox (ISS with pallet discount), a repair/fabrication workstation, external platforms with payloads (based upon Columbus Module and Express Logistics Carrier), external avionics (based upon Shuttle), cold stowage based upon the (Minus Eighty-degree Laboratory Freezer for ISS) and notional human research payloads. 
The resultant baseline estimate was first reduced by applying a discount of $97.5 \mathrm{~kg}$ for using a pallet-based hardware support strategy over an ISS rack-based strategy. Finally, an allocation on utilization was enforced to achieve a $50 \%$ reduction in this baseline mass through the application of advanced technologies. Future work is needed to determine how to achieve this reduced allocation.

Robotics-Two types of robotics are included in this estimate: and external payload manipulator and an internal humanoid robot. The external robot was based upon an FCT design for a relatively small berthing/payload manipulation arm. This arm is assumed to provide external payload manipulation and telerobotic servicing of habitat exterior. The internal robot estimate is derived from work on the Valkyrie design. Transit habitats are expected to utilize these internal robotics to facilitate astronaut maintenance and inspection tasks. The baseline assumption is two Valkyrie/R3 class robots, which run with a 6 hour run time utilizing batteries. One charge at $200 \mathrm{~W}$ hr of a battery should give if more than 10 hours of battery life. These robots are assumed to monitor and service systems design

\section{Interior Layout}

A final method of capturing habitat design data is the interior layout design of the resultant Transit Habitat. The EMC configuration shown in Figure 1 is 7.2 meters in diameter and includes some propulsion capability with an axial port at the forward end for docking to the Orion capsule and a window in a radial port location. Other options have included radial ports for docking logistics modules, internal airlocks with an EVA hatch at a radial port, and an external airlock attached to a radial port. Depending on the configuration and propulsion method, the aft end of the module would either include an additional docking port or a permanently attached propulsion stage. Surface mounted radiators are shown on the cylinder section, and deployable solar arrays are provided as attached elements where habitat power is not provided by the propulsion bus. These variations are highly dependent on the final architecture for transfer out to Mars and back, and on the servicing scenarios in cislunar space.
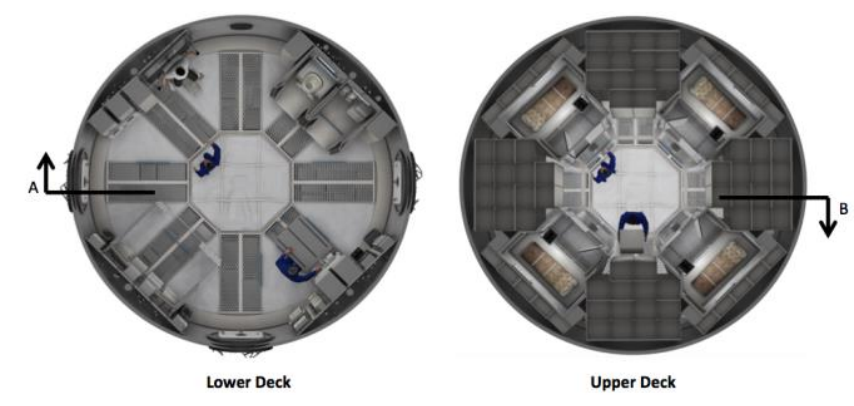

Figure 6. Transit Habitat Internal Floor Plans

The internal volume is designed to be open to the greatest extent possible in a vertical orientation on two deck levels as shown in Figure 6. A vertical orientation with the circular floor plan was selected due to the potential commonality with a large surface habitat for both Mars surface and Phobos missions. All the major life support systems, crew accommodations, and radial docking ports are located on the lower deck, and the stowage and crew quarters are located on the upper deck. This arrangement works for both an in-space transit habitat and a surface habitat. The primary difference is that the transit habitat accommodates 1100 days of stowage on the upper deck and the surface habitat would require only 500 days of stowage. This would permit significantly reducing the height of the module for the surface application, or removal of the upper deck entirely if logistics modules capable of accommodating 500 days of logistics and crew quarters can be attached to the lower radial ports.
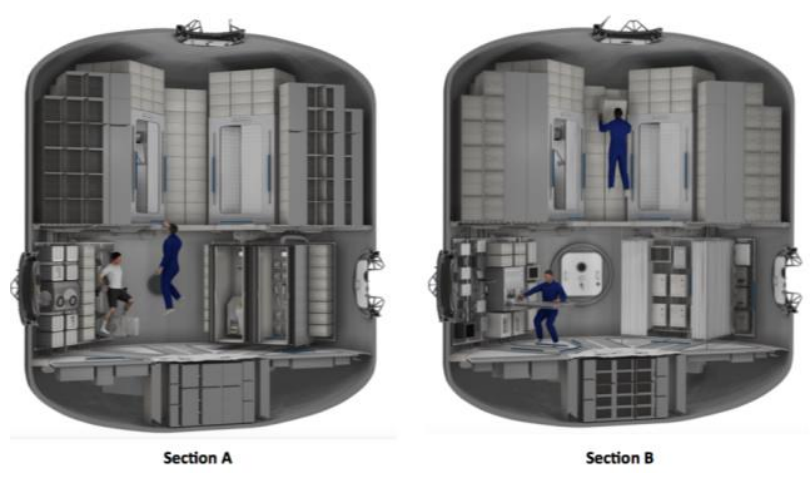

Figure 7. Transit Habitat Sections

Figure 7 provides section cuts through the module showing all of the utility systems and functional spaces. The module illustrated has a forward axial port at the top of the module and three radial docking ports with a window at the fourth port location. The forward port is intended for primary docking of the Orion capsule in cislunar space and a Mars lander upon arrival in Mars orbit. Radial port functions include attachment of an external airlock at one port, and attachment of logistics module at the other ports for outfitting and servicing while in cislunar space. At Mars the radial port attachments would include the airlock, a crew taxi for transport to Phobos, and one spare port or a disposable logistics module.

As noted, the lower deck includes all major life support systems and crew work areas. Sixteen equipment pallets about $0.5 \mathrm{~m}$ wide by $2.0 \mathrm{~m}$ long form the lower floor deck and are designed to be removable for servicing the equipment mounted below and extending into the lower dome volume. Spaces between the pallets provide servicing access and mounting locations for larger tanks and equipment. Four wall panels between the radial ports form an octagonal volume, providing an additional twenty-four pallets for the primary crew systems accommodations. These include research workstations, exercise equipment, waste and hygiene compartments, avionics stations, a galley, and a medical station.

The upper deck includes stowage for the 1100-day mission, shown here in the volume required using standard double sized crew transfer bags. The stowage wraps the crew 
quarters to maximize radiation protection for the crew during solar particle events. A variety of stowage systems and crew quarter layouts have been under consideration to make this volume as efficient as possible, including utilization of stowage bags for wall systems and dividers, and recycling stowage bags into other products using 3D printing technology.

The interior layout shown above in Figure 6 and Figure 7 is not the only approach under consideration. Horizontal layouts have also been examined with three floor levels in both $7.2 \mathrm{~m}$ and $8.4 \mathrm{~m}$ diameters. They provide efficient volume for more stowage and internal workspaces that might be desirable for a laboratory layout, but do not work as well for commonality with surface habitats. Research is ongoing regarding dual-volume habitats, to explore ways for providing a safe haven that will protect the crew from any potential adverse effects resulting from smoke, fire, and pressure loss in one of the volumes. This has included the same layout shown above with a central bulkhead and internal airlock, as well as a two-module version with a connecting airlock for both IVA and EVA access between the pressure vessels.

\section{Achieving 41 Ton Habitat Mass Stretch Goal}

In order achieve the stretch goal of designing a transit habitat with a mass under 41 metric tons, an additional $\sim 1,300 \mathrm{~kg}$ of mass savings are necessary. There are several possible options to achieve this goal which warrant further investigation. First, secondary support structure which was designed conservatively for launch conditions and is no longer critical once the habitat is in a microgravity environment can be removed and staged prior to Mars departure burns. Liberally estimating this potential material at $50 \%$ of secondary structure would reduce the habitat mass by $\sim 750 \mathrm{~kg}$. Additional materials staging could include launch packaging that is no longer necessary after launch and outfitting of the habitat.

Second, alternate structural materials could be leveraged for primary and/or secondary structure. Composites have been estimated to be able to achieve as much as $25 \%$ mass savings over typical spacecraft aluminums. If composites were applied to primary or secondary structures, they could achieve savings of as much as $\sim 1390 \mathrm{~kg}$ or $\sim 380 \mathrm{~kg}$, respectively. Use of composite structures for primary shells has been an area of development, but faces cultural challenges due to the perception that composites are difficult to certify. Technology investment in composites have significant justification if these challenges can be overcome.

Third, redesign of crew equipment with mass reduction in mind could have a substantial impact. Very few advanced manufacturing techniques were assumed in the development of this MEL. Redesign of heavy items could have a substantial impact. For example, fecal canisters represent about one ton of mass and wipes three-quarters of a ton. Redesigning for fewer canisters or revising the waste storage and/or disposal operational paradigm could eliminate much of this mass. Reusable wipes could cut the wipes mass as well.

Finally, a last resort measure could be to further reduce utilization payload on the transit habitat only, leveraging Mars surface or Mars moons habitats, which are delivered uncrewed to provide more utilization. Designers should be cautioned that this mass represents high value provided it does not prevent mission success with available transportation systems.

In summary, there are several options for further reduction of the habitat mass which make $1,300 \mathrm{~kg}$ a reasonable target. Further investigations in the solutions mentioned here and in the next section should be pursued by interested researchers.

\section{RESULTS}

The Mars Transit Habitat design presented in the previous section is a snapshot capturing some of the latest thinking on long duration habitat designs. This design and mass breakdown in Table 3 shows that the mass constraint of 43 metric tons at Trans Mars Injection is achievable for an assumed set of capabilities with the following caveats. First the capability performances and component masses detailed in Appendix A and Section 4 must advance moderately beyond the current state of the art in order to enable this estimate. For example, the lightweight exercise suite must be developed and tested to confirm that such a suite would be clinically effective. Furthermore, these capabilities must be tested sufficiently to ensure their performance, reliability, and maintainability actually improve for analogous missions. This rationale makes ground, ISS, and cislunar testing vital. Additionally, while this design attempted to only leverage substantial technology development efforts where reasonable, an analysis of the cost and schedule of these developments must be performed. For example, if one or many of the chosen capabilities requires more time due to schedule or cost constraints than is allotted before the proposed vehicle launch date, there is a disconnect which must be addressed.

Alternative options are much needed to further reduce this habitat mass without substantially compromising habitat or crew performance. Several additional opportunities are identified which could be studied in future efforts to further reduce habitat mass or improve habitat performance.

- Optimal launch configuration and in-space outfitting

- Improved structural materials

- Staging of materials prior to TMI

- Regenerative fuel

- Vacuum-based, lightweight, low-power freezers

- Increased food rehydration

- Fecal canister redesign

- Use of in-situ manufacturing to decrease mass through commonality and on-demand spares 
- Reduced crew

- Reduced utilization

Similarly, there are several mass threats which require investigation to ensure the current habitat designs are valid. They generally fall into one of three categories and include, but are not limited to:

\section{Requirements Changes}

- Structures: Additional safe haven protection required to protect crew from atmospheric depress

- Structures: Fracture mechanics risk posture more stringent, requiring more mass

- Utilization: Programmatic required increased utilization

- Crew Support Equipment: Unanticipated additional medical requirements

Modeling Changes

- Structures: Secondary structures is not disassemble friendly

- Structures: Airlock mass increases

- Launch/Lander Integration: In-space adapters mass growth, particularly for vibration loads

- Power/Thermal: Power growth exceeds 20kW

- Crew Support Equipment: More substantial exercise suite (particularly vibration isolation systems)

- Crew Support Equipment: Freezers estimates may be aggressive

- Logistics: Radiation protection on return trip \& trash disposal may increase cost

- All: Installation/wiring/cabling

- All: Volume growth

Lack of System Development

- Passive docking system

- Communications: No Mars communications relay

- Life Support: Reliable, maintainable, scaled ISS tech hardware

- Crew Support Equipment: No Trash to Gas system

- Crew Support Equipment: Lightweight exercise

- Crew Support Equipment: lightweight cold storage

Many of these opportunities and threats can be better understood through capability testing on the ground, ISS, and cislunar habitats. Prioritization of test objectives which could have a positive impact on the habitat design should be considered by flight projects.

Finally, there are a few comments on potential uses of the MEL and other data contained in this paper. This paper is primarily intended to serve as a report documenting the Habitat Refinement Activity. However it also has multiple secondary goals. First, it seeks to make habitat design data public so that the spaceflight community can review and suggest alternatives to the current capabilities and design practices. It is hoped that universities and contractors will refer to this data and utilize it in Mars mission planning and technology research efforts. Furthermore, this data is to be used to inform ongoing cislunar habitat designs and may be used to inform mass and other performance targets for subsystem designs. All of this data should inform the Mars Shakedown mission being planned for the mid-2020s. Finally, this data can be used to identify further trade analyses particularly those involving modifying the minimal launch mass and outfitting/sparing method trades.

\section{ACKNOWLEDGEMENTS}

The authors thank the many subject matter expert and integrators who contributed to the habitat refinement activity.

Activity Coordination
Matthew Simon (LaRC)
Kara Latorella (LaRC)
Lynn Bowman (LaRC)
EMC Habitation:
Matthew Simon (LaRC)
Kara Latorella (LaRC)
Scott Howe (JPL)
David Smitherman (MSFC)
Mike Gernhardt (JSC)
John Martin (LaRC)
Roger Lepsch (LaRC)
Jeffrey Cerro (LaRC)
Carey McCleskey (KSC)
Chel Stromgren (LaRC-Binera)
EMC Integration:
Sharon Jefferies (LaRC)

Sharon Jefferies (LaRC)

Patrick Troutman (LaRC)

SMT Integration:

Julie Williams-Byrd (LaRC)

Erica Rodgers (LaRC)

Dale Arney (LaRC)

FCT Integration:

Mark Mcdonald (JSC)

James J. Hill (JSC)

Kriss Kennedy (JSC)

Robert Howard (JSC)

Paul Gilbert (MSFC)

Pedro Lopez (JSC)

EVA:

Raul Blanco (JSC)

Jesse Buffington (JSC)

Natalie Mary (JSC)

Liana Rodriggs (JSC)

Lindsay Aitchison (JSC)

David Autrey (JSC)

Christine Kovich (JSC)

Robotics:

Rob Ambrose (JSC)

Phillip Callen (JSC)

Fire Safety:

Gary Ruff (GRC)

David Urban (GRC)
Life Support:

Robyn Gatens (HQ)

Walter Schneider (MSFC)

Sarah Shull (JSC)

Molly Anderson (JSC)

Imelda Stambaugh (JSC)

Thermal:

Craig Dinsmore (JSC)

Gene Ungar (JSC)

Rubik Sheth (JSC)

Autonomous Mission Ops:

Jeremy Frank (ARC)

Communications and Nav.:

Marc Seibert (KSC)

James Schier (HQ)

Avionics:

Wesley Powell (GSFC)

Glenn Rakow (GRC)

Power:

James Soeder (GRC)

James T. Lawrence (JSC)

Structures:

Jeff Cerro (LaRC)

Timothy Collins (LARC)

Phillip Williams (LARC)

John Zipay (JSC)

Logistics/Spares:

Jim Broyan (JSC)

Mike Ewert (JSC)

Bryan D Mattfeld (LaRC-

Binera)

In-Space Manufacturing:

Mary J. (Niki) Werkheiser

(MSFC)

Michael Fiske (MSFC)

Human Factors:

Jennifer Rochlis (JSC)

Robert Howard (JSC)

Sherry Thaxton (JSC)

Crew Health/Radiation:

Bobbie G. Swan (JSC)

Lisa Stephenson (JSC)

Catherine Mcleod (JSC)

Utilization/Payloads:

Ruthan Lewis (GSFC) 


\section{REFERENCES}

[1] D. A. Craig et al., "The Evolvable Mars Campaign - Study Status," in IEEE Aerospace Conference 2015, Big Sky, MT, 2015.

[2] D. A. Craig et al., "Pioneering Space through the Evolvable Mars Campaign," in 2015 AIAA SPACE Conference and Exposition, Pasadena, CA, 2015.

[3] T. Percy et al., "In-space Transportation for NASA's Evolvable Mars Campaign," in 2015 AIAA SPACE Conference and Exposition, Pasadena, CA, 2015.

[4] R. G. Merrill et al., "An Integrated Hybrid Transportation Architecture for Human Mars Expeditions," in 2015 AIAA SPACE Conference and Exposition, Pasadena, CA, 2015.

[5] K. Goodliff et al., "Comparison of Human Exploration Architecture and Campaign Approaches," in 2015 AIAA Space Conference and Exposition, Pasadena, CA, 2015.

[6] M. A. Simon et al., "Evolvable Mars Campaign Long Duration Habitation Strategies: Architectural Approaches to Enable Human Exploration Missions (AIAA 20154514)," in AIAA SPACE 2015 Conference and Exposition, Pasadena, CA, 2015.

[7] "Mass Properties Control for Space Systems", AIAA-S120A-2015, AIAA, 2015.

[8] K. S. Bernstein et al., "Structural Design Requirements and Factors of Safety for Spaceflight Hardware: For Human Spaceflight. Revision A.," JSC 65828 Rev. A, NASA, 2011.

[9] A. Whitmire et al., "Minimum Acceptable Net Habitable Volume for Long-Duration Exploration Missions." NASA/TM-2015-218564, NASA, 2015.

[10] J. Robinson, "An Overview of NASA's Integrated Design and Engineering Analysis (IDEA) Environment," in AIAA 2011-2392, AIAA, 2011.

[11] TechnoSoft Corporation, "Adaptive Modeling Language," [Online]. Available: http://www.technosoft.com.

[12] Collier Research Corporation, "HyperSizer," [Online]. Available: http://www.hypersizer.com.

[13] B. Doggett et al., "Non-Axisymmetric Inflatable Pressure Structure (NAIPS) Concept that Enables Efficient Packageable Pressure Vessels with Sealable Openings", AIAA 2016-1475, AIAA SciTech Conference, San Diego, CA, 2016.

[14] M. D. Squire et al, "Micrometeoroid and Orbital Debris (MMOD) Design and Analysis Improvements," NASA/TM-2014-218268, Volume I, Appendix A., Figure A-8, NASA, 2014.
[15] H. Y. Yeh et al., "ALSSAT Development Status," Tech. Report, NASA, July 2009.

[16] W. Larson et al., "Human Spaceflight Mission Analysis and Design,” McGraw-Hill, New York, NY, USA, 1999.

[17] "International Space Station CHeCS Medical Hardware Catalog: Version 10.0, NASA, 2011.

[18] M. Anderson et al., "Life Support Baseline Values and Assumptions Document", NASA/TP-2015-218570, NASA, 2015.

[19] "Human Integration Design Handbook," NASA/SP2010-3407, NASA, Washington, DC, 2010.

[20] P. Lopez et al., "Logistics Needs for Potential Deep Space Mission Scenarios Post Asteroid Redirect Crewed Mission," in 2015 IEEE Aerospace Conference, Big Sky, MT, March 2015.

[21] C. Stromgren et al., "Design and Application of the Exploration Maintainability Analysis Tool," AIAA-20125323, in AIAA Space 2012 Conference and Exposition, Pasadena, CA, 2012. 


\section{BIOGRAPHY}

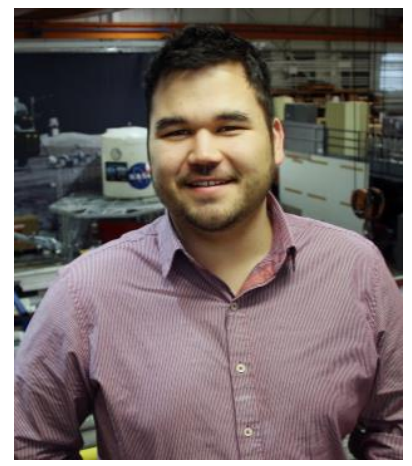

Matthew Simon currently serves as the Habitation and Crew Systems Design Lead for NASA's Human Spaceflight Architecture Team (HAT) supporting the Human Exploration and Operations Mission Directorate (HEOMD). In this role, he is responsible for leading multidisciplinary, multi-center teams to design habitats and crew systems, which support capability development/testing and NASA's Journey to Mars planning efforts. He also supports NASA's Human Research Program as the Exploration Medical Capability Element of NASA Human Research Program, leading systems analyses and integration of future medical hardware into habitat designs. In addition to these roles, Dr. Simon supports multiple other agency and center projects on spacecraft design, habitation, radiation, medical capability development, strategic decision analysis, and technology portfolio characterization. Dr. Simon recently received his Ph. D. in Aerospace Engineering from Georgia Tech. He also has a Master's degree in Aerospace Engineering from Georgia Tech and a Bachelor's degree in Aerospace Engineering from the University of Oklahoma.

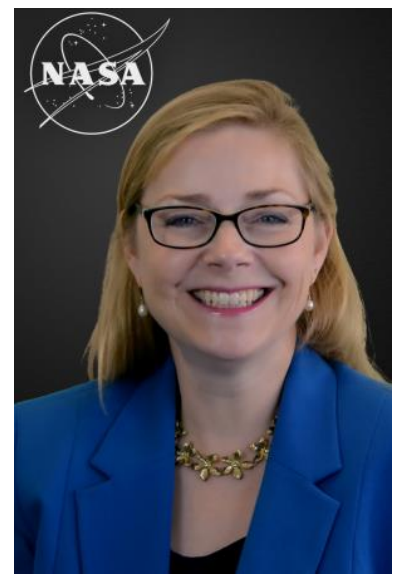

Kara Latorella received a B.S. degree from Cornell University in 1987, an individuallydesigned curriculum for Human Factors Engineering; a M.S. Industrial Engineering degree in 1989 from The Pennsylvania State University, with Human Factors focus; and the Ph.D. in Industrial Engineering from The State University of New York at Buffalo, also with Human Factors focus. She received a NASA Graduate Student Research Fellowship award to conduct her dissertation, "Investigating Interruptions: Implications for Flightdeck Performance," at NASA Langley Research Center, and the Stanley Roscoe award for best Human Factors dissertation from the Aerospace Human Factors Association for this work. Following this, she was awarded a Post-Doc to investigate the extension of human performance modeling toward flightdeck interface design from the National Research Council. In 1997, she began her aerospace human factors civil servant career; work topics including: aviation weather information systems, human performance testing and modeling, and development of nextgeneration airspace system efficiency tools. In 2015, she transitioned to the Space Mission Analysis Branch, and currently investigates habitation, exploration medical, and coordination and decision support with geospatial data in support of the human mission to Mars. She is a full member of the Human Factors and Ergonomics Society, and Sigma Xi

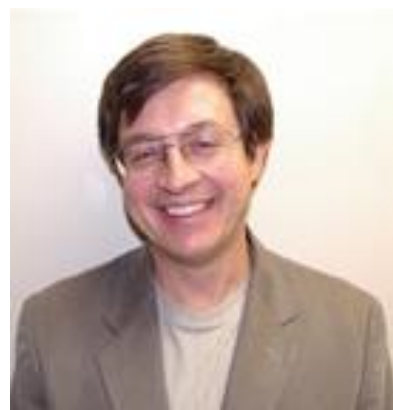

Jeff Cerro has 35 years of involvement at the NASA Langley Research Center as a thermal/structural analyst, mass properties engineer, vehicle concept developer, and project technical lead. $\mathrm{He}$ recently concluded working as a systems analyst in the Vehicle Analysis Branch as technical lead for NASA LaRC's Habitation Radiation Protection "Storm Shelter" project. In recent years Mr. Cerro has been on the NASA Langley Comprehensive Digital Transformation team where he represents the viewpoint of Systems Analysis and Trade Study needs in relation to LaRC's future goals in Model Based Engineering integrated with increased digital capabilities in Big Data, and High Performance Computing. $\mathrm{He}$ assists in developing center strategies for formalizing LaRC engineering needs in Research, Engineering Development and Systems Analysis thru promotion of formal modern standards approaches such as SysML and associated distributed digital collaboration means. Mr. Cerro is actively involved in AIAA Standards development activities in Mass Properties Control for Space Vehicles, and is also Chairman of the Standards Review Board for the Society of Allied Weight Engineers (SAWE). He is a registered Professional Engineer with a Masters in Mechanical Engineering from Rensselaer Polytechnic Institute.

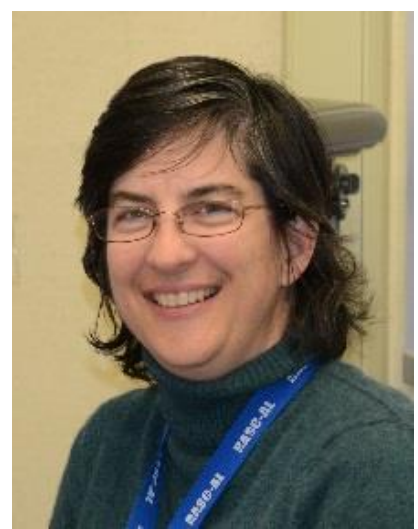

Sharon Jefferies is an aerospace engineer in the Space Mission Analysis Branch at NASA Langley Research Center. She has been at NASA since 2006 and has supported systems concept and mission designs for lunar, NEA, and Mars mission studies under the Human spaceflight Architecture Team (HAT) and for NASA's Asteroid Redirect Mission. Her background is in crew mobility and robotic systems concept development, mission concept-ofoperations development, and capability needs assessment. Ms. Jefferies most recently led the integration of systems and operations across the Evolvable Mars Campaign and supported system concept development for Mars missions. Ms. Jefferies has a Bachelor of Science in Mechanical Engineering from the United States Military Academy 


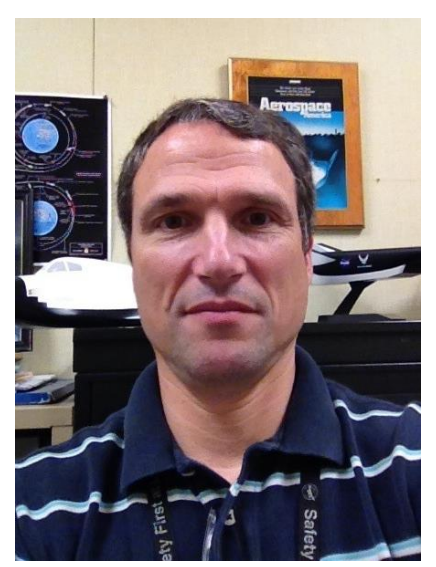

John Martin is a senior aerospace engineer in the Vehicle Analysis Branch at NASA's Langley Research Center in Hampton, Virginia. He has 34 years of experience with aerospace systems analysis and design with significant focus on reusable launch and entry vehicle design and has supported the Commercial Cargo (COTS) and Commercial Crew Program's since their beginnings. Mr. Martin has a Bachelor of Science in Aerospace Engineering from the University of Michigan (1982) and received the NASA Exceptional Service Metal in 2014.

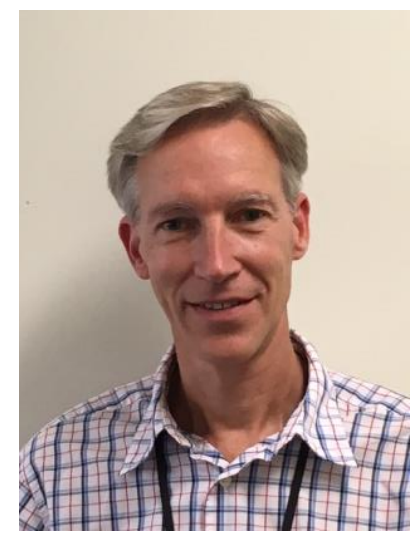

Roger Lepsch is a senior aerospace engineer for the Vehicle Analysis Branch at NASA's Langley Research Center in Hampton, Virginia. He has more than 30 years of experience in the conceptual design of advanced vehicle concepts. He has both led and participated in a large number of team activities to identify promising, future vehicle systems and determine accompanying technology requirements. His experience encompasses a wide range of vehicle types from high-speed aircraft to space systems. Mr. Lepsch has a Master of Science degree in Astronautics Engineering from George Washington University (1993) and a Bachelor of Science degree in Aerospace Engineering from the University of Cincinnati (1984).

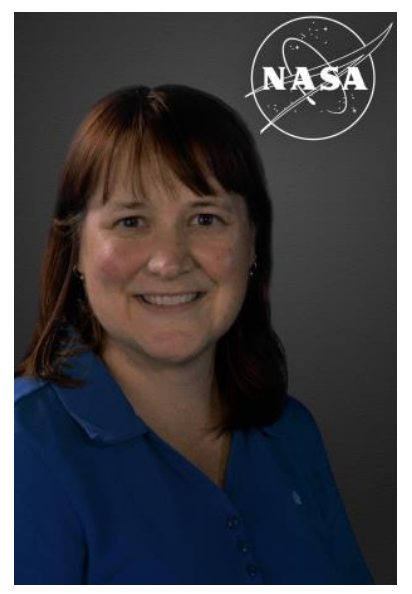

Kandyce Goodliff is an aerospace engineer at NASA Langley Research Center in Hampton, VA, with the Space Mission Analysis Branch (SMAB). Her primary roles as a systems analyst for SMAB are conceptual design and sizing of human and robotic spacecraft, mission and spacecraft analysis, and campaign analysis for human exploration. She has a Bachelor of Science in Aerospace Engineering from Embry-Riddle Aeronautical University and a Master of Science in Mechanical Engineering from the George Washington University

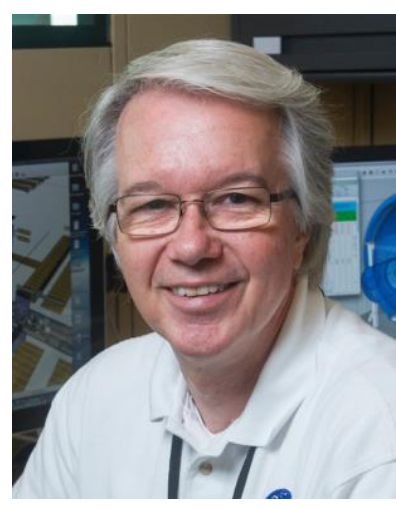

David Smitherman is an architect and study manager of future projects for the Advanced Concept Office at NASA's Marshall Space Flight Center in Huntsville Alabama. His work focuses on space habitats, lunar and Mars habitation systems, space transportation infrastructures, and overall mission planning. He worked as an architect in the 1980 's, as a planner during the redesign of the space station and various space station payloads in the 1990's, and since 1998 has been a study lead for various advanced concepts studies including Space Business Parks, New Space Industries, Space Elevators, Solar Power Satellites, Propellant Production Depots, and a wide variety of Deep Space Habitat concepts. Mr. Smitherman has a Master of Science degree in Space Architecture from the University of Houston (2008), and Bachelor of Architecture and Bachelor of Science in Environmental Design degrees from Auburn University (1980). He is a registered architect in the State of Alabama and holds a national certification from the National Council of Architectural Registration Boards.

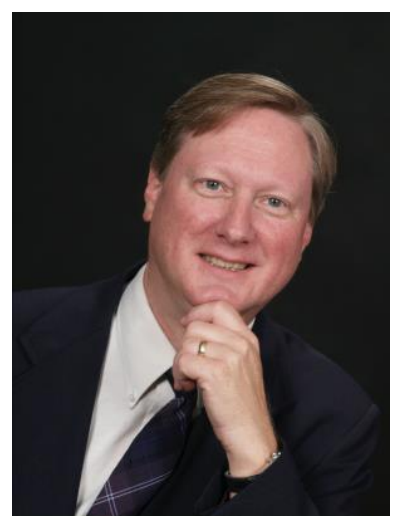

Carey McCleskey currently serves as Technical Manager in the Modeling and Simulation Branch in NASA Kennedy Space Center's (KSC's) Engineering \& Technology Directorate. Mr. McCleskey has worked for NASA at the Kennedy Space Center for 38 years. After earning a bachelor's degree in aerospace engineering (BAE) at the Georgia Institute of Technology in 1983, he became supervisor of KSC's Flight Controls Systems Section in the early 1990s. He is currently engaged in concept analysis and technology studies with NASA's Integrated Analysis and Mars Study Teams, and performing support systems architecture analysis for KSC's Exploration Research and Technology Programs Directorate. $\mathrm{He}$ is a Senior Member of the American Institute of Aeronautics and Astronautics, earned NASA's "Snoopy" Award for Shuttle Return-to-Flight in 1988, and received NASA's Exceptional Service Medal in 2005 for contributions to the NASA Exploration Systems Architecture Study (ESAS). 


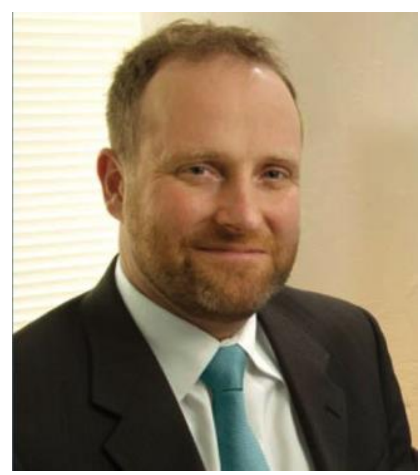

Chel Stromgren, Chief Scientist of Binera, Inc., has extensive experience in the development and application of stochastic modeling and analysis methodologies and has specialized in working with stakeholders to integrate probabilistic analysis into their planning processes. As part of this work, he has led efforts to develop probabilistic strategic analysis methodologies that allow users to optimize architecture and mission design in uncertain environments. With more than 23 years of experience in risk assessment, risk management, strategic policy analysis, and stochastic modeling, he has been a leader in the field, developing modeling best practices and integrating 


\section{APPENDICES}

\section{A. Master EquipMent List}

\begin{tabular}{|c|c|c|c|c|c|c|c|c|c|c|}
\hline \multirow[t]{3}{*}{ SBS ID } & \multicolumn{2}{|r|}{ COMMON FUNCTIONAL CATEGORY (TIER 1) } & \multirow[b]{3}{*}{ Qty } & \multirow[b]{3}{*}{$\begin{array}{c}\text { Unit Mass } \\
(\mathrm{kg})\end{array}$} & \multirow[b]{3}{*}{$\begin{array}{c}\text { Basic } \\
\text { Mass }(\mathrm{kg})\end{array}$} & \multirow[b]{3}{*}{$\begin{array}{l}\text { MGA } \\
(\%)\end{array}$} & \multirow[b]{3}{*}{$\begin{array}{c}\mathrm{MGA} \\
(\mathrm{kg})\end{array}$} & \multirow[b]{3}{*}{$\begin{array}{l}\text { Predicted } \\
\text { Manuf } \\
\text { Empty } \\
\text { Mass (kg) }\end{array}$} & \multirow[b]{3}{*}{\begin{tabular}{|c|} 
Predicted \\
Total \\
Operational \\
Items \\
Mass (kg)
\end{tabular}} & \multirow[b]{3}{*}{\begin{tabular}{|c} 
Predicted \\
Total Tier 1 \\
Category \\
Mass (kg)
\end{tabular}} \\
\hline & & COMMON EQUIPMENT GROUP (TIER 2) & & & & & & & & \\
\hline & & $\begin{array}{l}\text { UNIQUE COMPONENT/SUB-ASSEMBLY (TIER } \\
\text { 3) }\end{array}$ & & & & & & & & \\
\hline 0.0 .0 & HAB & & & & & & & & & \\
\hline 1.0 .0 & \multicolumn{2}{|c|}{ BODY STRUCTURES } & 10 & - & $6,166.65$ & $19.38 \%$ & $1,194.84$ & $7,361.49$ & 0.00 & 7,361.49 \\
\hline 1.1.0 & & PRIMARY STRUCTURE - PRESSURIZED & 9 & - & $4,890.65$ & $19.21 \%$ & 939.64 & $5,830.29$ & - & \\
\hline 1.1 .1 & & \begin{tabular}{|l|l|} 
& PRESSURE SHELL \\
\end{tabular} & 1 & $4,631.25$ & $4,631.25$ & $20.00 \%$ & 926.25 & $5,557.50$ & - & \\
\hline 1.1 .2 & & WINDOWS & 4 & 8.25 & 33.00 & $20.00 \%$ & 6.60 & 39.60 & - & - \\
\hline 1.1 .3 & & HATCHES & 4 & 56.60 & 226.40 & $3.00 \%$ & 6.79 & 233.19 & - & - \\
\hline 1.1 .4 & & DOORS & 0 & 0.00 & 0.00 & $0.00 \%$ & 0.00 & 0.00 & - & \\
\hline 1.2 .0 & & PRIMARY STRUCTURE - UNPRESSURIZED & 0 & - & 0.00 & 0.00 & 0.00 & 0.00 & - & - \\
\hline 1.2 .1 & & \begin{tabular}{|l|l|} 
& [ENTER COMPONENT/SUBASSY] \\
\end{tabular} & 0 & 0.00 & 0.00 & $0.00 \%$ & 0.00 & 0.00 & - & - \\
\hline 1.3.0 & & SECONDARY STRUCTURE - INTERNAL & 1 & - & $1,276.00$ & $20.00 \%$ & 255.20 & $1,531.20$ & - & - \\
\hline 1.3 .1 & & \begin{tabular}{|l|l|} 
& STRUCTURAL SUPPORT TRUSSES \\
\end{tabular} & 1 & $1,276.00$ & $1,276.00$ & $20.00 \%$ & 255.20 & $1,531.20$ & - & - \\
\hline 1.3 .2 & & WALLS & 0 & 0.00 & 0.00 & $20.00 \%$ & 0.00 & 0.00 & - & \\
\hline 1.3 .3 & & FLOORS & 0 & 0.00 & 0.00 & $20.00 \%$ & 0.00 & 0.00 & - & - \\
\hline 1.4 .0 & & SECONDARY STRUCTURE - EXTERNAL & 0 & - & 0.00 & 0.00 & 0.00 & 0.00 & - & - \\
\hline 1.4 .1 & & \begin{tabular}{|l|l} 
& [ENTER COMPONENT/SUBASSY] \\
\end{tabular} & 0 & 0.00 & 0.00 & $0.00 \%$ & 0.00 & 0.00 & - & \\
\hline $1 . B .0$ & & SPARE BODY STRUCTURES EQUIP \& PACKAGING & 0 & - & 0.00 & 0.00 & 0.00 & - & 0.00 & - \\
\hline 1.B.1 & & \begin{tabular}{|l|l|} 
& [ENTER COMPONENT/SUBASSY] \\
\end{tabular} & 0 & 0.00 & 0.00 & $0.00 \%$ & 0.00 & & 0.00 & \\
\hline 2.0 .0 & \multicolumn{2}{|r|}{ CONNECTION \& SEPARATION SYSTEMS } & 7 & - & 589.60 & $10.01 \%$ & 59.02 & 648.62 & 0.00 & 648.62 \\
\hline 2.1 .0 & & DOCKING/BERTHING INTERFACE MECHANISMS & 7 & - & 589.60 & $10.01 \%$ & 59.02 & 648.62 & - & - \\
\hline 2.1 .1 & & \begin{tabular}{|l|l|} 
PASSIVE IDSS-COMPLIANT DOCKING \\
MECHANISM
\end{tabular} & 2 & 128.60 & 257.20 & $10.00 \%$ & 25.72 & 282.92 & & \\
\hline 2.1 .2 & & $\begin{array}{l}\text { ACTIVE IDSS-COMPLIANT DOCKING } \\
\text { MECHANISM }\end{array}$ & 1 & 332.00 & 332.00 & $10.00 \%$ & 33.20 & 365.20 & - & \\
\hline 2.1 .3 & & FLEXIBLE PROBES WITH RESISTORS & 4 & 0.10 & 0.40 & $25.00 \%$ & 0.10 & 0.50 & & \\
\hline 2.2 .0 & & SEPARATION EQUIPMENT & 0 & - & 0.00 & \begin{tabular}{|l|}
0.00 \\
\end{tabular} & 0.00 & 0.00 & - & \\
\hline 2.2 .1 & & \begin{tabular}{|l|l} 
& [ENTER COMPONENT/SUBASSY] \\
\end{tabular} & 0 & 0.00 & 0.00 & $0.00 \%$ & 0.00 & 0.00 & & \\
\hline 2.9 .0 & & CONNECTION \& SEPARATION SYS INSTALLATION & 0 & - & 0.00 & 0.00 & 0.00 & 0.00 & - & - \\
\hline 2.9 .1 & & \begin{tabular}{|l|l|} 
& [ENTER COMPONENT/SUBASSY] \\
\end{tabular} & 0 & 0.00 & 0.00 & $0.00 \%$ & 0.00 & 0.00 & & \\
\hline 2.B.O & & $\begin{array}{l}\text { SPARE CONNECTION \& SEPARATION EQUIP \& } \\
\text { PACKAGING }\end{array}$ & 0 & & 0.00 & 0.00 & 0.00 & & 0.00 & - \\
\hline $2 . B .1$ & & \begin{tabular}{|l|l|} 
& [ENTER COMPONENT/SUBASSY] \\
\end{tabular} & 0 & 0.00 & 0.00 & $0.00 \%$ & 0.00 & & 0.00 & \\
\hline 2.C.O & & $\begin{array}{l}\text { CONNECTION \& SEPARATION SYSTEMS } \\
\text { CONSUMABLES \& PACKAGING }\end{array}$ & 0 & - & 0.00 & 0.00 & 0.00 & & 0.00 & \\
\hline $2 . C .1$ & & \begin{tabular}{|l|l|} 
& [ENTER COMPONENT/SUBASSY] \\
\end{tabular} & 0 & 0.00 & 0.00 & $0.00 \%$ & 0.00 & & 0.00 & \\
\hline 2.D.0 & & CONNECTION \& SEPARATION SYSTEM RESIDUALS & 0 & & 0.00 & 0.00 & 0.00 & & 0.00 & \\
\hline $2 . D .1$ & & \begin{tabular}{|l|l|} 
& [ENTER COMPONENT/SUBASSY] \\
\end{tabular} & 0 & 0.00 & 0.00 & $0.00 \%$ & 0.00 & & 0.00 & \\
\hline 3.0 .0 & LAUN & VCH/TAKEOFF \& LANDING SUPPORT SYSTEMS & 1 & - & 546.75 & $20.00 \%$ & 109.35 & 656.10 & 0.00 & 656.10 \\
\hline 3.1 .0 & & LAUNCH SUPPORT EQUIP & 1 & - & 546.75 & $20.00 \%$ & 109.35 & 656.10 & & 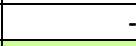 \\
\hline 3.1 .1 & & \begin{tabular}{|l|l|} 
& LAUNCH/LANDER INTEGRATION \\
\end{tabular} & 1 & 546.75 & 546.75 & $20.00 \%$ & 109.35 & 656.10 & & \\
\hline 3.2 .0 & & LANDING GEAR & 0 & - & 0.00 & 0.00 & 0.00 & 0.00 & - & - \\
\hline 3.2 .1 & & \begin{tabular}{|l|l|} 
& [ENTER COMPONENT/SUBASSY] \\
\end{tabular} & 0 & 0.00 & 0.00 & $0.00 \%$ & 0.00 & 0.00 & & \\
\hline 3.3 .0 & & DEPLOYABLE AERODYNAMIC DEVICES & 0 & - & 0.00 & 0.00 & 0.00 & 0.00 & - & - \\
\hline 3.3 .1 & & \begin{tabular}{|l|l|} 
& [ENTER COMPONENT/SUBASSY] \\
\end{tabular} & 0 & 0.00 & 0.00 & $0.00 \%$ & 0.00 & 0.00 & - & - \\
\hline 3.4 .0 & & VERTICAL LANDING DECELERATION EQUIP & 0 & - & 0.00 & 0.00 & 0.00 & 0.00 & - & - \\
\hline 3.4 .1 & & \begin{tabular}{|l|l|} 
& [ENTER COMPONENT/SUBASSY] \\
\end{tabular} & 0 & 0.00 & 0.00 & $0.00 \%$ & 0.00 & 0.00 & & \\
\hline 3.9 .0 & & $\begin{array}{l}\text { LAUNCH/TAKEOFF \& LANDING SPT SYS } \\
\text { INSTALLATION }\end{array}$ & 0 & & 0.00 & 0.00 & 0.00 & 0.00 & - & - \\
\hline 3.9 .1 & & \begin{tabular}{|l|l|} 
& [ENTER COMPONENT/SUBASSY] \\
\end{tabular} & 0 & 0.00 & 0.00 & $0.00 \%$ & 0.00 & 0.00 & - & - \\
\hline 3.B.0 & & SPARE LAUNCH/LANDING SPT EQUIP \& PACKAGING & 0 & - & 0.00 & 0.00 & 0.00 & & 0.00 & \\
\hline $3 . B .1$ & & \begin{tabular}{|l|l|} 
& [ENTER COMPONENT/SUBASSY] \\
\end{tabular} & 0 & 0.00 & 0.00 & $0.00 \%$ & 0.00 & & 0.00 & \\
\hline 3.C.O & & $\begin{array}{l}\text { LAUNCH AND LANDING SUPPORT CONSUMABLES \& } \\
\text { PACKAGING }\end{array}$ & 0 & & 0.00 & 0.00 & 0.00 & & 0.00 & \\
\hline 3.C.1 & & \begin{tabular}{|l|l|} 
& [ENTER COMPONENT/SUBASSY] \\
\end{tabular} & 0 & 0.00 & 0.00 & $0.00 \%$ & 0.00 & & 0.00 & \\
\hline
\end{tabular}




\begin{tabular}{|c|c|c|c|c|c|c|c|c|c|}
\hline \multirow[t]{3}{*}{ SBS ID } & COMMON FUNCTIONAL CATEGORY (TIER 1) & \multirow[b]{3}{*}{ Qty } & \multirow[b]{3}{*}{$\begin{array}{l}\text { Unit Mass } \\
(\mathrm{kg})\end{array}$} & \multirow[b]{3}{*}{$\left|\begin{array}{c}\text { Basic } \\
\text { Mass }(\mathrm{kg})\end{array}\right|$} & \multirow[b]{3}{*}{$\begin{array}{l}\text { MGA } \\
(\%)\end{array}$} & \multirow[b]{3}{*}{$\begin{array}{l}\text { MGA } \\
(\mathrm{kg})\end{array}$} & \multirow[b]{3}{*}{$\begin{array}{c}\text { Predicted } \\
\text { Manuf } \\
\text { Empty } \\
\text { Mass (kg) }\end{array}$} & \multirow[b]{3}{*}{\begin{tabular}{|c|} 
Predicted \\
Total \\
Operational \\
Items \\
Mass (kg) \\
\end{tabular}} & \multirow[b]{3}{*}{\begin{tabular}{|l} 
Predicted \\
Total Tier 1 \\
Category \\
Mass (kg)
\end{tabular}} \\
\hline & COMMON EQUIPMENT GROUP (TIER 2) & & & & & & & & \\
\hline & $\begin{array}{l}\text { UNIQUE COMPONENT/SUB-ASSEMBLY (TIER } \\
\text { 3) }\end{array}$ & & & & & & & & \\
\hline 3.D.0 & LAUNCH AND LANDING SUPPORT RESIDUALS & 0 & & 0.00 & 0.00 & 0.00 & & 0.00 & \\
\hline $3 . D .1$ & \begin{tabular}{|l|l|l|} 
& & [ENTER COMPONENT/SUBASSY] \\
\end{tabular} & 0 & 0.00 & 0.00 & $0.00 \%$ & 0.00 & & 0.00 & \\
\hline 4.0 .0 & NATURAL \& INDUCED ENVIRON PROTECT SYSTEMS & 1 & - & 567.00 & $20.00 \%$ & 113.40 & 680.40 & 0.00 & 680.40 \\
\hline 4.1 .0 & \begin{tabular}{|l|l|} 
& RADIATION PROTECTION EQUIP \\
\end{tabular} & 0 & - & 0.00 & 0.00 & 0.00 & 0.00 & & \\
\hline 4.1 .1 & \begin{tabular}{|l|l} 
& [ENTER COMPONENT/SUBASSY] \\
\end{tabular} & 0 & 0.00 & 0.00 & $0.00 \%$ & 0.00 & 0.00 & & \\
\hline 4.2 .0 & MMOD PROTECTION EQUIP & 1 & - & 567.00 & $20.00 \%$ & 113.40 & 680.40 & - & \\
\hline 4.2 .1 & \begin{tabular}{|l|l|} 
MMOD \\
\end{tabular} & 1 & 567.00 & 567.00 & $20.00 \%$ & 113.40 & 680.40 & - & \\
\hline 4.3 .0 & THERMAL PROTECTION EQUIP & 0 & - & 0.00 & 0.00 & 0.00 & 0.00 & - & \\
\hline 4.3 .1 & \begin{tabular}{|l|l} 
& [ENTER COMPONENT/SUBASSY]
\end{tabular} & 0 & 0.00 & 0.00 & $0.00 \%$ & 0.00 & 0.00 & & \\
\hline 4.4 .0 & VIBRO-ACOUSTIC PROTECTION EQUIP & 0 & - & 0.00 & 0.00 & 0.00 & 0.00 & - & \\
\hline 4.4 .1 & \begin{tabular}{|l|l|} 
& [ENTER COMPONENT/SUBASSY] \\
\end{tabular} & 0 & 0.00 & 0.00 & $0.00 \%$ & 0.00 & 0.00 & - & \\
\hline 4.5 .0 & PRESSURE DIFFERENTIAL PROTECTION EQPIPMENT & 0 & - & 0.00 & 0.00 & 0.00 & 0.00 & - & \\
\hline 4.5 .1 & \begin{tabular}{|l|l|} 
& [ENTER COMPONENT/SUBASSY] \\
\end{tabular} & 0 & 0.00 & 0.00 & $0.00 \%$ & 0.00 & 0.00 & - & \\
\hline 4.6 .0 & CONTAMINATION CONTROL EQUIP & 0 & - & 0.00 & 0.00 & 0.00 & 0.00 & - & 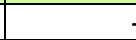 \\
\hline 4.6 .1 & \begin{tabular}{|l|l} 
& [ENTER COMPONENT/SUBASSY] \\
\end{tabular} & 0 & 0.00 & 0.00 & $0.00 \%$ & 0.00 & 0.00 & - & \\
\hline 4.7 .0 & COATINGS (CORROSION-PROTECTION) & 0 & - & 0.00 & 0.00 & 0.00 & 0.00 & - & \\
\hline 4.7 .1 & \begin{tabular}{|l|l|} 
[ENTER COMPONENT/SUBASSY] \\
\end{tabular} & 0 & 0.00 & 0.00 & $0.00 \%$ & 0.00 & 0.00 & - & \\
\hline 4.9 .0 & PROTECTION SYS INSTALLATION & 0 & - & 0.00 & 0.00 & 0.00 & 0.00 & - & 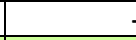 \\
\hline 4.9 .1 & \begin{tabular}{|l|l|} 
& [ENTER COMPONENT/SUBASSY] \\
\end{tabular} & 0 & 0.00 & 0.00 & $0.00 \%$ & 0.00 & 0.00 & & \\
\hline $4 . B .0$ & SPARE PROTECTION SYS EQUIP \& PACKAGING & 0 & - & 0.00 & 0.00 & 0.00 & - & 0.00 & \\
\hline $4 . B .1$ & \begin{tabular}{|l|l|} 
& [ENTER COMPONENT/SUBASSY] \\
\end{tabular} & 0 & 0.00 & 0.00 & $0.00 \%$ & 0.00 & - & 0.00 & \\
\hline $4 . C .0$ & PROTECTION SYS CONSUMABLES \& PACKAGING & 0 & - & 0.00 & 0.00 & 0.00 & - & 0.00 & \\
\hline $4 . C .1$ & \begin{tabular}{|l|l|} 
& [ENTER COMPONENT/SUBASSY] \\
\end{tabular} & 0 & 0.00 & 0.00 & $0.00 \%$ & 0.00 & & 0.00 & \\
\hline $4 . D .0$ & PROTECTION SYS RESIDUALS & 0 & - & 0.00 & 0.00 & 0.00 & - & 0.00 & \\
\hline $4 . D .1$ & \begin{tabular}{|l|l} 
& [ENTER COMPONENT/SUBASSY] \\
\end{tabular} & 0 & 0.00 & 0.00 & $0.00 \%$ & 0.00 & & 0.00 & \\
\hline 5.0 .0 & PROPULSION SYSTEMS & 0 & - & 0.00 & 0.00 & 0.00 & 0.00 & 0.00 & 0.00 \\
\hline 5.1 .0 & \begin{tabular}{|l|l|} 
& MAIN POWER PLANTS \\
\end{tabular} & 0 & - & 0.00 & 0.00 & 0.00 & 0.00 & - & \\
\hline 5.1 .1 & \begin{tabular}{|l|l} 
& [ENTER COMPONENT/SUBASSY] \\
\end{tabular} & 0 & 0.00 & 0.00 & $0.00 \%$ & 0.00 & 0.00 & - & 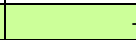 \\
\hline 5.2 .0 & MAIN PROPELLANT MGMT \& DISTRIB SYSTEMS & 0 & - & 0.00 & 0.00 & 0.00 & 0.00 & - & - \\
\hline 5.2 .1 & \begin{tabular}{|l|l|} 
& [ENTER COMPONENT/SUBASSY] \\
\end{tabular} & 0 & 0.00 & 0.00 & $0.00 \%$ & 0.00 & 0.00 & & \\
\hline 5.3 .0 & AUXILIARY POWER PLANTS & 0 & - & 0.00 & 0.00 & 0.00 & 0.00 & - & \\
\hline 5.3 .1 & \begin{tabular}{|l|l|} 
& [ENTER COMPONENT/SUBASSY] \\
\end{tabular} & 0 & 0.00 & 0.00 & $0.00 \%$ & 0.00 & 0.00 & & \\
\hline 5.4.0 & $\begin{array}{l}\text { AUXILIARY PROPELLANT MGMT \& DISTRIB } \\
\text { SYSTEMS }\end{array}$ & 0 & - & 0.00 & 0.00 & 0.00 & 0.00 & - & \\
\hline 5.4 .1 & \begin{tabular}{|l|l} 
& [ENTER COMPONENT/SUBASSY] \\
\end{tabular} & 0 & 0.00 & 0.00 & $0.00 \%$ & 0.00 & 0.00 & & \\
\hline 5.9 .0 & PROPULSION SYS INSTALLATION & 0 & - & 0.00 & 0.00 & 0.00 & 0.00 & - & - \\
\hline 5.9 .1 & \begin{tabular}{|l|l|} 
& [ENTER COMPONENT/SUBASSY] \\
\end{tabular} & 0 & 0.00 & 0.00 & $0.00 \%$ & 0.00 & 0.00 & & \\
\hline $5 . B .0$ & SPARE PROPULSION SYSTEM EQUIP \& PACKAGING & 0 & - & 0.00 & 0.00 & 0.00 & - & 0.00 & \\
\hline $5 . B .1$ & \begin{tabular}{|l|l|} 
& [ENTER COMPONENT/SUBASSY] \\
\end{tabular} & 0 & 0.00 & 0.00 & $0.00 \%$ & 0.00 & - & 0.00 & \\
\hline $5 . D .0$ & PRESS, PURGE \& PROP CTL RESIDUALS & 0 & - & 0.00 & 0.00 & 0.00 & - & 0.00 & 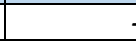 \\
\hline 5.D.1 & \begin{tabular}{|l|l} 
& [ENTER COMPONENT/SUBASSY] \\
\end{tabular} & 0 & 0.00 & 0.00 & $0.00 \%$ & 0.00 & - & 0.00 & \\
\hline $5 . F .0$ & MAIN PROPULSION SYSTEM PROPELLANT & 0 & - & 0.00 & 0.00 & 0.00 & & 0.00 & \\
\hline 5.F.1 & \begin{tabular}{|l|l|} 
& [ENTER COMPONENT/SUBASSY]
\end{tabular} & 0 & 0.00 & 0.00 & $0.00 \%$ & 0.00 & & 0.00 & \\
\hline $5 . G .0$ & AUXILIARY PROPULSION SYSTEM PROPELLANT & 0 & - & 0.00 & 0.00 & 0.00 & - & 0.00 & \\
\hline $5 . G .1$ & \begin{tabular}{|l|l|} 
& [ENTER COMPONENT/SUBASSY] \\
\end{tabular} & 0 & 0.00 & 0.00 & $0.00 \%$ & 0.00 & & 0.00 & \\
\hline 5.1 .0 & $\begin{array}{l}\text { PROPULSION CONTROL/START \& SHUTDOWN } \\
\text { CONSUMABLES }\end{array}$ & 0 & & 0.00 & 0.00 & 0.00 & & 0.00 & \\
\hline 5.1 .1 & \begin{tabular}{|l|l|} 
& [ENTER COMPONENT/SUBASSY] \\
\end{tabular} & 0 & 0.00 & 0.00 & $0.00 \%$ & 0.00 & & 0.00 & \\
\hline 5.J. 0 & $\begin{array}{l}\text { MAIN \& AUX PROP SYS PRESSURIZATION } \\
\text { CONSUMABLES }\end{array}$ & 0 & & 0.00 & 0.00 & 0.00 & & 0.00 & \\
\hline $5 . J .1$ & \begin{tabular}{|l|l|} 
& [ENTER COMPONENT/SUBASSY] \\
\end{tabular} & 0 & 0.00 & 0.00 & $0.00 \%$ & 0.00 & & 0.00 & \\
\hline $5 . K .0$ & $\begin{array}{l}\text { MAIN \& AUX PROP SYS PURGE CONSUMABLES \& } \\
\text { PACKAGING }\end{array}$ & 0 & & 0.00 & 0.00 & 0.00 & & 0.00 & \\
\hline $5 . K .1$ & \begin{tabular}{|l|l|} 
& [ENTER COMPONENT/SUBASSY]
\end{tabular} & 0 & 0.00 & 0.00 & $0.00 \%$ & 0.00 & & 0.00 & \\
\hline 6.0.0 & POWER SYSTEMS & 37 & - & $1,034.00$ & $19.02 \%$ & 196.68 & $1,230.68$ & 0.00 & $1,230.68$ \\
\hline 6.1 .0 & \begin{tabular}{|l|l|} 
& MAIN POWER SOURCE EQUIP \\
\end{tabular} & 12 & - & 648.00 & $12.22 \%$ & 79.20 & 727.20 & - & \\
\hline 6.1 .1 & \begin{tabular}{|l|l|} 
BCDU (6KW BATTERY CHARGE DISCHARGE \\
UNIT)
\end{tabular} & 6 & 30.00 & 180.00 & $18.00 \%$ & 32.40 & 212.40 & & \\
\hline 6.1 .2 & BATTERY (5400 W*HRS @ 60\% DOD) & 6 & 78.00 & 468.00 & $10.00 \%$ & 46.80 & 514.80 & - & \\
\hline
\end{tabular}




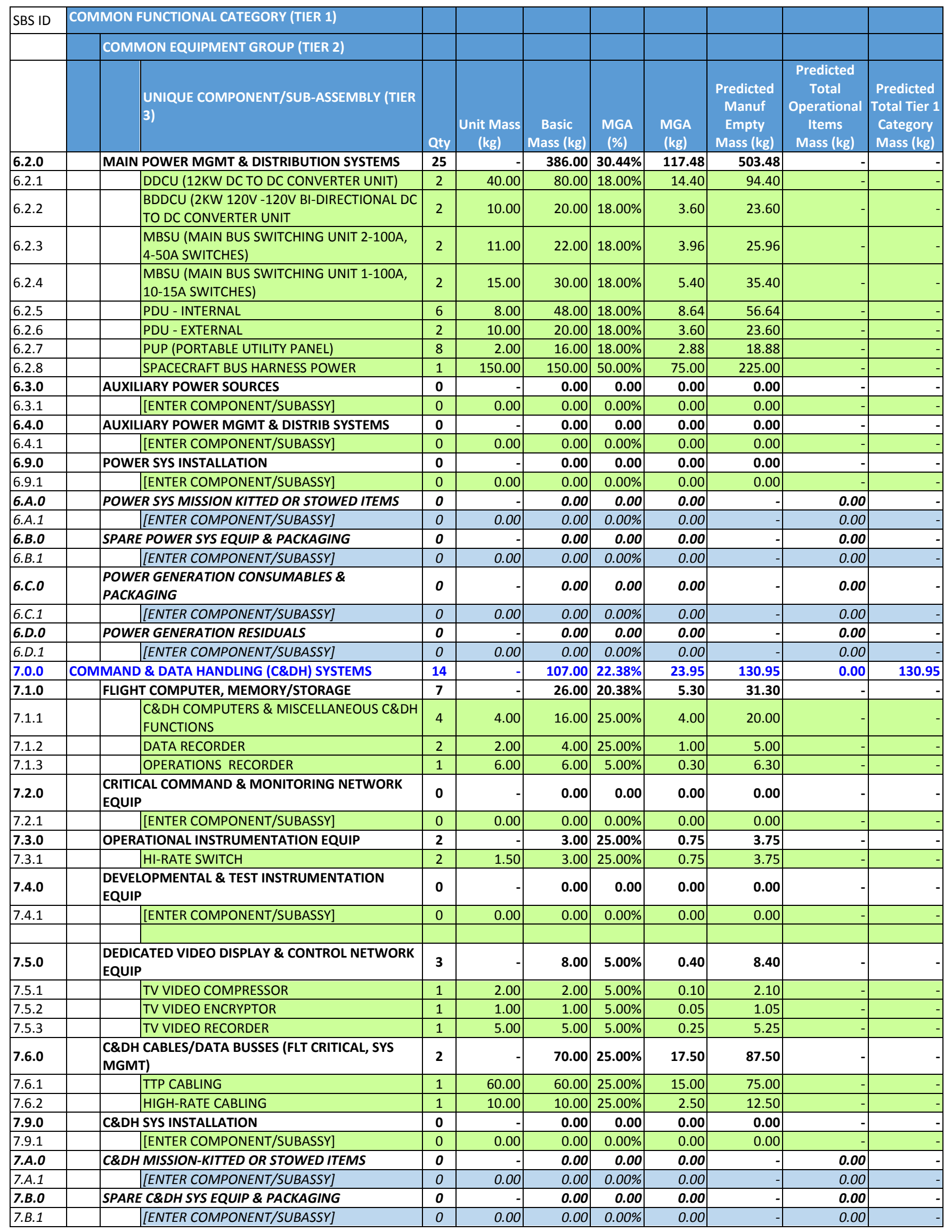




\begin{tabular}{|c|c|c|c|c|c|c|c|c|c|c|}
\hline \multirow[t]{3}{*}{ SBS ID } & \multicolumn{2}{|c|}{ COMMON FUNCTIONAL CATEGORY (TIER 1) } & \multirow[b]{3}{*}{ Qty } & \multirow[b]{3}{*}{$\begin{array}{c}\text { Unit Mass } \\
(\mathrm{kg})\end{array}$} & \multirow[b]{3}{*}{$\begin{array}{c}\text { Basic } \\
\text { Mass }(\mathrm{kg})\end{array}$} & \multirow[b]{3}{*}{$\begin{array}{l}\text { MGA } \\
(\%)\end{array}$} & \multirow[b]{3}{*}{$\begin{array}{c}\text { MGA } \\
(\mathrm{kg})\end{array}$} & \multirow[b]{3}{*}{$\begin{array}{c}\text { Predicted } \\
\text { Manuf } \\
\text { Empty } \\
\text { Mass (kg) }\end{array}$} & \multirow[b]{3}{*}{\begin{tabular}{|c|} 
Predicted \\
Total \\
Operational \\
Items \\
Mass (kg) \\
\end{tabular}} & \multirow[b]{3}{*}{$\begin{array}{c}\text { Predicted } \\
\text { Total Tier } 1 \\
\text { Category } \\
\text { Mass (kg) }\end{array}$} \\
\hline & & COMMON EQUIPMENT GROUP (TIER 2) & & & & & & & & \\
\hline & & $\begin{array}{l}\text { UNIQUE COMPONENT/SUB-ASSEMBLY (TIER } \\
\text { 3) }\end{array}$ & & & & & & & & \\
\hline 8.0 .0 & \multicolumn{2}{|r|}{ GUIDANCE, NAVIGATION \& CONTROL (GN\&C) SYSTEMS } & 8 & - & 28.00 & $18.00 \%$ & 5.04 & 33.04 & 0.00 & 33.04 \\
\hline 8.1 .0 & & DEDICATED GN\&C COMPUTERS/PROCESSORS & 0 & & 0.00 & 0.00 & 0.00 & 0.00 & - & \\
\hline 8.1 .1 & & \begin{tabular}{|l|l|} 
& [ENTER COMPONENT/SUBASSY] \\
\end{tabular} & 0 & 0.00 & 0.00 & $0.00 \%$ & 0.00 & 0.00 & - & \\
\hline 8.2 .0 & & NAVIGATIONAL AIDS \& CONTROL SENSORS & 8 & - & 28.00 & $18.00 \%$ & 5.04 & 33.04 & - & \\
\hline 8.2 .1 & & \begin{tabular}{|l|l|} 
& EXTERIOR RENDEZVOUS LIGHTS \\
\end{tabular} & 6 & 4.00 & 24.00 & $18.00 \%$ & 4.32 & 28.32 & - & \\
\hline 8.2 .2 & & EXTERIOR DOCKING LIGHTS & 2 & 2.00 & 4.00 & $18.00 \%$ & 0.72 & 4.72 & & \\
\hline 8.3.0 & & MOMEMTUM MANAGEMENT SYSTEMS & 0 & - & 0.00 & 0.00 & 0.00 & 0.00 & - & \\
\hline 8.3 .1 & & \begin{tabular}{|l|l} 
& [ENTER COMPONENT/SUBASSY] \\
\end{tabular} & 0 & 0.00 & 0.00 & $0.00 \%$ & 0.00 & 0.00 & & \\
\hline 8.9 .0 & & GN\&C SYS INSTALLATION & 0 & & 0.00 & 0.00 & 0.00 & 0.00 & & \\
\hline 8.9 .1 & & \begin{tabular}{l|l} 
& [ENTER COMPONENT/SUBASSY] \\
\end{tabular} & 0 & 0.00 & 0.00 & $0.00 \%$ & 0.00 & 0.00 & & \\
\hline $8 . A .0$ & & GN\&CMISSION-KITTED OR STOWED ITEMS & 0 & - & 0.00 & 0.00 & 0.00 & & 0.00 & \\
\hline $8 . A .1$ & & \begin{tabular}{l|l} 
& [ENTER COMPONENT/SUBASSY] \\
\end{tabular} & 0 & 0.00 & 0.00 & $0.00 \%$ & 0.00 & & 0.00 & \\
\hline $8 . B .0$ & & SPARE GN\&C SYS EQUIP \& PACKAGING & 0 & - & 0.00 & 0.00 & 0.00 & - & 0.00 & \\
\hline $8 . B .1$ & & \begin{tabular}{l|l} 
[ENTER COMPONENT/SUBASSY] \\
\end{tabular} & 0 & 0.00 & 0.00 & $0.00 \%$ & 0.00 & & 0.00 & \\
\hline 8.D.0 & & CONTROL SYS RESIDUAL & 0 & - & 0.00 & 0.00 & 0.00 & - & 0.00 & \\
\hline $8 . D .1$ & & \begin{tabular}{l|l} 
& [ENTER COMPONENT/SUBASSY] \\
\end{tabular} & 0 & 0.00 & 0.00 & $0.00 \%$ & 0.00 & & 0.00 & \\
\hline $8 . \mathrm{H.O}$ & & CONTROL SYS EXPENDABLES & 0 & - & 0.00 & 0.00 & 0.00 & - & 0.00 & \\
\hline $8 . H .1$ & & \begin{tabular}{l|l} 
& [ENTER COMPONENT/SUBASSY] \\
\end{tabular} & 0 & 0.00 & 0.00 & $0.00 \%$ & 0.00 & - & 0.00 & \\
\hline $8 . J .0$ & & CONTROL SYS PRESSURIZATION CONSUMABLES & 0 & - & 0.00 & 0.00 & 0.00 & - & 0.00 & \\
\hline 8.J.1 & & \begin{tabular}{l|l} 
& [ENTER COMPONENT/SUBASSY] \\
\end{tabular} & 0 & 0.00 & 0.00 & $0.00 \%$ & 0.00 & & 0.00 & \\
\hline $8 . K .0$ & & $\begin{array}{l}\text { CONTROL SYS PURGE CONSUMABLES \& } \\
\text { PACKAGING }\end{array}$ & 0 & & 0.00 & 0.00 & 0.00 & 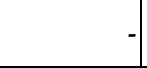 & 0.00 & \\
\hline $8 . K .1$ & & \begin{tabular}{l|l} 
& [ENTER COMPONENT/SUBASSY] \\
\end{tabular} & 0 & 0.00 & 0.00 & $0.00 \%$ & 0.00 & & 0.00 & \\
\hline 9.0 .0 & COMM & MUNICATIONS \& TRACKING (C\&T) SYSTEMS & 53 & - & 199.70 & $5.00 \%$ & 9.99 & 209.69 & 0.00 & 209.69 \\
\hline 9.1 .0 & & PROXIMITY RF COMM EQUIP & 4 & - & 21.70 & $5.00 \%$ & 1.09 & 22.79 & - & \\
\hline 9.1 .1 & & \begin{tabular}{l|l} 
UHF SPACE TO GROUND ANTENNA W/ \\
RADOME
\end{tabular} & 1 & 1.40 & 1.40 & $5.00 \%$ & 0.07 & 1.47 & & \\
\hline 9.1 .2 & & STRING SWITCH & 1 & 0.10 & 0.10 & $5.00 \%$ & 0.01 & 0.11 & & \\
\hline 9.1 .3 & & $\begin{array}{l}\text { ELECTRA TRANSCEIVER A (INCLUDES SOLID } \\
\text { STATE POWER AMPLIFIER-SSPA) }\end{array}$ & 1 & 10.10 & 10.10 & $5.00 \%$ & 0.51 & 10.61 & & \\
\hline 9.1 .4 & & $\begin{array}{l}\text { ELECTRA TRANSCEIVER B (INCLUDES SOLID } \\
\text { STATE POWER AMPLIFIER-SSPA) }\end{array}$ & 1 & 10.10 & 10.10 & $5.00 \%$ & 0.51 & 10.61 & & \\
\hline 9.1 .5 & & \begin{tabular}{l|l} 
& MISC CABLING AND BRACKETS (TBD) \\
\end{tabular} & 0 & 0.00 & 0.00 & $5.00 \%$ & 0.00 & 0.00 & & \\
\hline 9.2 .0 & & RANGING AND LOCATING EQUIP & 0 & - & 0.00 & 0.00 & 0.00 & 0.00 & - & \\
\hline 9.2 .1 & & \begin{tabular}{l|l} 
& [ENTER COMPONENT/SUBASSY] \\
\end{tabular} & 0 & 0.00 & 0.00 & $0.00 \%$ & 0.00 & 0.00 & & \\
\hline 9.3 .0 & & DEEP SPACE COMM/NAV EQUIP & 28 & & 134.00 & $5.00 \%$ & 6.70 & 140.70 & & \\
\hline 9.3 .1 & & \begin{tabular}{l|l} 
X-BAND LOW GAIN ANTENNA A (TX/RX) AND \\
POLARIZERS
\end{tabular} & 1 & 0.80 & 0.80 & $5.00 \%$ & 0.04 & 0.84 & & \\
\hline 9.3 .2 & & $\begin{array}{l}\text { X-BAND LOW GAIN ANTENNA B (TX/RX) AND } \\
\text { POLARIZERS }\end{array}$ & 1 & 0.80 & 0.80 & $5.00 \%$ & 0.04 & 0.84 & & \\
\hline 9.3 .3 & & $\begin{array}{l}\text { X\&KA-BAND HIGH GAIN ANTENNA PRIME } \\
\text { REFLECTOR (3M) }\end{array}$ & 1 & 19.10 & 19.10 & $5.00 \%$ & 0.96 & 20.06 & & \\
\hline 9.3 .4 & & HIGH GAIN ANTENNA FEED & 1 & 1.60 & 1.60 & $5.00 \%$ & 0.08 & 1.68 & & \\
\hline 9.3 .5 & & $\begin{array}{l}\text { HIGH GAIN ANTENNA GIMBALS AND DRIVE } \\
\text { MOTORS }\end{array}$ & 1 & 45.00 & 45.00 & $5.00 \%$ & 2.25 & 47.25 & & \\
\hline 9.3 .6 & & WAVEGUIDES AND COAX & 1 & 8.30 & 8.30 & $5.00 \%$ & 0.42 & 8.72 & & \\
\hline 9.3 .7 & & ANTENNA MISC & 1 & 1.10 & 1.10 & $5.00 \%$ & 0.06 & 1.16 & & \\
\hline 9.3 .8 & & $\begin{array}{l}\text { KA-BAND TRAVELING WAVE TUBE AMPLIFIER } \\
\text { (TWTA) }\end{array}$ & 1 & 0.80 & 0.80 & $5.00 \%$ & 0.04 & 0.84 & & \\
\hline 9.3 .9 & & KA-BAND ELECTRONIC POWER CONVERTERS & 1 & 1.50 & 1.50 & $5.00 \%$ & 0.08 & 1.58 & & \\
\hline 9.3 .10 & & $\begin{array}{l}\text { X-BAND TRAVELING WAVE TUBE AMPLIFIER } \\
\text { (TWTA) A }\end{array}$ & 1 & 0.95 & 0.95 & $5.00 \%$ & 0.05 & 1.00 & & \\
\hline 9.3 .11 & & $\begin{array}{l}\text { X-BAND TRAVELING WAVE TUBE AMPLIFIER } \\
\text { (TWTA) B }\end{array}$ & 1 & 0.95 & 0.95 & $5.00 \%$ & 0.05 & 1.00 & & \\
\hline 9.3 .12 & & X-BAND ELECTRONIC POWER CONVERTERS & 1 & 3.00 & 3.00 & $5.00 \%$ & 0.15 & 3.15 & & \\
\hline 9.3 .13 & & DIPLEXERS AND BRACKETS & 1 & 1.80 & 1.80 & $5.00 \%$ & 0.09 & 1.89 & & \\
\hline 9.3 .14 & & WAVEGUIDE TRANSFER SWITCHES & 1 & 1.50 & 1.50 & $5.00 \%$ & 0.08 & 1.58 & & \\
\hline 9.3 .15 & & MICROWAVE COMPONENTS & 1 & 1.40 & 1.40 & $5.00 \%$ & 0.07 & 1.47 & & \\
\hline 9.3 .16 & & MISC TWTA HARDWARE & 1 & 0.20 & 0.20 & $5.00 \%$ & 0.01 & 0.21 & & \\
\hline
\end{tabular}




\begin{tabular}{|c|c|c|c|c|c|c|c|c|c|}
\hline \multirow[t]{3}{*}{ SBS ID } & COMMON FUNCTIONAL CATEGORY (TIER 1) & \multirow[b]{3}{*}{ Qty } & \multirow[b]{3}{*}{$\begin{array}{c}\text { Unit Mass } \\
(\mathrm{kg})\end{array}$} & \multirow[b]{3}{*}{$\begin{array}{c}\text { Basic } \\
\text { Mass }(\mathrm{kg})\end{array}$} & \multirow[b]{3}{*}{$\begin{array}{c}\text { MGA } \\
(\%)\end{array}$} & \multirow[b]{3}{*}{$\begin{array}{l}\text { MGA } \\
(\mathrm{kg})\end{array}$} & \multirow[b]{3}{*}{$\begin{array}{l}\text { Predicted } \\
\text { Manuf } \\
\text { Empty } \\
\text { Mass (kg) }\end{array}$} & \multirow[b]{3}{*}{$\begin{array}{c}\text { Predicted } \\
\text { Total } \\
\text { Operational } \\
\text { Items } \\
\text { Mass (kg) }\end{array}$} & \multirow[b]{3}{*}{\begin{tabular}{|c} 
Predicted \\
Total Tier 1 \\
Category \\
Mass (kg)
\end{tabular}} \\
\hline & COMMON EQUIPMENT GROUP (TIER 2) & & & & & & & & \\
\hline & $\begin{array}{l}\text { UNIQUE COMPONENT/SUB-ASSEMBLY (TIER } \\
\text { 3) }\end{array}$ & & & & & & & & \\
\hline 9.3 .17 & $\begin{array}{l}\text { SMALL DEEP SPACE TRANSPONDER A } \\
\text { (FUTURE: UNIVERSAL SPACE TRANSPONDER- } \\
\text { UST) }\end{array}$ & 1 & 3.00 & 3.00 & $5.00 \%$ & 0.15 & 3.15 & & \\
\hline 9.3.18 & ULTRA-STABLE OSCILLATOR A & 1 & 1.70 & 1.70 & $5.00 \%$ & 0.09 & 1.79 & & \\
\hline 9.3 .19 & $\begin{array}{l}\text { SMALL DEEP SPACE TRANSPONDER B } \\
\text { (FUTURE: UNIVERSAL SPACE TRANSPONDER- } \\
\text { UST) }\end{array}$ & 1 & 3.00 & 3.00 & $5.00 \%$ & 0.15 & 3.15 & & \\
\hline 9.3 .20 & ULTRA-STABLE OSCILLATOR B & 1 & 1.70 & 1.70 & $5.00 \%$ & 0.09 & 1.79 & & \\
\hline 9.3 .21 & $\begin{array}{l}\text { FREQUENCY MULTIPLIER AND BRACKETS } \\
(A, B, C, D)\end{array}$ & 4 & 0.10 & 0.40 & $5.00 \%$ & 0.02 & 0.42 & & \\
\hline 9.3 .22 & $\begin{array}{l}\text { OPTICAL MODULE - CISLUNAR OPTION B } \\
\text { (10CM APERTURE) }\end{array}$ & 1 & 13.06 & 13.06 & $5.00 \%$ & 0.65 & 13.71 & & \\
\hline 9.3 .23 & MODEM MODULE & 1 & 11.52 & 11.52 & $5.00 \%$ & 0.58 & 12.10 & & \\
\hline 9.3.24 & CONTROLLER ELECTRONICS & 1 & 3.62 & 3.62 & $5.00 \%$ & 0.18 & 3.80 & & \\
\hline 9.3.25 & INTERFACE ELECTRONICS & 1 & 7.20 & 7.20 & $5.00 \%$ & 0.36 & 7.56 & & \\
\hline 9.3 .26 & INTERFACE CABLING (TBD) & 0 & 0.00 & 0.00 & $0.00 \%$ & 0.00 & 0.00 & & \\
\hline 9.4 .0 & TIMING EQUIP & 2 & & 10.00 & $5.00 \%$ & 0.50 & 10.50 & & \\
\hline 9.4 .1 & \begin{tabular}{|l|l|}
$\begin{array}{l}\text { DSAC: DEEP SPACE ATOMIC CLOCK (FUTURE } \\
\text { VERSION) }\end{array}$ \\
\end{tabular} & 2 & 5.00 & 10.00 & $5 \%$ & 0.50 & 10.50 & & \\
\hline 9.5 .0 & COMM/NAV POINTING AIDS & 1 & & 14.00 & $5.00 \%$ & 0.70 & 14.70 & & \\
\hline 9.5 .1 & \begin{tabular}{|l|l|} 
APIC: ADVANCED POINTING IMAGING \\
CAMERA (MEL FOR: FIRST DEMONSTRATION \\
VERSION)
\end{tabular} & 1 & 14.00 & 14.00 & $5.00 \%$ & 0.70 & 14.70 & & \\
\hline 9.6 .0 & COMM SECURITY (COMSEC) EQUIP & 16 & - & 8.00 & $5.00 \%$ & 0.40 & 8.40 & & \\
\hline 9.6 .1 & \begin{tabular}{|l|l|} 
& FIPS 140-2 APPROVED DECRYPTION UNIT \\
\end{tabular} & 4 & 0.50 & 2.00 & $5.00 \%$ & 0.10 & 2.10 & & \\
\hline 9.6 .2 & KEY STORAGE MEMORY DEVICE & 4 & 0.25 & 1.00 & $5.00 \%$ & 0.05 & 1.05 & & \\
\hline 9.6 .3 & $\begin{array}{l}\text { FIPS 140-2 APPROVED } \\
\text { ENCRYPTION/PROCESSING UNIT }\end{array}$ & 4 & 1.00 & 4.00 & $5.00 \%$ & 0.20 & 4.20 & & \\
\hline 9.6 .4 & KEY STORAGE MEMORY DEVICE & 4 & 0.25 & 1.00 & $5.00 \%$ & 0.05 & 1.05 & & \\
\hline 9.7 .0 & AUDIO-VISUAL EQUIP & 2 & - & 12.00 & $5.00 \%$ & 0.60 & 12.60 & & \\
\hline 9.7 .1 & \begin{tabular}{|l|l|} 
& TV CAMERA \\
\end{tabular} & 1 & 3.00 & 3.00 & $5.00 \%$ & 0.15 & 3.15 & - & \\
\hline 9.7 .2 & \begin{tabular}{|l} 
DIGITAL AUDIO SYSTEM \\
\end{tabular} & 1 & 9.00 & 9.00 & $5.00 \%$ & 0.45 & 9.45 & - & \\
\hline 9.8 .0 & COMM CABLES AND RF INTERCONNECTIONS & 0 & - & 0.00 & 0.00 & 0.00 & 0.00 & - & - \\
\hline 9.8 .1 & \begin{tabular}{|l|l|} 
& [ENTER COMPONENT/SUBASSY] \\
\end{tabular} & 0 & 0.00 & 0.00 & $0.00 \%$ & 0.00 & 0.00 & & \\
\hline 9.9 .0 & C\&T SYS INSTALLATION & 0 & - & 0.00 & 0.00 & 0.00 & 0.00 & - & - \\
\hline 9.9 .1 & \begin{tabular}{|l|l|} 
& [ENTER COMPONENT/SUBASSY] \\
\end{tabular} & 0 & 0.00 & 0.00 & $0.00 \%$ & 0.00 & 0.00 & & \\
\hline $9 . A .0$ & C\&T MISSION-KITTED OR STOWED ITEMS & 0 & & 0.00 & 0.00 & 0.00 & & 0.00 & \\
\hline 9.A.1 & \begin{tabular}{|l|l|} 
& [ENTER COMPONENT/SUBASSY] \\
\end{tabular} & 0 & 0.00 & 0.00 & $0.00 \%$ & 0.00 & & 0.00 & \\
\hline $9 . B .0$ & SPARE C\&T SYS EQUIP \& PACKAGING & 0 & - & 0.00 & 0.00 & 0.00 & & 0.00 & 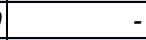 \\
\hline 9.B.1 & \begin{tabular}{|l|l} 
& [ENTER COMPONENT/SUBASSY] \\
\end{tabular} & 0 & 0.00 & 0.00 & $0.00 \%$ & 0.00 & & 0.00 & \\
\hline 10.0 .0 & CREW DISPLAYS \& CONTROLS & 3 & - & 61.00 & $25.00 \%$ & 15.25 & 76.25 & 0.00 & 76.25 \\
\hline 10.1 .0 & \begin{tabular}{|l|l|} 
& VISUAL DISPLAYS (E.G., MONITORS, INDICATORS) \\
\end{tabular} & 1 & - & 42.00 & $25.00 \%$ & 10.50 & 52.50 & - & - \\
\hline 10.1 .1 & \begin{tabular}{|l|l|} 
& DISPLAYS \\
\end{tabular} & 1 & 42.00 & 42.00 & $25.00 \%$ & 10.50 & 52.50 & - & - \\
\hline 10.2 .0 & TOUCH, MOTION \& VOICE CONTROL DEVICES & 2 & - & 19.00 & $25.00 \%$ & 4.75 & 23.75 & - & - \\
\hline 10.2 .1 & \begin{tabular}{|l|l|} 
& CONTROL SET \\
\end{tabular} & 1 & 10.00 & 10.00 & $25.00 \%$ & 2.50 & 12.50 & & \\
\hline 10.2 .2 & HAND CONTROLLER & 1 & 9.00 & 9.00 & $25.00 \%$ & 2.25 & 11.25 & - & - \\
\hline 10.3.0 & CAUTION \& WARNING ELECTRONICS & 0 & - & 0.00 & 0.00 & 0.00 & 0.00 & - & - \\
\hline 10.3 .1 & \begin{tabular}{|l|l|} 
& [ENTER COMPONENT/SUBASSY] \\
\end{tabular} & 0 & 0.00 & 0.00 & $0.00 \%$ & 0.00 & 0.00 & & \\
\hline 10.9 .0 & CREW DISPLAYS \& CONTROLS INSTALLATION & 0 & - & 0.00 & 0.00 & 0.00 & 0.00 & - & - \\
\hline 10.9.1 & \begin{tabular}{|l|l|} 
& [ENTER COMPONENT/SUBASSY] \\
\end{tabular} & 0 & 0.00 & 0.00 & $0.00 \%$ & 0.00 & 0.00 & & - \\
\hline 10.A.0 & $\begin{array}{l}\text { CREW DISP \& CTLS MISSION-KITTED OR STOWED } \\
\text { ITEMS }\end{array}$ & 0 & - & 0.00 & 0.00 & 0.00 & & 0.00 & \\
\hline 10.A.1 & \begin{tabular}{|l|l|} 
& [ENTER COMPONENT/SUBASSY] \\
\end{tabular} & 0 & 0.00 & 0.00 & $0.00 \%$ & 0.00 & & 0.00 & \\
\hline $10 . B .0$ & SPARE CREW DISP \& CTLS EQUIP \& PACKAGING & 0 & & 0.00 & 0.00 & 0.00 & & 0.00 & \\
\hline 10.B.1 & [ENTER COMPONENT/SUBASSY] & 0 & 0.00 & 0.00 & $0.00 \%$ & 0.00 & & 0.00 & \\
\hline
\end{tabular}




\begin{tabular}{|c|c|c|c|c|c|c|c|c|c|}
\hline \multirow[t]{3}{*}{ SBS ID } & COMMON FUNCTIONAL CATEGORY (TIER 1) & \multirow[b]{3}{*}{ Qty } & \multirow[b]{3}{*}{$\begin{array}{c}\text { Unit Mass } \\
(\mathrm{kg})\end{array} \mid$} & \multirow[b]{3}{*}{$\begin{array}{c}\text { Basic } \\
\text { Mass }(\mathrm{kg})\end{array}$} & \multirow[b]{3}{*}{$\begin{array}{c}\text { MGA } \\
(\%)\end{array}$} & \multirow[b]{3}{*}{$\begin{array}{l}\text { MGA } \\
(\mathrm{kg})\end{array}$} & \multirow[b]{3}{*}{$\begin{array}{c}\text { Predicted } \\
\text { Manuf } \\
\text { Empty } \\
\text { Mass (kg) }\end{array}$} & \multirow[b]{3}{*}{\begin{tabular}{c|} 
Predicted \\
Total \\
Operational \\
Items \\
Mass (kg)
\end{tabular}} & \multirow[b]{3}{*}{\begin{tabular}{|} 
Predicted \\
Total Tier 1 \\
Category \\
Mass (kg)
\end{tabular}} \\
\hline & COMMON EQUIPMENT GROUP (TIER 2) & & & & & & & & \\
\hline & $\begin{array}{l}\text { UNIQUE COMPONENT/SUB-ASSEMBLY (TIER } \\
\text { 3) }\end{array}$ & & & & & & & & \\
\hline 11.0.0 & ENVIRONMENTAL CONTROL SYSTEMS (ECS) & 453 & - & $2,346.98$ & $23.09 \%$ & 541.82 & $2,888.80$ & 729.53 & $3,618.33$ \\
\hline 11.1.0 & $\begin{array}{l}\text { ENVIRONMENTAL MONITORING \& PROTECTION } \\
\text { EQUIP }\end{array}$ & 1 & - & 20.00 & $20.00 \%$ & 4.00 & 24.00 & - & \\
\hline 11.1.1 & \begin{tabular}{|l|l|} 
& FIRE DETECTION AND SUPPRESSION \\
\end{tabular} & 1 & 20.00 & 20.00 & $20.00 \%$ & 4.00 & 24.00 & - & \\
\hline 11.2.0 & VENTILATION \& PRESSURE CTL EQUIP & 5 & & 226.14 & $20.00 \%$ & 45.23 & 271.37 & - & \\
\hline 11.2 .1 & \begin{tabular}{|l|l|} 
& ATMOSPHERIC CONTROL SYSTEM \\
\end{tabular} & 1 & 42.00 & 42.00 & $20.00 \%$ & 8.40 & 50.40 & - & \\
\hline 11.2 .2 & COMMON CABIN AIR ASSEMBLIES (CCAAS) & 1 & 58.65 & 58.65 & $20.00 \%$ & 11.73 & 70.38 & & \\
\hline 11.2 .3 & AVIONICS AIR ASSEMBLY & 1 & 12.40 & 12.40 & $20.00 \%$ & 2.48 & 14.88 & & \\
\hline 11.2 .4 & ATMOSPHERIC CIRCULATION & 1 & 9.87 & 9.87 & $20.00 \%$ & 1.97 & 11.84 & - & \\
\hline 11.2 .5 & ATMOSPHERIC MICROBIAL CONTROL & 1 & 103.22 & 103.22 & $20.00 \%$ & 20.64 & 123.86 & & \\
\hline 11.3.0 & ATMOSPHERIC REVITALIZATION EQUIP & 6 & - & 652.35 & $20.00 \%$ & 130.47 & 782.82 & - & \\
\hline 11.3.1 & \begin{tabular}{|l|l|} 
& CO2 REMOVAL \\
\end{tabular} & 1 & 141.12 & 141.12 & $20.00 \%$ & 28.22 & 169.34 & & \\
\hline 11.3 .2 & CO2 REDUCTION (SABATIER) & 1 & 131.15 & 131.15 & $20.00 \%$ & 26.23 & 157.38 & & \\
\hline 11.3 .3 & O2 GENERATION & 1 & 244.02 & 244.02 & $20.00 \%$ & 48.80 & 292.82 & - & \\
\hline 11.3.4 & $\begin{array}{l}\text { TRACE CONTAMINANT CONTROL } \\
\text { SUBASSEMBLY (TCCS) }\end{array}$ & 1 & 46.65 & 46.65 & $20.00 \%$ & 9.33 & 55.99 & & \\
\hline 11.3 .5 & $\begin{array}{l}\text { ACM - ATMOSPHERE COMPOSITION } \\
\text { MONITORING ASSEMBLY }\end{array}$ & 1 & 54.30 & 54.30 & $20.00 \%$ & 10.86 & 65.16 & & \\
\hline 11.3 .6 & $\begin{array}{l}\text { SAMPLE DELIVERY (CHANGE TO SAMPLE } \\
\text { ANALYSIS?) }\end{array}$ & 1 & 35.11 & 35.11 & $20.00 \%$ & 7.02 & 42.13 & & \\
\hline 11.4.0 & ACTIVE THERMAL CONTROL SYSTEM & 206 & - & $1,125.92$ & $25.00 \%$ & 281.48 & $1,407.40$ & - & \\
\hline 11.4 .1 & $\begin{array}{l}\text { [WATER/PG COOLANT INCLUDED WITH } \\
\text { LINES] }\end{array}$ & 1 & 0.00 & 0.00 & $25.00 \%$ & 0.00 & 0.00 & & \\
\hline 11.4 .2 & INTERNAL TCS - WATER/PG COOLANT PUMPS & 2 & 6.75 & 13.50 & $25.00 \%$ & 3.38 & 16.88 & & \\
\hline 11.4 .3 & INTERNAL TCS - WATER/PG ACCUMULATORS & 2 & 21.60 & 43.20 & $25.00 \%$ & 10.80 & 54.00 & - & \\
\hline 11.4 .4 & $\begin{array}{l}\text { INTERNAL TCS - WATER/PG LINES (WITH } \\
\text { COOLANT) }\end{array}$ & 1 & 35.21 & 35.21 & $25.00 \%$ & 8.80 & 44.01 & - & \\
\hline 11.4 .5 & INTERNAL TCS - FLOW CONTROL VALVE & 1 & 4.00 & 4.00 & $25.00 \%$ & 1.00 & 5.00 & & \\
\hline 11.4 .6 & INTERNAL TCS - SURVIVAL HEATER & 1 & 3.00 & 3.00 & \begin{tabular}{|l|}
$25.00 \%$ \\
\end{tabular} & 0.75 & 3.75 & & \\
\hline 11.4 .7 & INTERNAL TCS - COLDPLATES (SS) & 8 & 4.00 & 32.00 & $25.00 \%$ & 8.00 & 40.00 & - & \\
\hline 11.4 .8 & INTERNAL TCS - FILTERS & 4 & 0.40 & 1.60 & $25.00 \%$ & 0.40 & 2.00 & - & \\
\hline 11.4 .9 & $\begin{array}{l}\text { INTERNAL TCS - LIQUID TO LIQUID HEAT } \\
\text { EXCHANGER }\end{array}$ & 1 & 15.00 & 15.00 & $25.00 \%$ & 3.75 & 18.75 & & \\
\hline 11.4 .10 & INTERNAL TCS - ISOLATION VALVES & 2 & 0.24 & 0.48 & $25.00 \%$ & 0.12 & 0.60 & & \\
\hline 11.4 .11 & INTERNAL TCS - CHECK VALVES & 2 & 1.73 & 3.46 & $25.00 \%$ & 0.87 & 4.33 & - & \\
\hline 11.4 .12 & INTERNAL TCS - FILL PORTS & 2 & 0.60 & 1.20 & $25.00 \%$ & 0.30 & 1.50 & - & \\
\hline 11.4 .13 & INTERNAL TCS - AVIONICS FAN & 1 & 2.00 & 2.00 & $25.00 \%$ & 0.50 & 2.50 & & \\
\hline 11.4 .14 & INTERNAL TCS - AVIONICS HEAT EXCHANGER & 1 & 11.00 & 11.00 & $25.00 \%$ & 2.75 & 13.75 & - & \\
\hline 11.4 .15 & INTERNAL TCS - TEMPERATURE SENSORS & 3 & 0.10 & 0.30 & $25.00 \%$ & 0.08 & 0.38 & - & \\
\hline 11.4 .16 & INTERNAL TCS - FLOW SENSORS & 1 & 0.60 & 0.60 & $25.00 \%$ & 0.15 & 0.75 & & \\
\hline 11.4 .17 & INTERNAL TCS - LIQUID LEVEL SENSORS & 2 & 0.25 & 0.50 & $25.00 \%$ & 0.13 & 0.63 & & \\
\hline 11.4 .18 & INTERNAL TCS - PRESSURE SENSORS & 3 & 0.10 & 0.30 & $25.00 \%$ & 0.08 & 0.38 & - & \\
\hline 11.4 .19 & [HFE 7200 COOLANT INCLUDED WITH LINES] & 1 & 0.00 & 0.00 & $25.00 \%$ & 0.00 & 0.00 & & \\
\hline 11.4 .20 & EXTERNAL TCS - HFE 7200 COOLANT PUMPS & 2 & 6.75 & 13.50 & $25.00 \%$ & 3.38 & 16.88 & & \\
\hline 11.4 .21 & $\begin{array}{l}\text { EXTERNAL TCS - HFE } 7200 \text { PRIMARY } \\
\text { ACCUMULATOR }\end{array}$ & 1 & 97.60 & 97.60 & $25.00 \%$ & 24.40 & 122.00 & & \\
\hline 11.4 .22 & $\begin{array}{l}\text { EXTERNAL TCS - HFE } 7200 \text { BACKUP } \\
\text { ACCUMULATOR }\end{array}$ & 1 & 32.50 & 32.50 & $25.00 \%$ & 8.13 & 40.63 & & \\
\hline 11.4 .23 & $\begin{array}{l}\text { EXTERNAL TCS - HFE } 7200 \text { LINES (WITH } \\
\text { COOLANT) }\end{array}$ & 1 & 42.10 & 42.10 & $25.00 \%$ & 10.53 & 52.63 & & \\
\hline 11.4 .24 & EXTERNAL TCS - COLDPLATES & 8 & 1.31 & 10.48 & $25.00 \%$ & 2.62 & 13.10 & & \\
\hline 11.4 .25 & EXTERNAL TCS - FILTERS & 4 & 0.40 & 1.60 & $25.00 \%$ & 0.40 & 2.00 & & \\
\hline 11.4 .26 & EXTERNAL TCS - REGENERATOR & 1 & 12.66 & 12.66 & $25.00 \%$ & 3.16 & 15.82 & & \\
\hline 11.4 .27 & $\begin{array}{l}\text { EXTERNAL TCS - RADIATOR FLOW SPLIT } \\
\text { VALVE }\end{array}$ & 1 & 2.00 & 2.00 & $25.00 \%$ & 0.50 & 2.50 & & \\
\hline 11.4 .28 & $\begin{array}{l}\text { EXTERNAL TCS - REGENERATOR FLOW } \\
\text { CONTROL VALVE }\end{array}$ & 2 & 4.00 & 8.00 & $25.00 \%$ & 2.00 & 10.00 & & \\
\hline 11.4 .29 & EXTERNAL TCS - ISOLATION VALVES & 8 & 1.73 & 13.84 & $25.00 \%$ & 3.46 & 17.30 & & \\
\hline 11.4 .30 & EXTERNAL TCS - CHECK VALVES & 6 & 0.24 & 1.44 & $25.00 \%$ & 0.36 & 1.80 & & \\
\hline
\end{tabular}




\begin{tabular}{|c|c|c|c|c|c|c|c|c|c|}
\hline \multirow[t]{2}{*}{ SBS ID } & COMMON FUNCTIONAL CATEGORY (TIER 1) & \multirow[b]{3}{*}{ Qty } & \multirow[b]{3}{*}{$\begin{array}{c}\text { Unit Mass } \\
(\mathrm{kg})\end{array}$} & \multirow[b]{3}{*}{$\begin{array}{c}\text { Basic } \\
\text { Mass (kg) }\end{array}$} & \multirow[b]{3}{*}{$\begin{array}{l}\text { MGA } \\
(\%)\end{array}$} & \multirow[b]{3}{*}{$\begin{array}{l}\text { MGA } \\
(\mathrm{kg})\end{array}$} & \multirow[b]{3}{*}{$\begin{array}{c}\text { Predicted } \\
\text { Manuf } \\
\text { Empty } \\
\text { Mass (kg) }\end{array}$} & \multirow[b]{3}{*}{\begin{tabular}{|c|} 
Predicted \\
Total \\
Operational \\
Items \\
Mass (kg)
\end{tabular}} & \multirow[b]{3}{*}{$\begin{array}{l}\text { Predicted } \\
\text { Total Tier } 1 \\
\text { Category } \\
\text { Mass (kg) }\end{array}$} \\
\hline & COMMON EQUIPMENT GROUP (TIER 2) & & & & & & & & \\
\hline & $\begin{array}{l}\text { UNIQUE COMPONENT/SUB-ASSEMBLY (TIER } \\
\text { 3) }\end{array}$ & & & & & & & & \\
\hline 11.4 .31 & EXTERNAL TCS - FILL PORTS & 2 & 0.60 & 1.20 & $25.00 \%$ & 0.30 & 1.50 & & \\
\hline 11.4 .32 & EXTERNAL TCS - TEMPERATURE SENSORS & 3 & 0.10 & 0.30 & $25.00 \%$ & 0.08 & 0.38 & & \\
\hline 11.4 .33 & EXTERNAL TCS - FLOW SENSOR & 1 & 0.60 & 0.60 & $25.00 \%$ & 0.15 & 0.75 & & \\
\hline 11.4 .34 & EXTERNAL TCS - LIQUID LEVEL SENSORS & 2 & 0.25 & 0.50 & $25.00 \%$ & 0.13 & 0.63 & & \\
\hline 11.4 .35 & EXTERNAL TCS - PRESSURE SENSORS & 3 & 0.10 & 0.30 & $25.00 \%$ & 0.08 & 0.38 & & \\
\hline 11.4 .36 & RADIATORS & 121 & 5.95 & 719.95 & $25.00 \%$ & 179.99 & 899.94 & & \\
\hline 11.5 .0 & PASSIVE THERMAL CONTROL SYSTEM & 235 & - & 322.57 & $25.00 \%$ & 80.64 & 403.21 & - & \\
\hline 11.5 .1 & \begin{tabular}{|l|l|} 
WALL HEATERS \\
\end{tabular} & 2 & 3.00 & 6.00 & $25.00 \%$ & 1.50 & 7.50 & & \\
\hline 11.5 .2 & HATCH HEATER & 4 & 3.00 & 12.00 & $25.00 \%$ & 3.00 & 15.00 & & \\
\hline 11.5 .3 & MLI BLANKETS & 229 & 1.33 & 304.57 & $25.00 \%$ & 76.14 & 380.71 & & \\
\hline 11.9 .0 & ECS INSTALLATION & 0 & - & 0.00 & 0.00 & 0.00 & 0.00 & - & \\
\hline 11.9 .1 & \begin{tabular}{|l|l} 
& [ENTER COMPONENT/SUBASSY]
\end{tabular} & 0 & 0.00 & 0.00 & $0.00 \%$ & 0.00 & 0.00 & - & \\
\hline $11 . A .0$ & ECS MISSION-KITTED OR STOWED ITEMS & 0 & - & 0.00 & 0.00 & 0.00 & - & 0.00 & \\
\hline 11.A.1 & \begin{tabular}{|l|l|} 
& [ENTER COMPONENT/SUBASSY] \\
\end{tabular} & 0 & 0.00 & 0.00 & $0.00 \%$ & 0.00 & & 0.00 & \\
\hline $11 . B .0$ & SPARE ECS EQUIP \& PACKAGING & 0 & & 0.00 & 0.00 & 0.00 & - & 0.00 & \\
\hline 11.B.1 & \begin{tabular}{|l|l} 
& [ENTER COMPONENT/SUBASSY] \\
\end{tabular} & 0 & 0.00 & 0.00 & $0.00 \%$ & 0.00 & - & 0.00 & \\
\hline $11 . C .0$ & ECS CONSUMABLES \& PACKAGING & 3 & - & 637.69 & $14.40 \%$ & 91.84 & - & 729.53 & \\
\hline 11.C.1 & \begin{tabular}{|l|l|} 
O2 STORAGE AND SUPPLY (INCLUDES O2 \\
MASS?)
\end{tabular} & 1 & 124.30 & 124.30 & $20.00 \%$ & 24.86 & & 149.16 & \\
\hline 11.C.2 & $\begin{array}{l}\text { N2 STORAGE AND SUPPLY (INCLUDES N2 } \\
\text { MASS?) }\end{array}$ & 1 & 303.39 & 303.39 & $20.00 \%$ & 60.68 & & 364.07 & \\
\hline 11.C.3 & \begin{tabular}{|l|l|} 
& LIOH CANISTERS (30 DAYS) \\
\end{tabular} & 1 & 210.00 & 210.00 & $3.00 \%$ & 6.30 & & 216.30 & \\
\hline 11.D.0 & ECS RESIDUALS & 0 & - & 0.00 & 0.00 & 0.00 & - & 0.00 & \\
\hline 11.D.1 & \begin{tabular}{|l|l} 
& [ENTER COMPONENT/SUBASSY] \\
\end{tabular} & 0 & 0.00 & 0.00 & $0.00 \%$ & 0.00 & & 0.00 & \\
\hline 12.0 .0 & CREW/HABITATION SUPPORT SYSTEMS & 206 & - & $1,910.25$ & $19.55 \%$ & 373.37 & $2,283.62$ & $13,773.29$ & $16,056.91$ \\
\hline 12.1.0 & \begin{tabular}{|l|l|} 
& LIVING \& WORKSPACE ACCOMMODATIONS \\
\end{tabular} & 110 & - & 280.08 & $16.90 \%$ & 47.34 & 327.42 & - & \\
\hline 12.1 .1 & \begin{tabular}{|l|l} 
HANDRAILS AND WORK INTERFACE FIXTURES \\
(FCDT ASSUMPTIONS)
\end{tabular} & 1 & 52.00 & 52.00 & $11.00 \%$ & 5.72 & 57.72 & & \\
\hline 12.1 .2 & RESTRAINTS & 1 & 50.00 & 50.00 & $20.00 \%$ & 10.00 & 60.00 & & \\
\hline 12.1.3 & $\begin{array}{l}\text { MAINTENANCE WORKSTATION STRUCTURES } \\
\text { AND PARTITIONS }\end{array}$ & 0 & 85.00 & 0.00 & $20.00 \%$ & 0.00 & 0.00 & & \\
\hline 12.1 .4 & GENERAL LIGHT & 40 & 1.00 & 40.00 & $20.00 \%$ & 8.00 & 48.00 & & \\
\hline 12.1 .5 & TASK LIGHT & 40 & 0.50 & 20.00 & $20.00 \%$ & 4.00 & 24.00 & & \\
\hline 12.1 .6 & MANUAL LIGHTING CONTROL & 8 & 0.01 & 0.08 & $20.00 \%$ & 0.02 & 0.10 & & \\
\hline 12.1 .7 & WORK SURFACES & 1 & 40.00 & 40.00 & $10.00 \%$ & 4.00 & 44.00 & & \\
\hline 12.1 .8 & CLOSEOUT PANELS (GALLEY) & 3 & 6.00 & 18.00 & $20.00 \%$ & 3.60 & 21.60 & & \\
\hline 12.1 .9 & CREW WORK DESK & 4 & 3.00 & 12.00 & $20.00 \%$ & 2.40 & 14.40 & & \\
\hline 12.1 .10 & \begin{tabular}{|l|l|} 
& ACOUSTIC PARTITIONS \\
\end{tabular} & 12 & 4.00 & 48.00 & $20.00 \%$ & 9.60 & 57.60 & & \\
\hline 12.2 .0 & WATER SYSTEM & 8 & - & 551.75 & $20.00 \%$ & 110.35 & 662.10 & - & \\
\hline 12.2 .1 & \begin{tabular}{|l|l|} 
& WATER TREATMENT \\
\end{tabular} & 1 & 388.67 & 388.67 & $20.00 \%$ & 77.73 & 466.40 & & \\
\hline 12.2 .2 & $\begin{array}{l}\text { WATER RECOVERY SYSTEM (WRS) WITH } \\
\text { TANKAGE }\end{array}$ & 1 & 72.04 & 72.04 & $20.00 \%$ & 14.41 & 86.44 & & \\
\hline 12.2 .3 & MICROBIAL CHECK & 1 & 1.84 & 1.84 & $20.00 \%$ & 0.37 & 2.21 & & \\
\hline 12.2 .4 & PROCESS CONTROLLER & 1 & 36.91 & 36.91 & $20.00 \%$ & 7.38 & 44.29 & & \\
\hline 12.2 .5 & WATER QUALITY MONITORING & 1 & 8.64 & 8.64 & $20.00 \%$ & 1.73 & 10.37 & & \\
\hline 12.2 .6 & WATER DELIVERY SYSTEM & 1 & 20.65 & 20.65 & $20.00 \%$ & 4.13 & 24.79 & & \\
\hline 0.2 .6 & $\begin{array}{l}\text { SINK, SPIGOT FOR HYDRATION OF FOOD \& } \\
\text { DRINKING WATER }\end{array}$ & 1 & 15.00 & 15.00 & $20.00 \%$ & 3.00 & 18.00 & & \\
\hline 12.2 .7 & HANDWASH/MOUTHWASH FAUCET & 1 & 8.00 & 8.00 & $20.00 \%$ & 1.60 & 9.60 & & \\
\hline 12.3.0 & FOOD SYSTEMS & 3 & & 612.20 & $20.00 \%$ & 122.44 & 734.64 & & \\
\hline 12.3 .1 & \begin{tabular}{|l|l|} 
& FREEZERS (NOT INCLUDING FOOD) \\
\end{tabular} & 1 & 496.00 & 496.00 & $20.00 \%$ & 99.20 & 595.20 & & \\
\hline 12.3 .2 & \begin{tabular}{|l|l|} 
FOOD WARMERS \\
\end{tabular} & 2 & 58.10 & 116.20 & $20.00 \%$ & 23.24 & 139.44 & - & \\
\hline 12.4 .0 & WASTE SYSTEMS & 4 & - & 183.75 & $20.00 \%$ & 36.75 & 220.50 & - & \\
\hline 12.4 .1 & \begin{tabular}{|l|l|} 
& URINE COLLECTION SYSTEM \\
\end{tabular} & 1 & 4.55 & 4.55 & $20.00 \%$ & 0.91 & 5.46 & & \\
\hline 12.4 .2 & SOLID WASTE COLLECTION & 1 & 58.40 & 58.40 & $20.00 \%$ & 11.68 & 70.08 & - & \\
\hline 12.4 .3 & SOLID WASTE BULK COMPACTOR/STORAGE & 1 & 8.80 & 8.80 & $20.00 \%$ & 1.76 & 10.56 & & \\
\hline 12.4 .4 & TRASH COMPACTOR/TRASH LOCK & 0 & 150.00 & 0.00 & $20.00 \%$ & 0.00 & 0.00 & & \\
\hline 12.4 .5 & TRASH TO GAS SYSTEM & 1 & 112.00 & 112.00 & $20.00 \%$ & 22.40 & 134.40 & & \\
\hline
\end{tabular}




\begin{tabular}{|c|c|c|c|c|c|c|c|c|c|}
\hline \multirow[t]{3}{*}{ SBS ID } & COMMON FUNCTIONAL CATEGORY (TIER 1) & \multirow[b]{3}{*}{ Qty } & \multirow[b]{3}{*}{$\begin{array}{c}\text { Unit Mass } \\
(\mathrm{kg})\end{array}$} & \multirow[b]{3}{*}{$\begin{array}{c}\text { Basic } \\
\text { Mass }(\mathrm{kg})\end{array}$} & \multirow[b]{3}{*}{$\begin{array}{l}\text { MGA } \\
(\%)\end{array}$} & \multirow[b]{3}{*}{$\begin{array}{c}\text { MGA } \\
(\mathrm{kg})\end{array}$} & \multirow[b]{3}{*}{$\begin{array}{l}\text { Predicted } \\
\text { Manuf } \\
\text { Empty } \\
\text { Mass (kg) }\end{array}$} & \multirow[b]{3}{*}{$\begin{array}{l}\text { Predicted } \\
\text { Total } \\
\text { Operational } \\
\text { Items } \\
\text { Mass (kg) }\end{array}$} & \multirow[b]{3}{*}{$\begin{array}{c}\text { Predicted } \\
\text { Total Tier } 1 \\
\text { Category } \\
\text { Mass (kg) }\end{array}$} \\
\hline & COMMON EQUIPMENT GROUP (TIER 2) & & & & & & & & \\
\hline & $\begin{array}{l}\text { UNIQUE COMPONENT/SUB-ASSEMBLY (TIER } \\
\text { 3) }\end{array}$ & & & & & & & & \\
\hline 12.5 .0 & EXERCISE SYSTEMS & 1 & & 282.00 & $20.00 \%$ & 56.40 & 338.40 & & \\
\hline 12.5 .1 & \begin{tabular}{|l|l} 
FIXED EXERCISE EQUIPMENT \\
\end{tabular} & 1 & 282.00 & 282.00 & $20.00 \%$ & 56.40 & 338.40 & & \\
\hline 12.6 .0 & MEDICAL SYSTEMS & 0 & - & 0.00 & 0.00 & 0.00 & 0.00 & - & \\
\hline 12.6 .1 & \begin{tabular}{|l|l} 
& [ENTER COMPONENT/SUBASSY] \\
\end{tabular} & 0 & 0.00 & 0.00 & $0.00 \%$ & 0.00 & 0.00 & & \\
\hline 12.7 .0 & FIXED CREW EMERGENCY EQUIP & 80 & - & 0.47 & $20.00 \%$ & 0.09 & 0.57 & & \\
\hline 12.7 .1 & \begin{tabular}{|l|l|} 
& EMERGENCY LIGHT \\
\end{tabular} & 8 & 0.05 & 0.40 & $20.00 \%$ & 0.08 & 0.48 & & \\
\hline 12.7 .2 & EMERGENCY LIGHTING MARKERS & 72 & 0.00 & 0.07 & $20.00 \%$ & 0.01 & 0.09 & - & \\
\hline 12.9 .0 & CREW/HAB SPT SYS INSTALLATION & 0 & - & 0.00 & 0.00 & 0.00 & 0.00 & - & \\
\hline 12.9 .1 & \begin{tabular}{|l|l} 
& [ENTER COMPONENT/SUBASSY] \\
\end{tabular} & 0 & 0.00 & 0.00 & $0.00 \%$ & 0.00 & 0.00 & & \\
\hline $12 . A .0$ & CREW/HAB MISSION-KITTED OR STOWED ITEMS & 28 & - & 903.34 & $12.68 \%$ & 114.57 & - & $1,017.91$ & \\
\hline 12.A.1 & \begin{tabular}{|l|l|} 
& VACUUM (PRIME +2 SPARES) \\
\end{tabular} & 3 & 8.67 & 26.01 & $20.00 \%$ & 5.20 & & 31.21 & \\
\hline 12.A.2 & LIGHTWEIGHT TRAUMA MODULE & 1 & 26.00 & 26.00 & $20.00 \%$ & 5.20 & & 31.20 & \\
\hline 12.A.3 & $A E D$ & 1 & 3.73 & 3.73 & $20.00 \%$ & 0.75 & & 4.48 & \\
\hline 12.A.4 & ECG & 1 & 8.50 & 8.50 & $20.00 \%$ & 1.70 & & 10.20 & \\
\hline 12.A.5 & ULTRASOUND & 1 & 3.70 & 3.70 & $20.00 \%$ & 0.74 & & 4.44 & \\
\hline 12.A.6 & PATIENT RESTRAINT SYSTEM & 1 & 18.20 & 18.20 & $20.00 \%$ & 3.64 & & 21.84 & \\
\hline $12 . A .7$ & MEDICAL WORKSTATION STRUCTURE & 1 & 18.20 & 18.20 & $20.00 \%$ & 3.64 & & 21.84 & \\
\hline 12.A.8 & PRIVACY CURTAIN & 1 & 8.00 & 8.00 & $20.00 \%$ & 1.60 & - & 9.60 & \\
\hline 12.A.9 & $\begin{array}{l}\text { MISCELLANEOUS LONG DURATION MEDICAL } \\
\text { DEVICES }\end{array}$ & 1 & 100.00 & 100.00 & $20.00 \%$ & 20.00 & & 120.00 & \\
\hline $12 . A .10$ & EMERGENCY O2 MASKS & 4 & 1.50 & 6.00 & $20.00 \%$ & 1.20 & & 7.20 & \\
\hline $12 . A .11$ & FIRE EXTINGUISHER & 1 & 20.00 & 20.00 & $0.00 \%$ & 0.00 & & 20.00 & \\
\hline $12 . A .12$ & OPERATIONAL SUPPLIES & 1 & 80.00 & 80.00 & $3.00 \%$ & 2.40 & & 82.40 & \\
\hline 12.A.13 & LAPTOP & 3 & 2.00 & 6.00 & $20.00 \%$ & 1.20 & & 7.20 & \\
\hline $12 . A .14$ & PRINTER & 1 & 9.00 & 9.00 & $20.00 \%$ & 1.80 & & 10.80 & \\
\hline 12.A.15 & OCSS SUITS AND 2 SHORT UMBILICALS & 4 & 21.25 & 85.00 & $11.00 \%$ & 9.35 & & 94.35 & \\
\hline 12.A.16 & $\begin{array}{l}\text { OCSS SUIT KITS (ARCM SERVICING AND SUIT } \\
\text { KITS FOR } 2 \text { SUITS) }\end{array}$ & 1 & 265.00 & 265.00 & $11.00 \%$ & 29.15 & & 294.15 & \\
\hline 12.A.17 & $\begin{array}{l}\text { EQUIPMENT (STILL \& VIDEO CAMERAS, } \\
\text { LENSES, ETC.) }\end{array}$ & 1 & 120.00 & 120.00 & $20.00 \%$ & 24.00 & & 144.00 & \\
\hline 12.A.18 & $\begin{array}{l}\text { PORTABLE EXERCISE EQUIPMENT } \\
\text { ALLOCATION }\end{array}$ & 0 & 0.00 & 0.00 & $20.00 \%$ & 0.00 & & 0.00 & \\
\hline 12.C.25 & RECREATION \& PERSONAL STOWAGE & 1 & 100.00 & 100.00 & $3.00 \%$ & 3.00 & & 103.00 & \\
\hline 12. B.o & SPARE CREW/HAB SPT SYS EQUIP \& PACKAGING & 0 & - & 0.00 & 0.00 & 0.00 & - & 0.00 & \\
\hline $12 . B .1$ & \begin{tabular}{|l|l|} 
& [ENTER COMPONENT/SUBASSY] \\
\end{tabular} & 0 & 0.00 & 0.00 & $0.00 \%$ & 0.00 & & 0.00 & \\
\hline 12.C.0 & CREW/HAB SPT SYS CONSUMABLES \& PACKAGING & 25 & - & $12,373.61$ & $3.09 \%$ & 381.77 & & $12,755.38$ & \\
\hline 12.C.1 & \begin{tabular}{|l|l|} 
FOOD \\
\end{tabular} & 1 & $8,276.12$ & $8,276.12$ & $3.00 \%$ & 248.28 & & $8,524.40$ & \\
\hline 12.C.2 & $\mathrm{H} 2 \mathrm{O}$ & 1 & 384.00 & 384.00 & $3.00 \%$ & 11.52 & & 395.52 & \\
\hline $12 . C .3$ & COOKING/EATING SUPPLIES & 1 & 8.00 & 8.00 & $20.00 \%$ & 1.60 & & 9.60 & \\
\hline 12.C.4 & PERSONAL HYGEINE KIT & 1 & 19.80 & 19.80 & $3.00 \%$ & 0.59 & & 20.39 & \\
\hline 12.C.5 & HYGIENE CONSUMABLES / WCS WIPES & 1 & 709.64 & 709.64 & $3.00 \%$ & 21.29 & & 730.93 & \\
\hline 12.C.6 & TOWELS & 1 & 139.32 & 139.32 & $3.00 \%$ & 4.18 & & 143.50 & \\
\hline 12.C.7 & COMMUNITY HYGIENE KIT & 1 & 4.72 & 4.72 & $20.00 \%$ & 0.94 & & 5.66 & \\
\hline 12.C.8 & WASTE COLLECTION - FECAL CANISTERS & 1 & 990.00 & 990.00 & $3.00 \%$ & 29.70 & & $1,019.70$ & \\
\hline $12 . C .9$ & WASTE COLLECTION - URINE PREFILTER & 1 & 275.00 & 275.00 & $3.00 \%$ & 8.25 & & 283.25 & \\
\hline 12.C.10 & $\begin{array}{l}\text { FECAL/URINE COLLECTION BAGS } \\
\text { (CONTINGENCY) }\end{array}$ & 1 & 167.20 & 167.20 & $3.00 \%$ & 5.02 & & 172.22 & \\
\hline 12.C.11 & TRASH BAGS & 1 & 135.60 & 135.60 & $3.00 \%$ & 4.07 & & 139.67 & \\
\hline 12.C.12 & HEALTH CARE CONSUMABLES & 1 & 406.80 & 406.80 & $3.00 \%$ & 12.20 & & 419.00 & \\
\hline 12.C.13 & WIPES (HOUSEKEEPING) & 1 & 198.88 & 198.88 & $3.00 \%$ & 5.97 & & 204.85 & \\
\hline 12.C.14 & FIRST AID KIT & 2 & 9.10 & 18.20 & $20.00 \%$ & 3.64 & & 21.84 & \\
\hline 12.C.15 & CONVENIENCE MEDICATION PACK & 1 & 2.81 & 2.81 & $20.00 \%$ & 0.56 & & 3.37 & \\
\hline 12.C.16 & EMERGENCY MEDICAL TREATMENT PACK & 1 & 2.81 & 2.81 & $20.00 \%$ & 0.56 & & 3.37 & \\
\hline 12.C.17 & IV SUPPLY PACK & 1 & 6.17 & 6.17 & $20.00 \%$ & 1.23 & & 7.40 & \\
\hline 12.C.18 & MEDICAL DIAGNOSTIC PACK & 1 & 4.04 & 4.04 & $20.00 \%$ & 0.81 & & 4.85 & \\
\hline 12.C.19 & MEDICAL SUPPLY PACK & 1 & 2.92 & 2.92 & $20.00 \%$ & 0.58 & & 3.50 & \\
\hline 12.C.20 & MINOR TREATMENT PACK & 1 & 3.88 & 3.88 & $20.00 \%$ & 0.78 & & 4.66 & \\
\hline 12.C.21 & ORAL MEDICATION PACK & 1 & 2.67 & 2.67 & $20.00 \%$ & 0.53 & & 3.20 & \\
\hline 12.C.22 & PHYSICIAN EQUIPMENT PACK & 1 & 2.54 & 2.54 & $20.00 \%$ & 0.51 & & 3.05 & \\
\hline
\end{tabular}




\begin{tabular}{|c|c|c|c|c|c|c|c|c|c|}
\hline \multirow[t]{3}{*}{ SBS ID } & COMMON FUNCTIONAL CATEGORY (TIER 1) & \multirow[b]{3}{*}{ Qty } & \multirow[b]{3}{*}{$\begin{array}{c}\text { Unit Mass } \\
(\mathrm{kg})\end{array}$} & \multirow[b]{3}{*}{$\begin{array}{c}\text { Basic } \\
\text { Mass }(\mathrm{kg})\end{array}$} & \multirow[b]{3}{*}{$\begin{array}{c}\text { MGA } \\
\text { (\%) }\end{array}$} & \multirow[b]{3}{*}{$\begin{array}{l}\text { MGA } \\
(\mathrm{kg})\end{array}$} & \multirow[b]{3}{*}{$\begin{array}{l}\text { Predicted } \\
\text { Manuf } \\
\text { Empty } \\
\text { Mass (kg) }\end{array}$} & \multirow[b]{3}{*}{\begin{tabular}{c|} 
Predicted \\
Total \\
Operational \\
Items \\
Mass (kg)
\end{tabular}} & \multirow[b]{3}{*}{$\begin{array}{l}\text { Predicted } \\
\text { Total Tier } 1 \\
\text { Category } \\
\text { Mass (kg) }\end{array}$} \\
\hline & COMMON EQUIPMENT GROUP (TIER 2) & & & & & & & & \\
\hline & $\begin{array}{l}\text { UNIQUE COMPONENT/SUB-ASSEMBLY (TIER } \\
\text { 3) }\end{array}$ & & & & & & & & \\
\hline 12.C.23 & TOPICAL \& INJECTABLE PACK & 1 & 3.37 & 3.37 & $20.00 \%$ & 0.67 & & 4.04 & \\
\hline 12.C.24 & CLOTHING (LAUNDRY) & 1 & 609.12 & 609.12 & $3.00 \%$ & 18.27 & & 627.39 & \\
\hline $12 . D .0$ & CREW/HAB SPT SYS RESIDUALS & 0 & - & 0.00 & 0.00 & 0.00 & & 0.00 & \\
\hline 12.D.1 & \begin{tabular}{|l|l} 
[ENTER COMPONENT/SUBASSY] \\
\end{tabular} & 0 & 0.00 & 0.00 & $0.00 \%$ & 0.00 & & 0.00 & \\
\hline 13.0 .0 & EXTRAVEHICULAR ACTIVITY (EVA) SUPPORT SYSTEMS & 14 & - & 968.30 & $17.16 \%$ & 166.16 & $1,134.46$ & 222.73 & $1,357.19$ \\
\hline 13.1.0 & \begin{tabular}{|l|l|} 
& EVA EQUIP AND SERVICE INTERFACES \\
\end{tabular} & 9 & - & 196.00 & $11.29 \%$ & 22.12 & 218.12 & - & 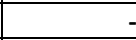 \\
\hline 13.1.1 & EVA PATH LIGHTING & 8 & 1.00 & 8.00 & $18.00 \%$ & 1.44 & 9.44 & & \\
\hline 13.1 .2 & \begin{tabular}{|l|} 
PERMANENT HARDWARE (DON/DOFF STAND, \\
UMBILICALS, UMBILICAL INTERFACE PANEL, \\
POWER SUPPLY, BATTERY CHARGER, FPR, \\
VACUUM PORT, ETC.) \\
\end{tabular} & 1 & 188.00 & 188.00 & $11.00 \%$ & 20.68 & 208.68 & & \\
\hline 13.2.0 & INTERNAL AIRLOCK EQUIPMENT & 5 & & 772.30 & $18.65 \%$ & 144.04 & 916.34 & - & \\
\hline 13.2 .1 & \begin{tabular}{|l|l|} 
& AIRLOCK STRUCTURE \\
\end{tabular} & 1 & 420.00 & 420.00 & $18.00 \%$ & 75.60 & 495.60 & - & \\
\hline 13.2 .2 & AIRLOCK CO2 REMOVAL & 1 & 181.30 & 181.30 & $20.00 \%$ & 36.26 & 217.56 & - & - \\
\hline 13.2 .3 & DEPRESSURIZATION PUMP \& SUPPORT & 1 & 98.00 & 98.00 & $18.00 \%$ & 17.64 & 115.64 & - & \\
\hline 13.2 .4 & AIRLOCK RECYCLE PUMP & 1 & 70.00 & 70.00 & $20.00 \%$ & 14.00 & 84.00 & & \\
\hline 13.2 .5 & AUDIO SYSTEM (AIRLOCK) & 1 & 3.00 & 3.00 & $18.00 \%$ & 0.54 & 3.54 & - & \\
\hline 13.3.0 & EVA SYSTEMS FIXED STORAGE SPACE & 0 & - & 0.00 & 0.00 & 0.00 & 0.00 & - & - \\
\hline 13.3 .1 & \begin{tabular}{|l|l} 
& [ENTER COMPONENT/SUBASSY] \\
\end{tabular} & 0 & 0.00 & 0.00 & $0.00 \%$ & 0.00 & 0.00 & - & \\
\hline 13.9 .0 & EVA SPT SYS INSTALLATION & 0 & - & 0.00 & 0.00 & 0.00 & 0.00 & - & - \\
\hline 13.9.1 & [ENTER COMPONENT/SUBASSY] & 0 & 0.00 & 0.00 & $0.00 \%$ & 0.00 & 0.00 & - & \\
\hline 13.A.0 & EVA SUITS, TOOLS \& PACKAGING & 3 & - & 92.37 & $11.00 \%$ & 10.16 & & 102.53 & 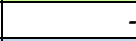 \\
\hline 13.A.1 & \begin{tabular}{|l|l|} 
& PLSS - PORTABLE LIFE SUPPORT SYSTEM \\
\end{tabular} & 0 & 355.00 & 0.00 & $11.00 \%$ & 0.00 & & 0.00 & \\
\hline 13.A.2 & EVA SUIT & 0 & 540.00 & 0.00 & $11.00 \%$ & 0.00 & & 0.00 & \\
\hline 13.A.3 & M-EMU (MARS SURFACE SUITS) & 0 & 190.00 & 0.00 & $11.00 \%$ & 0.00 & & 0.00 & \\
\hline 13.A.4 & EVA TOOLS AND EQUIPMENT & 1 & 69.37 & 69.37 & $11.00 \%$ & 7.63 & & 77.00 & \\
\hline 13.A.5 & \begin{tabular}{|l|} 
LARGE HABITAT COMMUNICATION (ARCM \\
COMM. KITS) (STOWABLE OR \\
PERMANENT??)
\end{tabular} & 2 & 11.50 & 23.00 & $11.00 \%$ & 2.53 & & 25.53 & \\
\hline $13 . B .0$ & SPARE EVA SPT SYS EQUIP \& PACKAGING & 0 & - & 0.00 & 0.00 & 0.00 & & 0.00 & - \\
\hline 13.B.1 & \begin{tabular}{|l|l|} 
& [ENTER COMPONENT/SUBASSY] \\
\end{tabular} & 0 & 0.00 & 0.00 & $0.00 \%$ & 0.00 & & 0.00 & \\
\hline 13.C.O & EVA SPT SYS CONSUMABLES \& PACKAGING & 2 & - & 116.70 & $3.00 \%$ & 3.50 & - & 120.20 & 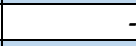 \\
\hline 13.C.1 & \begin{tabular}{|l|l|} 
& O2 (AIRLOCK REPRESS?) \\
\end{tabular} & 1 & 98.40 & 98.40 & $3.00 \%$ & 2.95 & & 101.35 & \\
\hline 13.C.2 & \begin{tabular}{|l|l|} 
& N2 (AIRLOCK REPRESS?) \\
\end{tabular} & 1 & 18.30 & 18.30 & $3.00 \%$ & 0.55 & & 18.85 & \\
\hline 13.D.0 & EVA SPT SYS RESIDUALS & 0 & - & 0.00 & 0.00 & 0.00 & & 0.00 & - \\
\hline 13.D.1 & \begin{tabular}{|l|l|l|} 
& & [ENTER COMPONENT/SUBASSY] \\
\end{tabular} & 0 & 0.00 & 0.00 & $0.00 \%$ & 0.00 & & 0.00 & \\
\hline 14.0 .0 & $\begin{array}{l}\text { IN-SITU RESOURCE ACQUISITION \& CONSUMABLES } \\
\text { PRODUCTION SYSTEMS }\end{array}$ & 0 & - & 0.00 & 0.00 & 0.00 & 0.00 & 0.00 & 0.00 \\
\hline 14.1.0 & \begin{tabular}{|l|l|} 
& RAW MATERIAL EXTRACTION EQUIP \\
\end{tabular} & 0 & - & 0.00 & 0.00 & 0.00 & 0.00 & - & - \\
\hline 14.1.1 & \begin{tabular}{|l|l} 
& [ENTER COMPONENT/SUBASSY] \\
\end{tabular} & 0 & 0.00 & 0.00 & $0.00 \%$ & 0.00 & 0.00 & & \\
\hline 14.2.0 & $\begin{array}{l}\text { PROPELLANTS, FLUIDS/GASES PROCESSING \& } \\
\text { HANDLING EQUIP }\end{array}$ & 0 & & 0.00 & 0.00 & 0.00 & 0.00 & & \\
\hline 14.2 .1 & \begin{tabular}{|l|l|} 
& [ENTER COMPONENT/SUBASSY] \\
\end{tabular} & 0 & 0.00 & 0.00 & $0.00 \%$ & 0.00 & 0.00 & -1 & \\
\hline 14.3.0 & MATERIAL PROCESSING \& HANDLING EQUIP & 0 & - & 0.00 & 0.00 & 0.00 & 0.00 & - & - \\
\hline 14.3 .1 & \begin{tabular}{|l|l|} 
& [ENTER COMPONENT/SUBASSY] \\
\end{tabular} & 0 & 0.00 & 0.00 & $0.00 \%$ & 0.00 & 0.00 & & \\
\hline 14.9.0 & $\begin{array}{l}\text { RESOURCE ACQ \& CONSUM PROD SYS } \\
\text { INSTALLATION }\end{array}$ & 0 & & 0.00 & 0.00 & 0.00 & 0.00 & & \\
\hline 14.9 .1 & \begin{tabular}{|l|l} 
& [ENTER COMPONENT/SUBASSY] \\
\end{tabular} & 0 & 0.00 & 0.00 & $0.00 \%$ & 0.00 & 0.00 & - & \\
\hline 14.A.O & $\begin{array}{l}\text { RESOURCE ACQ \& CONSUM PROD MISSION-KITTED } \\
\text { OR STOWED ITEMS }\end{array}$ & 0 & & 0.00 & 0.00 & 0.00 & & 0.00 & \\
\hline 14.A.1 & \begin{tabular}{|l|l|} 
& [ENTER COMPONENT/SUBASSY] \\
\end{tabular} & 0 & 0.00 & 0.00 & $0.00 \%$ & 0.00 & & 0.00 & \\
\hline 14.B.O & $\begin{array}{l}\text { SPARE RESOURCE ACQ \& CONSUM PROD SYS } \\
\text { EQUIP \& PACKAGING }\end{array}$ & 0 & & 0.00 & 0.00 & 0.00 & & 0.00 & \\
\hline 14.B.1 & \begin{tabular}{|l|l|} 
& [ENTER COMPONENT/SUBASSY] \\
\end{tabular} & 0 & 0.00 & 0.00 & $0.00 \%$ & 0.00 & & 0.00 & \\
\hline 14.C.O & $\begin{array}{l}\text { RESOURCE ACQ \& CONSUM PROD SUPPLY STOCKS } \\
\text { \& PACKAGING }\end{array}$ & 0 & & 0.00 & 0.00 & 0.00 & & 0.00 & \\
\hline 14.C.1 & \begin{tabular}{|l|l|} 
& [ENTER COMPONENT/SUBASSY] \\
\end{tabular} & 0 & 0.00 & 0.00 & $0.00 \%$ & 0.00 & & 0.00 & \\
\hline
\end{tabular}




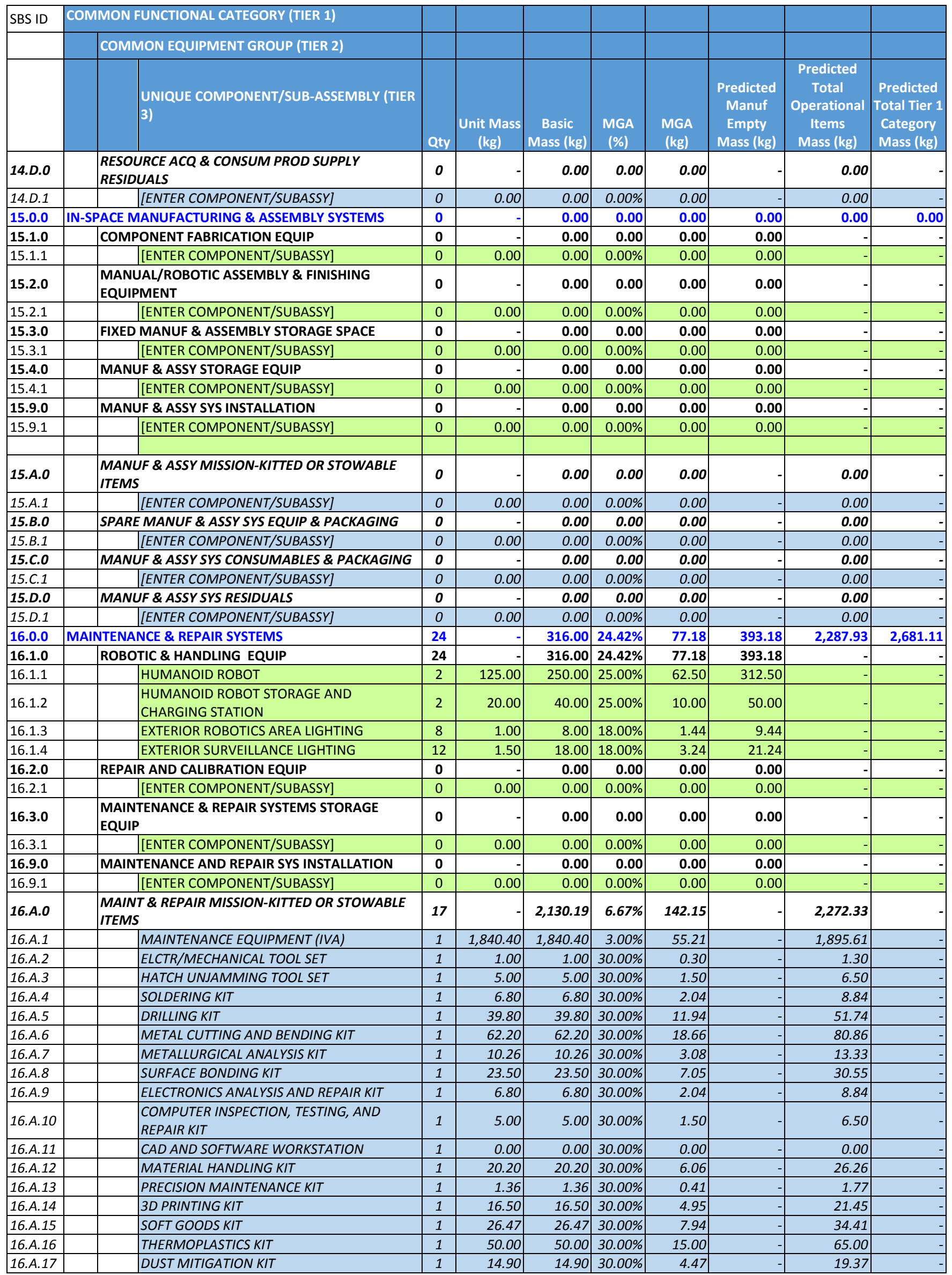




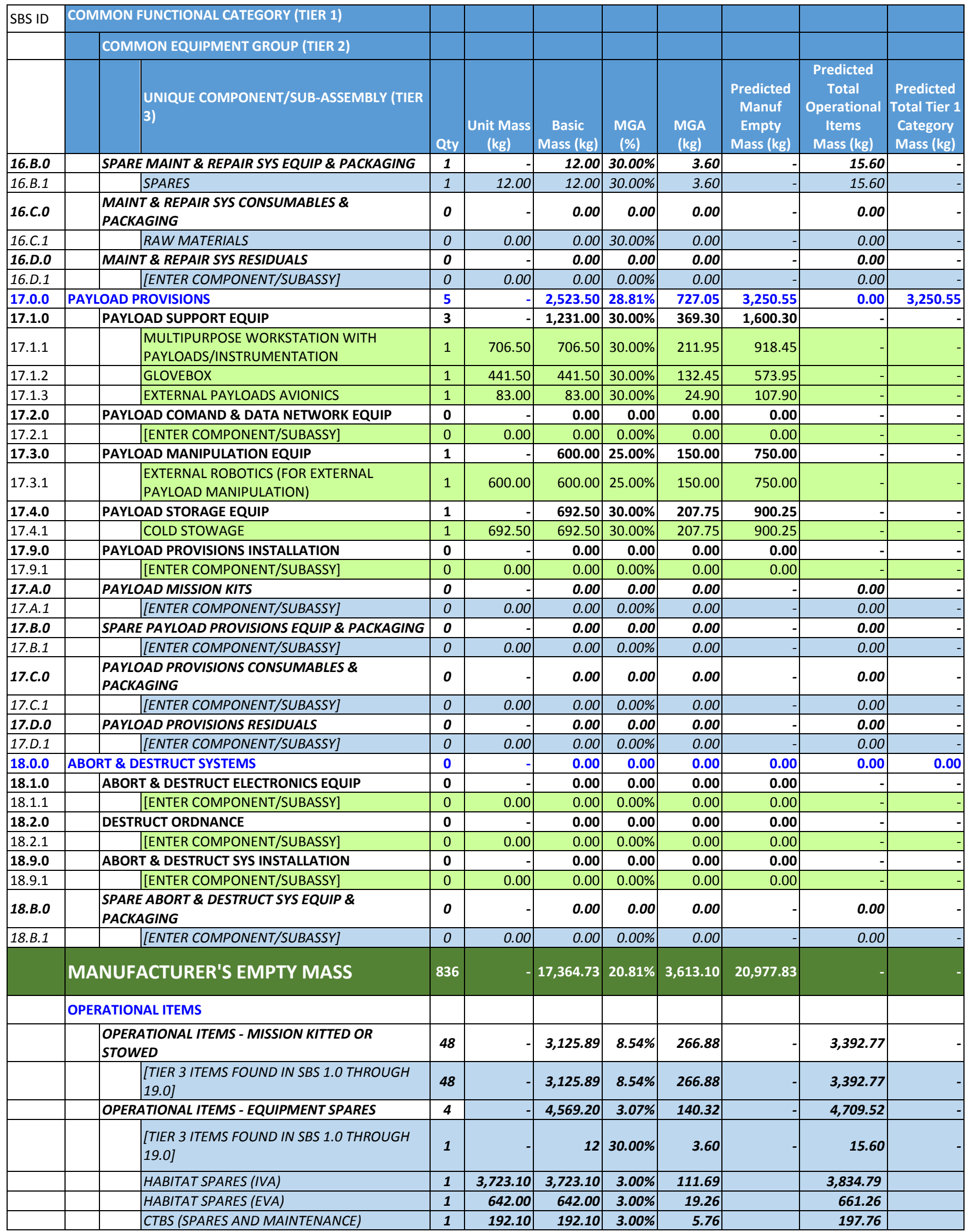




\begin{tabular}{|c|c|c|c|c|c|c|c|c|c|}
\hline \multirow[t]{2}{*}{ SBS ID } & COMMON FUNCTIONAL CATEGORY (TIER 1) & \multirow[b]{3}{*}{ Qty } & \multirow[b]{3}{*}{$\begin{array}{c}\text { Unit Mass } \\
(\mathrm{kg})\end{array}$} & \multirow[b]{3}{*}{$\begin{array}{c}\text { Basic } \\
\text { Mass }(\mathrm{kg})\end{array}$} & \multirow[b]{3}{*}{$\begin{array}{l}\text { MGA } \\
(\%)\end{array}$} & \multirow[b]{3}{*}{$\begin{array}{c}\text { MGA } \\
(\mathrm{kg})\end{array}$} & \multirow[b]{3}{*}{$\begin{array}{c}\text { Predicted } \\
\text { Manuf } \\
\text { Empty } \\
\text { Mass (kg) }\end{array}$} & \multirow[b]{3}{*}{$\begin{array}{l}\text { Predicted } \\
\text { Total } \\
\text { Operational } \\
\text { Items } \\
\text { Mass (kg) } \\
\end{array}$} & \multirow[b]{3}{*}{\begin{tabular}{|} 
Predicted \\
Total Tier 1 \\
Category \\
Mass (kg)
\end{tabular}} \\
\hline & COMMON EQUIPMENT GROUP (TIER 2) & & & & & & & & \\
\hline & $\begin{array}{l}\text { UNIQUE COMPONENT/SUB-ASSEMBLY (TIER } \\
\text { 3) }\end{array}$ & & & & & & & & \\
\hline & OPERATIONAL ITEMS - CONSUMABLES & 31 & & $13,850.10$ & $3.60 \%$ & 498.77 & & $14,348.88$ & \\
\hline & $\begin{array}{l}\text { [TIER } 3 \text { ITEMS FOUND IN SBS } 1.0 \text { THROUGH } \\
\text { 19.0] }\end{array}$ & 30 & & $13,128.00$ & $3.63 \%$ & 477.11 & & $13,605.11$ & \\
\hline & CTBS (CONSUMABLES) & 1 & 722.10 & 722.10 & $3.00 \%$ & 21.66 & & 743.76 & \\
\hline & OPERATIONAL ITEMS - RESIDUALS & & & & & & & & \\
\hline & \begin{tabular}{|l|l|} 
[TIER 3 ITEMS FOUND IN SBS 1.0 THROUGH \\
19.0]
\end{tabular} & 0 & & 0.00 & 0.00 & 0.00 & & 0.00 & \\
\hline & OPERATIONAL ITEMS - CREW & & & & & & & & \\
\hline & [ACCOUNTED AT VEHICLE LEVEL] & - & - & & & - & & - & \\
\hline & OPERATIONAL ITEMS & 919 & & $38,909.93$ & $11.61 \%$ & $4,519.06$ & - & 22451.17 & \\
\hline 19.0 .0 & PAYLOADS \& RESEARCH & 2 & - & $1,556.50$ & $30.00 \%$ & 466.95 & - & - & $2,023.45$ \\
\hline 19.1.0 & CARGO & 0 & - & 0.00 & 0.00 & 0.00 & - & - & 0.00 \\
\hline 19.1.1 & [ENTER COMPONENT/SUBASSY] & 0 & 0.00 & 0.00 & $0.00 \%$ & 0.00 & & & 0.00 \\
\hline 19.2.0 & SCIENTIFIC RESEARCH EXPERIMENTS & 2 & - & $1,556.50$ & $30.00 \%$ & 466.95 & - & - & $2,023.45$ \\
\hline 19.2 .1 & \begin{tabular}{|l|l|} 
EXTERNAL PAYLOAD PLATFORM WITH \\
PAYLOADS
\end{tabular} & 1 & 370.00 & 370.00 & $30.00 \%$ & 111.00 & & & 481.00 \\
\hline 19.2.2 & $\begin{array}{l}\begin{array}{l}\text { NOTIONAL HUMAN RESEARCH PROGRAM } \\
\text { (HRP) PAYLOADS }\end{array} \\
\end{array}$ & 1 & $1,186.50$ & $1,186.50$ & $30.00 \%$ & 355.95 & & & $1,542.45$ \\
\hline 19.3.0 & TECHNOLOGY R\&D EXPERIMENTS & 0 & - & 0.00 & 0.00 & 0.00 & - & - & 0.00 \\
\hline 19.3.1 & \begin{tabular}{|l|l|} 
& [ENTER COMPONENT/SUBASSY] \\
\end{tabular} & 0 & 0.00 & 0.00 & $0.00 \%$ & 0.00 & & - & 0.00 \\
\hline 19.4.0 & ENGINEERING R\&D EXPERIMENTS & 0 & & 0.00 & 0.00 & 0.00 & - & - & 0.00 \\
\hline 19.4.1 & $\begin{array}{l}\text { [ENTER COMPONENT/SUBASSY] } \\
\end{array}$ & 0 & 0.00 & 0.00 & $0.00 \%$ & 0.00 & - & - & 0.00 \\
\hline 19.5.0 & EDUCATION \& PUBLIC OUTREACH EXPERIMENTS & 0 & - & 0.00 & 0.00 & 0.00 & - & - & 0.00 \\
\hline 19.5.1 & \begin{tabular}{|l|l|} 
& [ENTER COMPONENT/SUBASSY] \\
\end{tabular} & 0 & 0.00 & 0.00 & $0.00 \%$ & 0.00 & & & 0.00 \\
\hline 19.6.0 & PASSENGERS \& CARRIED ITEMS & 0 & - & 0.00 & 0.00 & 0.00 & - & - & 0.00 \\
\hline 19.6.1 & \begin{tabular}{|l|l} 
& [ENTER COMPONENT/SUBASSY] \\
\end{tabular} & 0 & 0.00 & 0.00 & $0.00 \%$ & 0.00 & & - & 0.00 \\
\hline 19.7.0 & STANDARD CONTAINERS \& CARRIERS & 0 & - & 0.00 & 0.00 & 0.00 & - & - & 0.00 \\
\hline 19.7.1 & [ENTER COMPONENT/SUBASSY] & 0 & 0.00 & 0.00 & $0.00 \%$ & 0.00 & & & 0.00 \\
\hline 19.8.0 & CUSTOM CONTAINERS \& CARRIERS & 0 & - & 0.00 & 0.00 & 0.00 & - & - & 0.00 \\
\hline 19.8 .1 & \begin{tabular}{l|l} 
& \\
\end{tabular} & 0 & 0.00 & 0.00 & $0.00 \%$ & 0.00 & & - & 0.00 \\
\hline & PROPULSION \& REACTION CONTROL EXPENDABLES & 0 & - & 0.00 & 0.00 & 0.00 & & - & 0.00 \\
\hline & GROSS ITEM CONTRIBUTIONS & 0 & - & $1,556.50$ & $30.00 \%$ & 466.95 & & & $2,023.45$ \\
\hline GROS & S MASS & 919 & & $40,466.43$ & $12.32 \%$ & $4,986.01$ & $20,977.83$ & 22451.17 & 45,452 \\
\hline
\end{tabular}




\section{B. COMMON FUNCTIONAL MEL Functional Category Definitions}

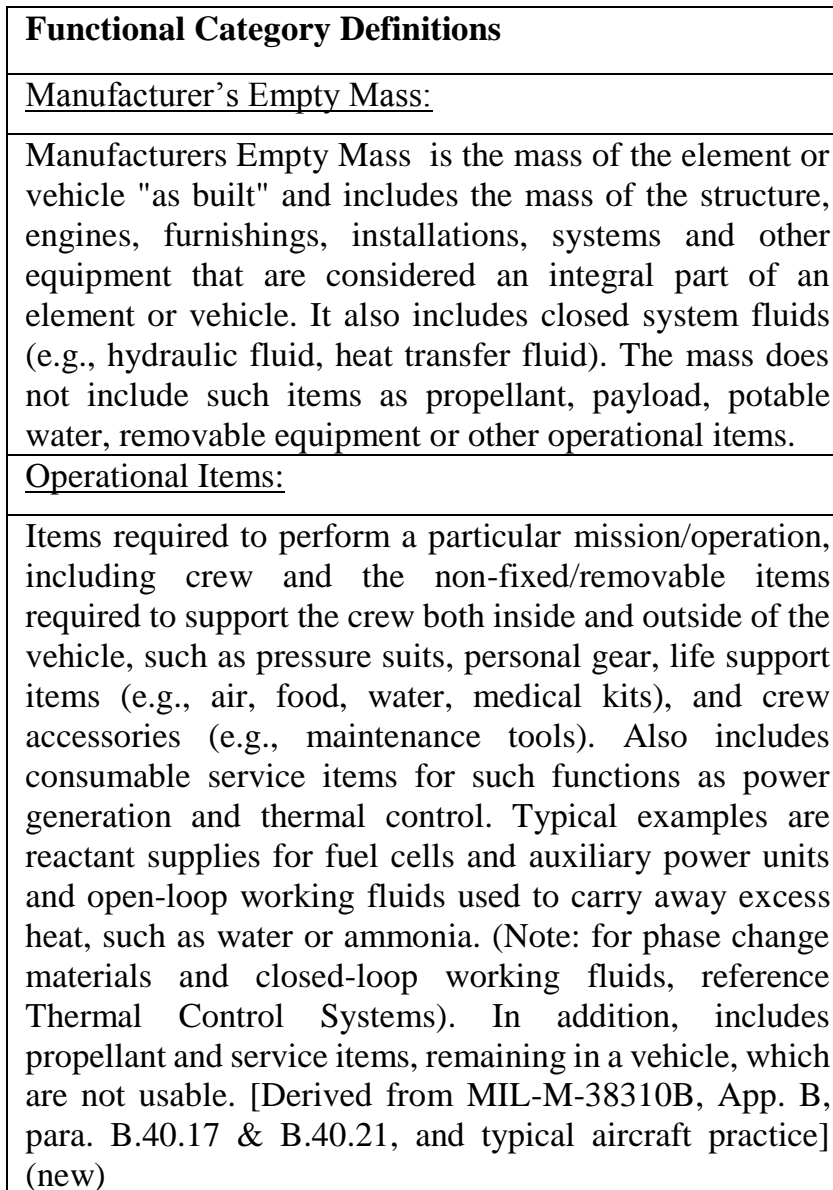

Operational Empty Mass:

Operational Empty Mass is the sum of the Manufacturer's Empty Mass and the mass of the Operational Items. It is the mass of the element or vehicle including items necessary for operation, excluding usable propellant and the payload.

\section{1 . Body Structures}

The basic and secondary load carrying members, exclusive of the non-structural components used for induced environmental protection. (MIL-M-38310B, App. B, para. B.40.2)

Primary Structure (Pressurized and/or Unpressurized) That part of a flight vehicle or element which sustains the significant applied loads and provides main load paths for distributing reactions to applied loads. Also the main structure which is required to sustain the significant applied loads, including pressure and thermal loads, and which if it fails creates a catastrophic hazard. If a component is small enough and in an environment where no serious threat is imposed if it breaks, then it is not primary

structure.

Secondary Structure - The internal or external structure which is used to attach small components, provide storage, and to make either an internal volume or external surface usable. Secondary structure attaches to and is supported by primary structure.

\section{Connection and Separation Systems}

Physical interfacing equipment required to connect (and/or separate) one or more element structural load paths, electrical paths, and/or fluid paths during its use. This may also include any external ground handling or launch or transit vehicle services (mounts, power, purges, etc.). (New)

3. Launch/Takeoff and Landing Support Systems

Items that provide the vehicle with the capability to be launched from or brought to rest with respect to a mass. Enter descriptive or location data, as appropriate, for clarification of the function served. (MIL-M-38310B, App. B, para. B.40.4)

4. Natural and Induced Environments Protection Systems

The devices which in themselves, or in combination, protect the vehicle or element structure and its contents from the detrimental effects of radiation (e.g., solar, ionizing and galactic cosmic), micrometeoroids and orbital debris (MMOD), induced heat and noise, contamination (e.g., surface dust), and corrosion. [derived from: MIL-M-38310B, App. B, para. B.40.3]

5. Propulsion Systems

Propulsive items which provide flight path thrust and acceleration and include rocket engines, nuclear engines, propulsive devices, and related equipment, such as fuel systems, oxidizer systems, and pressurizing systems. Also includes propellant tanks, if not integral with the body structure. [derived from: MIL-M-38310B, Appx. B, para. B.40.5; JSC 23303, p. 5]

\section{Power Systems}

Devices and systems for collecting and storing energy, as well as generating or converting various forms of energy into available power that is distributed to vehicle system electrical and/or mechanical loads from centralized sources. Includes: dedicated energy storage source material and their containers (e.g., electrochemical storage devices); storage containers and distribution equipment for consumable energy source materials, along with associated heaters, insulation, and instrumentation); dedicated mechanical and/or electrical power converters such as distributed high pressure hydraulic or pneumatic pumps, or fuel cell devices, power inverters; and a means of distributing and regulating power to various vehicle systems loads, including such equipment as pressurized fluid distribution lines, hoses, accumulators, valves, and/or electrical controllers, instrumentation, and switch gear, cables, harnesses, etc. (Note: localized or distributed power systems are nominally bookkept with the equipment they are in direct support of). [New]

\section{Command and Data Handling Systems}

Avionics equipment that: programs and commands various vehicle elements, modules and subsystems; monitors and predicts vehicle performance and equipment status, and reconfigures systems for safe, stable, or 
advantageous configuration; and distributes, collects, formats and/or stores information for other on- and offboard purposes. [New]

\section{Guidance, Navigation, and Control Systems}

Equipment and associated algorithms for directing vehicle motion, subdivided into the following functions: Guidance - Determines the vehicle's desired location/path, velocity, and attitude (orientation)

Navigation - Provides estimates for the vehicle's current state (position, velocity, attitude, attitude rate, etc.)

Control - Steers attitude of vehicle to follow guidance commands while achieving good dynamic response (stability)

Note: Control equipment includes the devices for spatial alignment and stabilization (typically thrusters, reaction wheels, control moment gyroscopes, or aerodynamic surfaces), termed effectors, that produce reactive forces on the vehicle. Aerodynamic and spatial controls include the electro-mechanical, hydraulic, or pneumatic actuation system, from the actuator source to the item actuated. [derived from: MIL-M-38310B, Appx. B, para. B.40.6]

9. Communications and Tracking Systems

The equipment required for all means of communication within, emanating from, and received by the vehicle or element. Includes transmitters, receivers, antennas, power amplifiers and filers, as well as dedicated sensors, instrumentation, cabling, pointing and mounting hardware, and electronics. [derived from: MIL-M38310B, Appx. B, para. B.40.11, and JSC 23303, p. 7]

\section{Crew Displays and Controls}

Crew displays and controls are the items consisting of operator input control devices at crew stations and other locations of all types, including various touch/motion controllers and other hybrid display and control devices, as well as other manual input devices, such as switches, pedestals, and levers. Actuation of the controls may be accomplished manually, or with power-assisted devices and equipment. Displays include those that are permanently installed or movable. Does not include carryon operational items such as laptop computers and other mobile electronic devices (see Operational Items).. (MILM-38310B, App. B, para. B.40.15)

\section{Thermal Control Systems}

The devices which collect, transport, distribute, and radiate/reject internally generated forms of heat. [New]

\section{Environmental Control Systems}

Controls internal atmospheric environmental conditions such as temperature, pressure, humidity, atmospheric constituents, and odor for personnel and equipment. [derived from: MIL-M-38310B, App. B, para. B.40.12]

\section{Crew/Habitation Support Systems}

Items within the crew cabin, such as accommodations, fixed life support equipment, cargo handling, furnishings and built-in emergency equipment. (MIL-M-38310B,
App. B, para. B.40.14)

\section{EVA Support Systems}

Systems, services and equipment that are permanently fixed to the element or module to support extravehicular activity by crew personnel. Includes fluid and gas services provided, internal airlocks (external airlocks are generally covered as a seperate element).

15. In-situ Resource Acquistion and Consumables Production Systems

Equipment that generates and transfers fluids for consumption or use by other equipment and/or crew; e.g., propellants, breathing air supply, and water. Includes fixed equipment that extracts or acquires raw materials from vehicle surroundings and any necessary test equipment and storage areas and/or containers. (New)

16. In-space Manufacturing and Assembly Systems

Equipment that manufactures/fabricates items or provides off-line sub-assembly and test of such items. (New)

17. Maintenance and Repair Systems

Includes equipment used for conducting maintenance and support tasks, such as handling/manipulation, disassembly/reassembly, calibration and repair. Includes equipment for storage of tools and instruments associated with these routine maintenance and on-demand repairs.

18. Payload Provisions

Items consisting of payload structural attachments and those for providing electrical power, command, data handling, thermal control, and payload handling/manipulation services (e.g., Remote Manipulator System). (New)

\section{Abort and Destruct Systems}

Systems that act on malfunctions which will endanger personnel or damage equipment. These systems may also initiate remedial action automatically or perform upon command for emergency conditions detected by the system. [derived from MIL-M-38310B, App. B, para. B.40.16]

$\underline{\text { Payload }}$

Items stored aboard the spacecraft typically comprising cargo, passengers, scientific instruments, or experiments. Also includes non-fixed carriers or pallets that are required to structurally support payloads. (New)

\section{Propulsion and Reaction Control Expendables}

Expendable items for propulsion and flight control functions, including any reserve and bias amounts. This includes propellant for a main propulsion system that provides the bulk of the propulsive energy (i.e., delta V), as well as propellant for an auxiliary propulsion system (e.g., orbital maneuver system). Also included are propellants dedicated to reaction or attitude control of the vehicle (i.e., propellants for control jet thrusters). Additionally, this category includes any solids/fluids/gases used for the purpose of propulsion system starting/igniting, pressurizing propellant tanks, or for purging of propulsion system lines and components of 
contaminants, such as debris and moisture. 